\title{
Detection and determination of degradation and metabolic products of drugs of abuse and explosives
}

\author{
Melissa Gayton Ely \\ West Virginia University
}

Follow this and additional works at: https://researchrepository.wvu.edu/etd

\section{Recommended Citation}

Ely, Melissa Gayton, "Detection and determination of degradation and metabolic products of drugs of abuse and explosives" (2009). Graduate Theses, Dissertations, and Problem Reports. 4459.

https://researchrepository.wvu.edu/etd/4459

This Dissertation is protected by copyright and/or related rights. It has been brought to you by the The Research Repository @ WVU with permission from the rights-holder(s). You are free to use this Dissertation in any way that is permitted by the copyright and related rights legislation that applies to your use. For other uses you must obtain permission from the rights-holder(s) directly, unless additional rights are indicated by a Creative Commons license in the record and/ or on the work itself. This Dissertation has been accepted for inclusion in WVU Graduate Theses, Dissertations, and Problem Reports collection by an authorized administrator of The Research Repository @ WVU.

For more information, please contact researchrepository@mail.wvu.edu. 


\title{
DETECTION AND DETERMINATION OF DEGRADATION AND METABOLIC PRODUCTS OF DRUGS OF ABUSE AND EXPLOSIVES
}

\author{
by \\ Melissa Gayton Ely \\ Dissertation submitted to the Eberly College of Arts and Sciences \\ at West Virginia University \\ in partial fulfillment of the requirements \\ for the degree of
}

Doctor of Philosophy

in

Chemistry

\author{
Approved by \\ Suzanne C. Bell, Ph.D., Chair \\ Ronald Smart, Ph.D. \\ Fred King, Ph.D. \\ Kenneth Showalter, Ph.D. \\ Patrick Callery, Ph.D.
}

C. Eugene Bennett Department of Chemistry

Morgantown, West Virginia

2009

Keywords: Cocaine, Methamphetamine, Explosives, Pyrolysis, Metabolism, Environmental Degradation, LC/MS/MS

Copyright $\odot 2009$ Melissa Gayton Ely 


\title{
Abstract \\ DETECTION AND DETERMINATION OF DEGRADATION AND METABOLIC PRODUCTS OF DRUGS OF ABUSE AND EXPLOSIVES
}

\author{
by Melissa Gayton Ely
}

\begin{abstract}
Among the different means of decomposition, thermal, environmental, and metabolic degradation play a significant role in how forensic related compounds are analyzed. In the first stage of this research, cocaine and methamphetamine were pyrolyzed utilizing a pyroprobe to detect reported products of pyrolytic/thermal degradation and smoked markers. This simple and rapid method has laid the groundwork for future smoked drug analyses. In the second stage of research, a new focus was developed on detection of explosives in soil from detonated UXO at the West Virginia Maneuver Area. TNT, RDX, HMX, tetryl, and TNT environmental degradation products were analyzed using a modified sampling method based on EPA 8330b and LC/MS/MS. Human exposure to explosives can be a consequence of environmental contamination or involvement with the synthesis, fabrication, or construction of an improvised explosive device (IED). Therefore, the final stage of this research focuses on human metabolic markers (biomarkers) of TNT, RDX, HMX, and tetryl which were determined using an in-vitro metabolism procedure and LC/MS/MS.
\end{abstract}




\section{Dedication}

To my husband (Brian), my parents (Carl and Yong Gayton), my sister and brotherin-law (Candice and Cole Spalding), my in-laws (Mark and Debra Ely), my high school chemistry teacher (Mr. Pitts), and to all who have helped me along the way. 


\section{Acknowledgments}

I would like to acknowledge:

Dr. Suzanne Bell, for her help, advice, mentorship, support, and friendship

Dr. Diaa Shakleya, for his assistance with the pyrolysis and metabolism procedures

Dr. Jenny Moshin from $A B I$, for her training on the $L C / M S$

Dr. Patrick Callery, for all of his help with the data interpretation for Chapter 2

Dr. John Quaranta, for allowing me to be part of the Dolly Sods project (Chapter 3) and for his friendship

members of my committee, Dr. Suzanne Bell, Dr. Ronald Smart, Dr. Fred King, Dr. Kenneth Showalter, and Dr. Patrick Callery for taking the time to review this work

members of the Bell research group, Lucy Oldfield, Jennifer Mercer, Rona Nishikawa, and Xinya Zhang for their assistance and support

and past members of the Bell research group, Amy Aylor, Josh Gunn, and Heidi Nawrocki for their support.

This material is based upon work supported by the National Institute of Justice, \#2001-RC-CX-K003 and research grant No.1003786R from the National Environmental Education and Training Center (NEETC), Indiana, PA. 


\section{Table of Contents}

Abstract

Dedication ......................................................................................................................

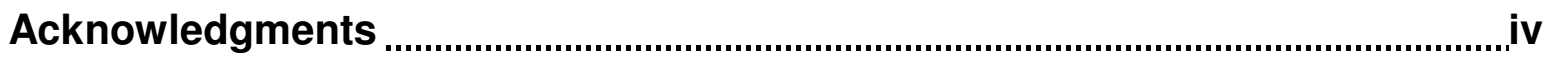

Table of Contents

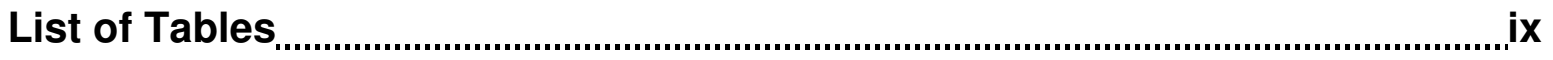

List of Figures

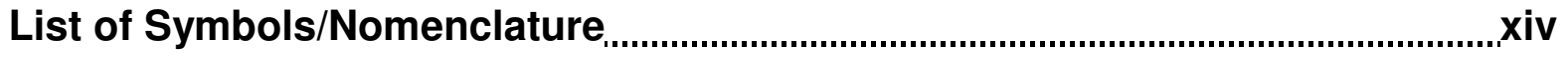

Chapter 1: Introduction

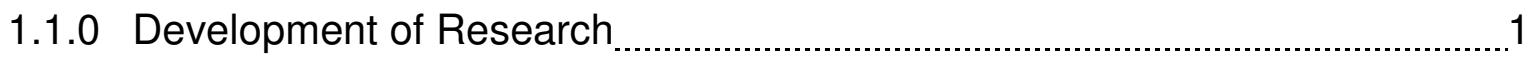

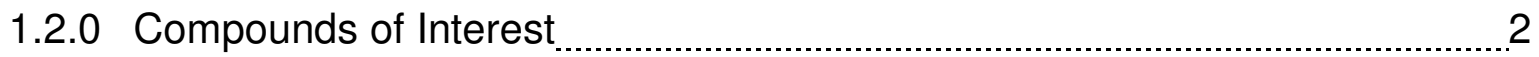

1.2.1 Cocaine and Methamphetamine

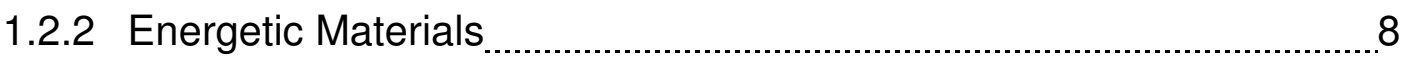

1.3.0 Methods of Degradation

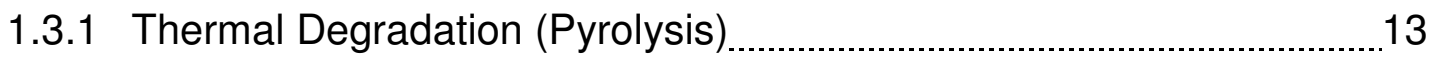

1.3.2 Environmental Degradation of TNT, RDX, HMX and Tetryl ................18

1.3.3 Human Metabolism of TNT, RDX, HMX and Tetryl …...........................2

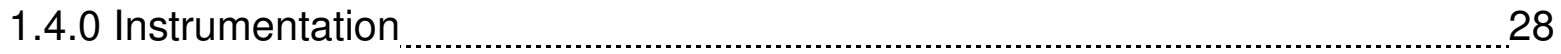

Chapter 2: Application of a Pyroprobe to Simulate Smoking of Abused Drugs through Analytical Pyrolysis.

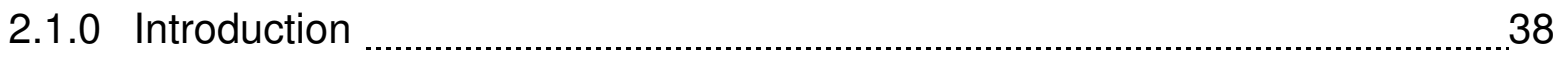

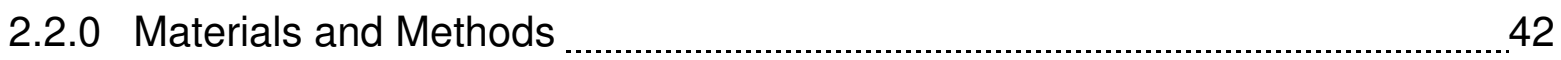

2.2.1 Pyrolysis/GC/MS Instrumentation and Conditions ............................... 42 
2.2.2 Reactant Gas Pyrolysis/GC/MS Instrumentation and Conditions .........47

2.2.3 Drug Sample Preparation $\ldots$

2.2.4 Cutting Agent/Drug Mixture Control _........................................................ 51

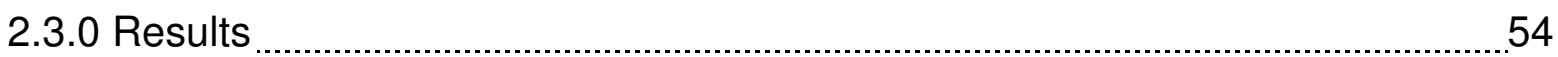

2.3.1 Analytical Pyrolysis of Drugs ................................................................... 54

2.3.2 Results of Analytical Pyrolysis with Trap and Reactant Gas (Air)........61

2.4.0 Conclusions

Chapter 3: Application of LC/MS/MS and Adapted Sampling to UXO and

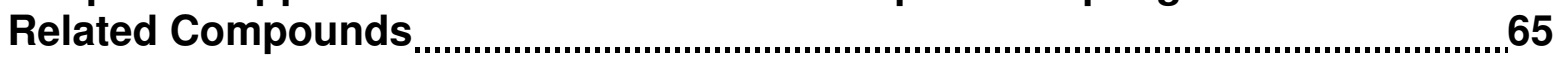

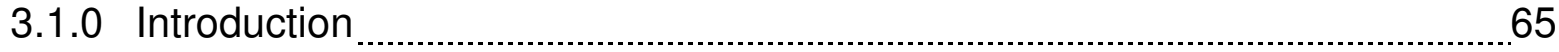

3.2.0 Materials and Methods

3.2.1 Site Locations

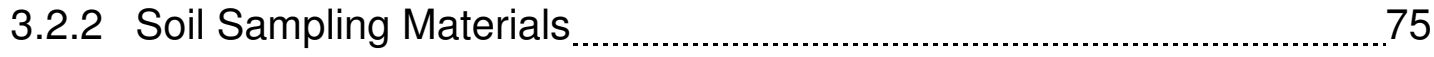

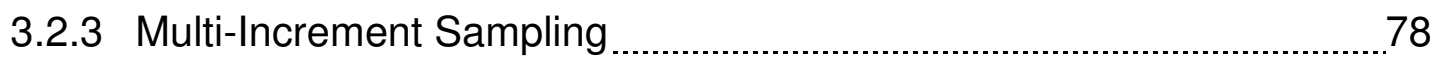

3.2.4 Soil Extraction

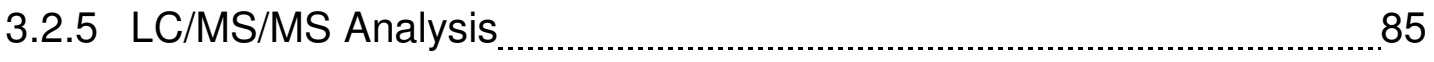

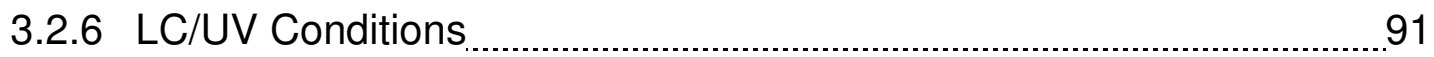

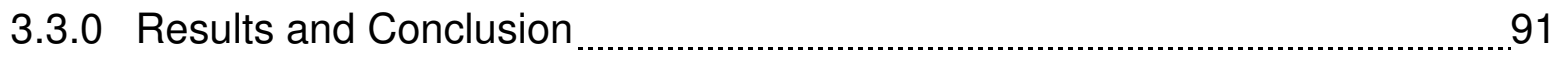

3.3.1 Quality Assurance Data

3.3.2 Example field sites: Grid 14

3.3.3 Example field sites: Grid 15

3.3.4 Example field sites: Grid 16

3.3.5 Example field sites: Grid 19

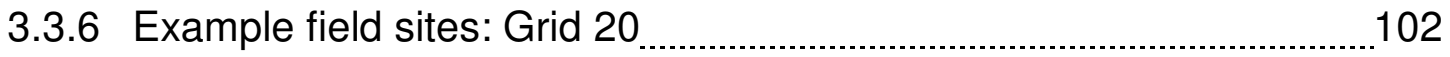


Chapter 4: Determination of Human Biomarkers of RDX, HMX, and Tetryl.....117

4.1.0 Introduction.

4.2.0 Materials and Methods. 123

4.2.1 In-vitro Metabolism Procedure 124

4.2.2 Large Volume TNT Solution 126

4.2.3 Quantitation 126

4.2.4 HPLC Conditions 127

4.2.5 LC/MS/MS Conditions 127

4.3.0 Results and Discussion. 133

4.3.1 Testing the in-vitro metabolism procedure 133

4.3.2 Results for RDX, HMX, and Tetryl. 139

4.3.3 Concentration issues: solubility 141

4.3.4 Enzyme efficiency 144

4.4.0 Conclusions 146

Appendices.

Appendix A: Example GC chromatogram and MS spectra of the pyrolysis of methamphetamine

Appendix B: Example GC chromatogram and MS spectra of the pyrolysis of cocaine.

Appendix C: Example of LOD determination using MRM spectra of 1,3,5-TNB: a) noise and peak are highlighted from extracted MRM, b) Analyst software calculates $\mathrm{S} / \mathrm{N}$ ratio

Appendix D: LC/MS/MS (MRM) data from Chapter 3 158 
References

Curriculum Vitae ...................................................................................................... 172 


\section{List of Tables}

Table 1 - Chemical properties of cocaine and methamphetamine

Table 2 - Characteristics of TNT, RDX, HMX and Tetryl 9

Table 3 - Summary of Reported Metabolic and Biodegradation Products*. 24

Table 4 - Reported pyrolytic products of cocaine and methamphetamine 40

Table 5 - Pyrolysis and GC conditions. 46

Table 6 - Pyrolytic products of the diluents, and diluents with cocaine and methamphetamine. Products were tentatively identified using a NIST MS library.

Table 7 - Physical, Chemical and Structural information of TNT, RDX, HMX and

Tetryl.

Table 8 - Remaining EPA 8330 explosives and transformation products 70

Table 9 - MS conditions used for explosives detection.

Table 10 - Monitored MRM transitions of explosives. 88

Table 11 - Quantitation parameters of each explosive. 90

Table 12 - Results for ERA soil standard using LC/UV and LC/MS/MS. All concentrations are in units of $\mu \mathrm{g} / \mathrm{kg}$.

Table 13 - Reproducibility results using LC/UV and LC/MS/MS, $n=3$ (the same extraction preparation and LC conditions were used).

Table 14 - Results for multi-increment, random grab, and cored soil samples from Grid 20.

Table 15 - Results for random grab samples from Grid XD. 108

Table 16 - MS/MS conditions of TNT, Tetryl, RDX and HMX. 128

Table 17 - Phase I metabolism biotransformations screened using Lightsight (highlighted biotransformations are seen in TNT).

Table 18 - MRM transitions of reported human TNT metabolites 131 
Table 19 - MRM transitions of reported animal/microbial metabolites of RD. 132

Table 20 - Concentration of parent explosive in the control and metabolized samples: 


\section{List of Figures}

Figure 1 - Structure of cocaine hydrochloride. 5

Figure 2 - Structure of methamphetamine. 7

Figure 3 - An example of an elimination reaction using a free radical mechanism commonly seen in pyrolysis.

Figure 4 - An example of a 1,2 shift rearrangement reaction, 16

Figure 5 - Pathway for the environmental degradation of TNT. Figure adapted from [40].

Figure 6 - A proposed pathway for the aerobic biotransformation of HMX. Figure adapted from [41].

Figure 7 - Generalized P450 cycle. Figure adapted from [45]. 26

Figure 8 - A schematic of positive mode electrospray ionization (ESI). Figure adapted from [66].

Figure 9 - A schematic of atmospheric pressure chemical ionization (APCI). Figure adapted from [65].

Figure 10 - A schematic of a quadrupole linear ion trap. Figure obtained with permission from Applied Biosystems, Inc.

Figure 11 - Schematic of a pyroprobe unit used for pyrolysis. The sample is placed in a quartz tube which is inserted into a wire coil that is attached to the probe. The probe is inserted into a heated accessory region where pyrolysis occurs by the rapid heating of the wire coil. The pyrolytic products are swept into the valve oven by $\mathrm{N}_{2}$ and through the transfer line to the injector port of the GC:

Figure 12 - Pyroprobe temperature program with no reactant gas or trapping......... 45

Figure 13 - Photo of the CDS Analytical 5200 model (trapping + reactant gas)........ 48

Figure 14 - Picture of the two heated zones in the 5200 model (foil was used for insulation and to reduce cold spots).

Figure 15 - Gas flow with and without trapping: 50

Figure 16 - Pyroprobe temperature program with the reactant gas and trapping.....53 
Figure 17 - Bond dissociation energies $(\mathrm{kJ} / \mathrm{mol})$ for cocaine and methamphetamine.

Figure 18 - Pyrolysis results of methamphetamine utilizing a pyroprobe.

Products were tentatively identified using a NIST MS library.

Figure 19 - Pyrolysis results of cocaine utilizing a pyroprobe. The products, norcocaine and cocaethylene, are also known metabolites (pyrolytic products obtained by a pyroprobe $(P)$ and metabolites $(M)$ ). Products were tentatively identified using a NIST MS library.

Figure 20 - Structures of benzaldehyde and benzoic acid methyl ester. 63

Figure 21 - Location of the West Virginia Maneuver Area. Image obtained from [103].

Figure 22 - (A) Soil Step Probe developed by CRREL, (B) Commercially available step soil probe.

Figure 23 - The serpentine pattern used in multi-increment sampling.

Figure below represents a $10 \mathrm{~m} \times 10 \mathrm{~m}$ decision unit.

Figure 24 - The extraction procedure represented by photos. (1) Soil is spread out on an aluminum foil covered baking sheet and dried for 24 hours. (2) Soil is sieved using a \#10 sieve to remove the oversized $(>2 \mathrm{~mm})$ fraction. Soil is gently passed through the mesh using a spoon to break up clumps. (3) Soil is ground to approximately $10 \mu \mathrm{m}$ particle diameter using a mechanical grinder. (4) Onto a sheet of aluminum foil, ground soil is spread out and 30 increments are collected from the complete depth (approximately $0.3 \mathrm{~g}$ each) to form a $10 \mathrm{~g}$ composite sub-sample for extraction. (5) $20 \mathrm{~mL}$ of acetonitrile is added to each sample and placed on a platform shaker table to be mixed for $18 \mathrm{hrs}$ at $150 \mathrm{rpm}$. (6) Supernatant is collected from each sample.

Figure 25 - Photo of the grinding process: a) Only $<2 \mathrm{~mm}$ soil is used, b) soil is divided into small portions and put into the grinding dish with a puck, c) 3 dishes are placed into the Shatterbox and set to $60 \mathrm{~s}$ intervals for a total of 5 minutes, and d) soil is ground to $\sim 10 \mu \mathrm{m}$ particle size.

Figure 26 - Photograph of researchers staking the decision unit for Grid 14. The steep, rocky and heavily vegetated terrain presented challenges during sampling.

Figure 27 - Photograph of a research group member staking out the decision unit for Grid 15. 
Figure 28 - Photograph showing researchers navigating the rocky and vegetated terrain to collect samples for Grid 16.

Figure 29 - Photograph showing the $2 \mathrm{~m} \times 2 \mathrm{~m}$ decision unit surrounding the crater found within Grid 16.

Figure 30 - Photograph showing Grid 19. The crater was nestled in the cluster of rocks shown in the center of the image.

Figure 31 - Photograph showing members of the research team gathering soil samples from Grid 20 using the CRREL coring devise.

Figure 32 - Example of the total ion chromatogram (TIC) of the

$2^{\text {nd }}$ multi-increment sample (WVU_2007_20_MI_2) taken from Grid 20. 104

Figure 33 - Photograph showing the crater in the area where a $60 \mathrm{~mm}$ mortar was found and detonated during the first trip to Dolly Sods (June 2007).

The area was sampled as site XD during the August 2007 Field Campaign. 107

Figure 34 - TIC of the sample taken from the detonation crater of Site XD: 109

Figure 35 -Structures of TNT, RDX, HMX and Tetryl. 118

Figure 36 - Simplified Cytochrome p450 cycle. Figure Adapted from [116]. 121

Figure 37 - The 2 main pathways for TNT phase I metabolism. 122

Figure 38 - Schematic of the in-vitro metabolism procedure. 125

Figure 39 - Results of TNT metabolism using MRM: (a) control sample, (b) metabolized sample.

Figure 40 - Processed data of the replicate aqueous TNT standard, unmetabolized, and metabolized samples $(n=5)$.

Figure 41 - Prec scan of $46 \mathrm{~m} / \mathrm{z}$ for the control and metabolized sample of RDX. MS data shows that the peak corresponds to an $m / z$ of 281 , which is RDX. 140

Figure 42 - TNT metabolized sample after 6 freeze thaw cycles. 145 


\section{List of Abbreviations, Symbols/Nomenclature}

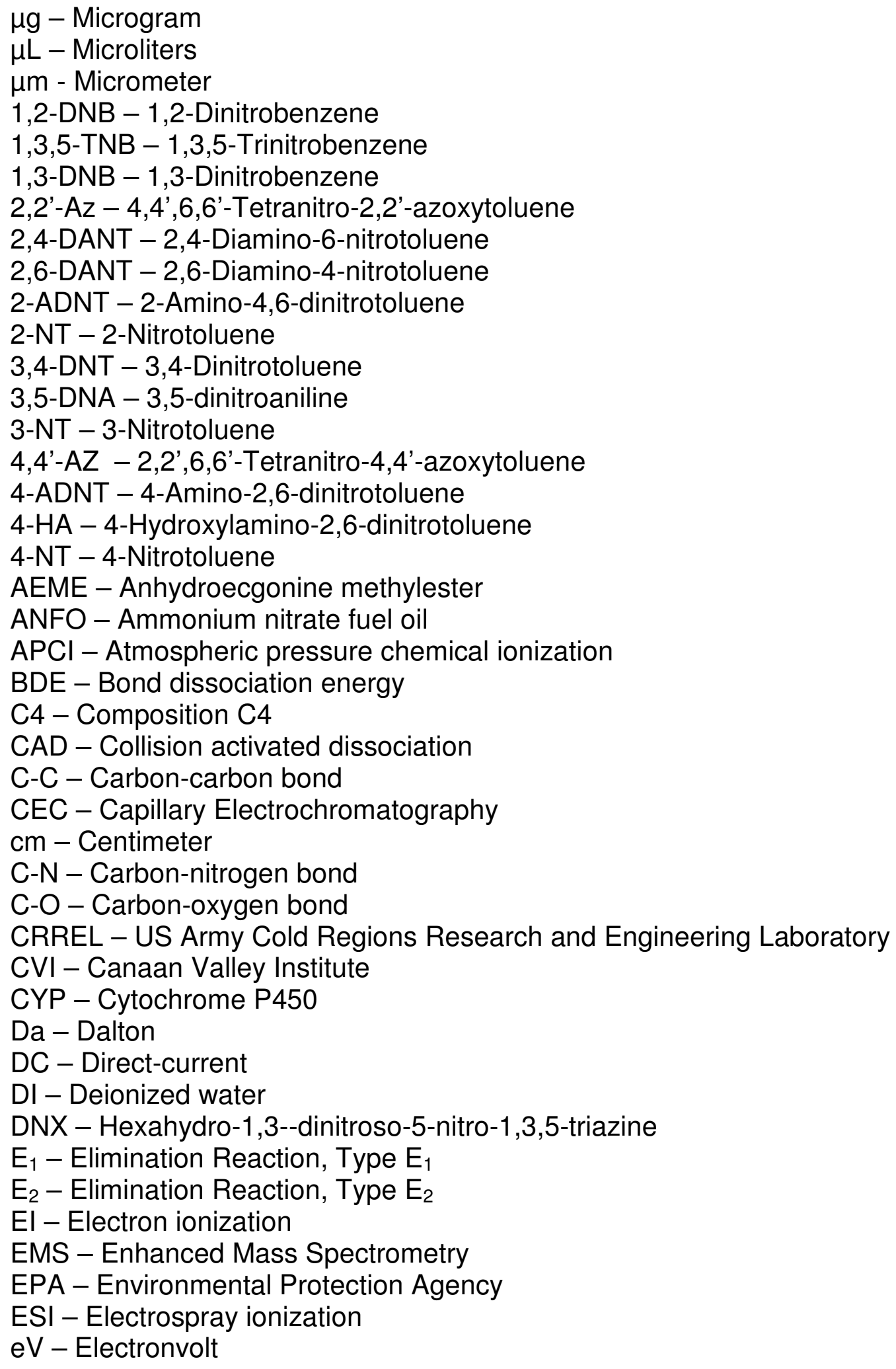




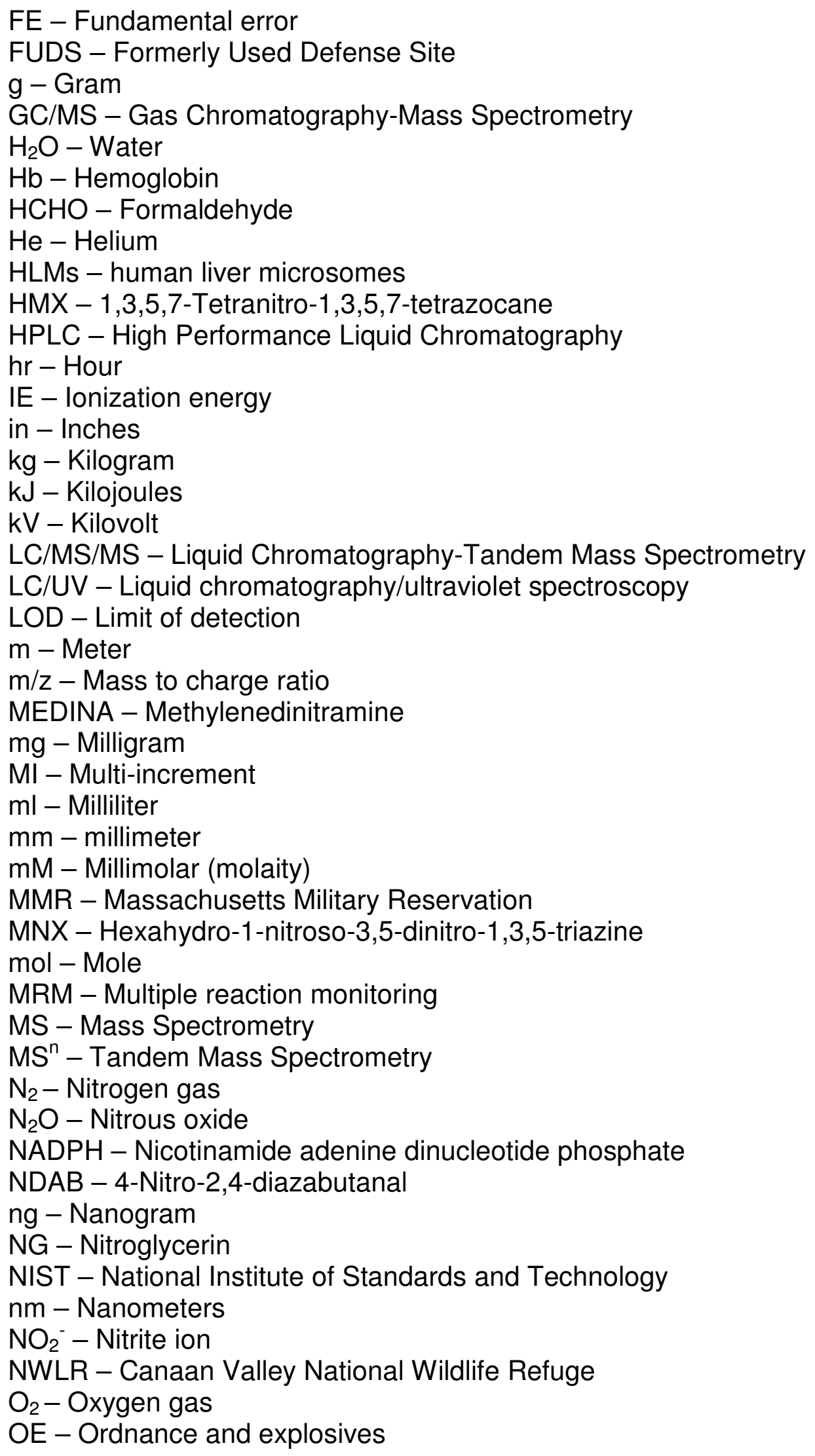




\author{
P450 - Cytochrome P450 \\ PDA - Photodiode array \\ PETN - Pentaerythritol tetranitrate \\ pg - Picogram \\ $\mathrm{ppb}$ - Parts per billion $(\mu \mathrm{g} / \mathrm{l})$ \\ ppm - Parts per million ( $\mathrm{mg} / \mathrm{l})$ \\ Prec - Precursor ion scan \\ Prod - Product ion scan \\ psi-Pounds per square inch \\ PTFE - Polytetrafluoroethene \\ QA/QC - Quality Assurance/Quality Control \\ QC PALs - QC Performance Acceptance Limits \\ RDX - 1,3,5-Trinitro-1,3,5-triazacyclohexane \\ RF - Radio-frequency \\ Rpm - Revolutions per minute \\ T - Temperature \\ TAX - 1-acetylhexahydro-3,5-dinitro-1,3,5-triazine \\ Tenax -2,6-diphenylene oxide polymer resin \\ Tetryl - 2,4,6-Trinitrophenyl-N-methylnitramine \\ TIC - Total ion chromatogram \\ TNB - 1,3,5-Trinitrobenzene \\ TNT - 2,4,6-Trinitrotoluene \\ TNX - Hexahydro-1,3,5-trinitroso-1,3,5-triazine \\ USACE - US Army Corps of Engineers \\ UXO - Unexploded ordnance \\ VOD - Velocity of detonation \\ WVMA - West Virginia Maneuver Area \\ $\Delta$ - heat \\ $\omega-$ Angular frequency
}




\section{Chapter 1: Introduction}

\subsubsection{Development of Research}

At a glance, it may be difficult to see how the topics addressed in this dissertation (drugs, explosives, pyrolysis, environmental degradation, and metabolism) all tie together. Therefore, I wanted to briefly explain the development leading up to this research. I first became interested in using a pyroprobe device to simulate smoking in order to identify biomarkers that arise from smoking (smoked biomarkers). As of 2004, a pyroprobe had not been used for drug analysis but rather for pyrolyzing and identifying polymers. Cocaine and methamphetamine were chosen for this study since both drugs are abused by smoking and the pyrolysis of both drugs had been widely studied (smoking temperatures range from $\left.400-830^{\circ} \mathrm{C}[31]\right)$. After pyrolyzing cocaine and methamphetamine using my method, I noticed that other significant products were produced in addition to the smoked biomarkers. The pyroprobe unit produced some of the reported human metabolites. The different mechanism of production of these degradation products intrigued me.

From that point on, metabolism became my point of interest due to the broader issues of human and ecotoxicity. I did not want to study the metabolism of drugs since this was already widely researched, but I wanted to choose a class of analytes where human metabolism had not been explored. It was during this time that I started another project that was in partnership with the West Virginia Waters Research Institute. The Army Corps of Engineers (USACE) (Huntington, WV Division) wanted a team of scientists to sample the soil at locations where UXO 
(unexploded ordnance) had been identified and blown-in-place in the West Virginia Maneuver Area. The detection of any residual explosives at these locations would present the USACE a question of whether or not remediation was needed. The analytes of interest included the military explosives, TNT, RDX, HMX, and Tetryl and TNT metabolites/degradation products. After completing this project, my choice of analytes to study human metabolism became clear. The presence of these military explosives can and has lead to groundwater contamination which becomes a threat to the health of people in the surrounding area [1-3]. Determining human biomarkers of these explosives can assist the military and toxicologists with a marker that can assist in establishing the level of human exposure. Although these projects are diverse from another, the common theme of this dissertation is compound degradation: degradation by thermal and metabolic mechanisms.

\subsubsection{Compounds of Interest}

\subsubsection{Cocaine and Methamphetamine}

The chemical properties of cocaine and methamphetamine are listed in Table 1. Cocaine has been used for thousands of years. In 1885, German chemist Friedrich Gaedecke extracted the active ingredient from coca leaves that are commonly found in Peru and Bolivia [4]. He called the active ingredient erythroxyline, which was later renamed "cocaine" by Albert Niemann. Leading into the $19^{\text {th }}$ century, cocaine was widely studied by both scientists and psychologists. 
Table 1 - Chemical properties of cocaine and methamphetamine [5-7].

\begin{tabular}{|l|l|l|}
\hline & Cocaine & Methamphetamine \\
\hline Molecular Formula & $\mathrm{C}_{17} \mathrm{H}_{21} \mathrm{NO}_{4}$ & $\mathrm{C}_{10} \mathrm{H}_{15} \mathrm{~N}$ \\
\hline Molecular weight $(\mathrm{g} / \mathrm{mol})$ & 303.4 & 149.2 \\
\hline pKa & 5.6 & 9.9 \\
\hline Solubility & $\begin{array}{l}\text { Soluble in water, alcohol, } \\
\text { and chloroform }\end{array}$ & $\begin{array}{l}\text { Soluble in water, alcohol, } \\
\text { and chloroform }\end{array}$ \\
\hline Melting Temperature $\left({ }^{\circ} \mathrm{C}\right)$ & 195 & $170-175$ \\
\hline Half-life, Blood (hours) & $0.7-1.5$ & $7-34$ \\
\hline
\end{tabular}


Among the psychologists was Sigmund Freud, who wrote a paper entitled, "On Coca," which discussed his observations on cocaine use. He stated, "long lasting intensive mental or physical work can be performed without fatigue; it is as though the need for food and sleep, which otherwise makes itself felt peremptorily at certain times of the day, were completely banished." His observations also lead him to discover that cocaine had the ability to relieve pain, thus making it the first local anesthetic [4].

Manufacturing cocaine involves extracting the Erythroxylon coca plant found at the eastern foothills of the Andes Mountains. The amount of cocaine found in the Erythroxylon coca plant is low, one half of $1 \%$ cocaine, and some strains of this plant contain no levels of cocaine. To make the coca paste, typically the leaves of the Erythroxylon coca plant are separated by soaking leaves in kerosene, water, sodium carbonate and sulfuric acid. About $1 \mathrm{~kg}$ of paste is produced by $100-200 \mathrm{~kg}$ of coca leaves. The paste can then be converted to cocaine hydrochloride by adding hydrochloric acid and water to allow the paste to dissolve. Potassium salt and ammonia are then added to remove any undesired products and to precipitate the cocaine as the hydrochloride salt (Figure 1). 
Figure 1 - Structure of cocaine hydrochloride.

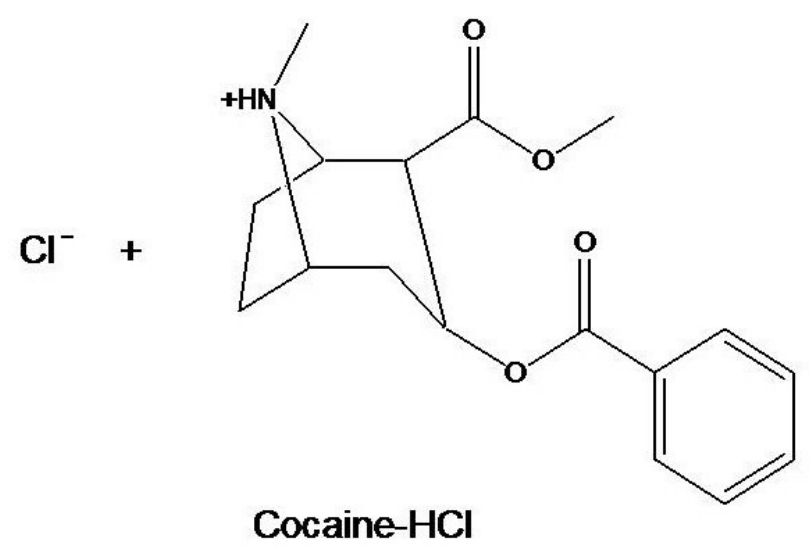


Cocaine and methamphetamine are highly addictive stimulants that acts on the central nervous system by increasing levels of dopamine in the brain [8,9]. Because the structure of methamphetamine is similar to certain neurotransmitters such as dopamine, norepinephrine, and epinephrine, methamphetamine can mimic them, blocking the reuptake of these neurotransmitters back into the originating neuron. Cocaine increases the amount of dopamine by attaching itself to the dopamine transporter. As a result, dopamine can not be recycled back to the originating neuron. Therefore, this increases the amount of dopamine in the brain causing a feeling of pleasure, excitement and alertness [9].

Methamphetamine, also referred to as "meth," "speed," "ice," "crystal," or "chalk," was first synthesized as amphetamine in 1887 by a German scientist named L. Edeleano. During the 1920's, scientists began to study amphetamine and realized it could be used for depression, narcolepsy and as a decongestant $[9,10]$. During World War II, the Japanese army used amphetamine to help stay alert and awake during missions [9, 11]. In 1919, a Japanese chemist named A. Ogata became the first to synthesize methamphetamine from ephedrine. First, ephedrine is converted to chloropseudoephedrine by the addition of $\mathrm{SOCl}_{2}, \mathrm{PCl}_{5}, \mathrm{POCl}_{3}$ or $\mathrm{PCl}_{3}$. Then, the chloro analog is reduced by catalytic hydrogenation to methamphetamine [11]. The structure of methamphetamine is shown in Figure 2. Similar to cocaine, meth can be taken orally, intranasally, intravenously and inhaled from smoking. 
Figure 2 - Structure of methamphetamine.

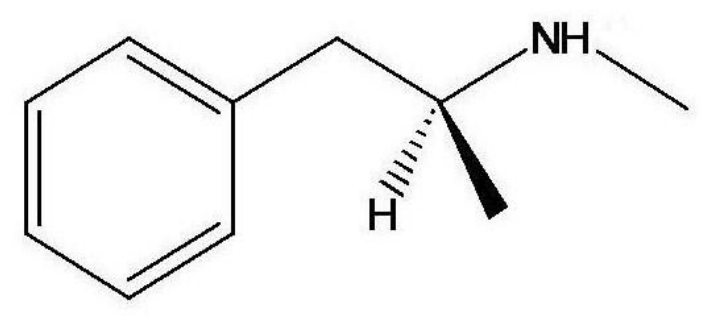

Methamphetamine 


\subsubsection{Energetic Materials}

The history of explosives can be dated as early as $220 \mathrm{BC}$ where Chinese chemists stumbled upon the first reported explosive, blackpowder [12]. Since then, other explosives such as nitroglycerin, nitrocellulose, ammonium nitrate, and ammonium nitrate fuel oil (ANFO) have been prepared. The military explosives which consist of TNT, tetryl, nitroguanidine, PETN, RDX, HMX, and picric acid, were all developed in the $19^{\text {th }}$ century [12]. This dissertation will focus on the military explosives, TNT, RDX, HMX, and tetryl. The physical and chemical properties of these explosives are shown in Table 2.

TNT was first prepared by a German chemist, Joseph Wilbrand, in 1863 [12]. Later, it became a widely used military explosive due to its chemical stability and moderate ability to withstand impact. During World War I, TNT became the standard explosive used by all armies. Compared to the other military explosives, TNT is not considered to be one of the more high performance explosives due to its lower velocity of detonation, VOD ( $\sim 6940 \mathrm{~m} / \mathrm{s})$ [13]. Consequently, during World War II, a more powerful explosive was commonly used as a second main component to TNT; this explosive was cyclotrimethylenetrinitramine, also known as RDX. The similarities between RDX and TNT include a cyclic structure with three nitro groups; however, the two differ with TNT having an aromatic ring compared to the triazine ring structure of RDX. 
Table 2 - Characteristics of TNT, RDX, HMX and Tetryl [14].

\begin{tabular}{|c|c|c|c|c|}
\hline & TNT & RDX & HMX & Tetryl \\
\hline Common Name & Trotyl & Cyclonite, hexogen & Octogen & Tetralite \\
\hline IUPAC Name & 2,4,6-trinitrotoluene & $\begin{array}{c}1,3,5- \\
\text { trinitroperhydro- } \\
1,3,5 \text {-triazine }\end{array}$ & $\begin{array}{c}\text { 1,3,5,7-tetranitro } \\
\text { perhydro-1,3,5,7- } \\
\text { tetra-azocine }\end{array}$ & $\begin{array}{l}\text { 2,4,6-trinitrophenyl- } \\
\mathrm{N} \text {-methyl nitramine }\end{array}$ \\
\hline Class & $\begin{array}{l}\text { High secondary } \\
\text { explosive }\end{array}$ & $\begin{array}{l}\text { High secondary } \\
\text { explosive }\end{array}$ & $\begin{array}{l}\text { High secondary } \\
\text { explosive }\end{array}$ & $\begin{array}{l}\text { High secondary } \\
\text { explosive }\end{array}$ \\
\hline Structure & $\mathrm{NO}_{2}$ & $\gamma_{N}-\mathrm{N}$ & $\mathrm{O}_{2} \mathrm{~N}^{\prime}$ & $\begin{array}{r}\mathrm{O}_{2} \mathrm{I} \\
\mathrm{O}_{2} \mathrm{~N}\end{array}$ \\
\hline Molecular Formula & $\mathrm{C}_{7} \mathrm{H}_{5} \mathrm{~N}_{3} \mathrm{O}_{6}$ & $\mathrm{C}_{3} \mathrm{H}_{6} \mathrm{~N}_{6} \mathrm{O}_{6}$ & $\mathrm{C}_{4} \mathrm{H}_{8} \mathrm{~N}_{8} \mathrm{O}_{8}$ & $\mathrm{C}_{7} \mathrm{H}_{5} \mathrm{~N}_{5} \mathrm{O}_{8}$ \\
\hline $\begin{array}{l}\text { CAS No. } \\
\text { Molecular weight ( } / \mathrm{mol})\end{array}$ & $\begin{array}{c}118-96-7 \\
227.1\end{array}$ & $\begin{array}{c}121-82-4 \\
222.1\end{array}$ & $\begin{array}{l}2691-41-0 \\
296.2\end{array}$ & $\begin{array}{c}479-45-8 \\
287.1\end{array}$ \\
\hline $\begin{array}{l}\text { Shock Sensitivity } \\
\text { Friction Sensitivity }\end{array}$ & $\begin{array}{l}\text { Insensitive } \\
\text { Insensitive }\end{array}$ & $\begin{array}{l}\text { Low } \\
\text { Low }\end{array}$ & $\begin{array}{l}\text { Low } \\
\text { Low }\end{array}$ & $\begin{array}{l}\text { Insensitive } \\
\text { Insensitive }\end{array}$ \\
\hline Melting Temperature $\left({ }^{\circ} \mathrm{C}\right)$ & 81 & 205.5 & $276-286$ & 129.5 \\
\hline Density $\left(\mathbf{g} / \mathbf{c m}^{3}\right)$ & 1.654 & 1.82 & 1.91 & 1.73 \\
\hline
\end{tabular}


Table 1 continued.

\begin{tabular}{|l|c|c|c|c|}
\hline $\begin{array}{l}\text { Thermal Ignition } \\
\text { Temperature }\left({ }^{\circ} \mathbf{C}\right)\end{array}$ & 300 & 260 & 335 & 185 \\
\hline $\begin{array}{l}\text { Decomposition } \\
\left.\text { Temperature ( }{ }^{\circ} \mathbf{C}\right)\end{array}$ & 295 & 170 & 280 & --- \\
\hline Solubility & $\begin{array}{c}\text { Soluble in benzene } \\
\text { and acetone }\end{array}$ & Soluble in acetone & Insoluble in water & $\begin{array}{c}\text { Slightly soluble in } \\
\text { water and other } \\
\text { solvents }\end{array}$ \\
\hline $\begin{array}{l}\text { Vapor Pressure } \\
(\mathbf{m m H g} \text { at 25 }\end{array}$ & $5.5 \times 10^{-6}$ & $4.6 \times 10^{-9}$ & $3 \times 10^{-9}$ & $5.7 \times 10^{-9}$ \\
\hline $\begin{array}{l}\text { Velocity of Detonation } \\
(\text { VOD) }(\mathbf{m} / \mathbf{s})\end{array}$ & $\sim 6940$ & $\sim 8440$ & $\sim 9110$ & $\sim 7920$ \\
\hline
\end{tabular}


RDX was first prepared for medicinal use by Henning in 1899 and then as an explosive by Herz in 1920. It was not manufactured as an explosive until 1925, when a more economical way to synthesize it was discovered by Hale at Picatinny Arsenal. From this process came the discovery of $\mathrm{HMX}$, an $8-12 \%$ byproduct from the synthesis of RDX [12]. RDX (VOD $\sim 8440 \mathrm{~m} / \mathrm{s}$ ) and HMX (VOD $~ 9110 \mathrm{~m} / \mathrm{s}$ ), are considered to be the most powerful explosives used in the US military and all over the world [13]. Although RDX and HMX are higher performing explosives, there are disadvantages to using them as the primary military explosive. Their lower stability

places them at risk for premature detonations and the cost to manufacture RDX and HMX exceeds that of TNT [13]. In addition, RDX has recently received special attention due to its possible carcinogenic and other health related effects [15-17]. As a result, there has been increasing interest in understanding the cytotoxicity and metabolism of this explosive.

Tetryl, on the other hand, is an explosive that was commonly used as a base charge in detonators/blasting caps and as a booster [13]. It was first prepared in 1877 and used as an explosive in 1906 [12]. Its VOD $(7920 \mathrm{~m} / \mathrm{s})$ is higher than TNT but is more sensitive to impact. Generally, tetryl is not found in today's military explosive devices, but is still found in landmines and some formulations [13].

\section{Cytotoxicity of TNT, RDX, HMX and Tetryl}

The first cases of TNT poisoning occurred during the World War I era in which thousands of TNT munition factory workers were reported to have had acute toxic 
jaundice in the US, England and Germany [1]. Besides toxic jaundice, other symptoms of TNT poisoning were appearing such as dermatitis, gastritis, cyanosis and aplastic anemia. It was shown that the poisoning affected the liver and red blood cells by destroying or damaging the cells. After the deaths of hundreds of workers, the TNT manufacturing industry changed their hygiene program which resulted in a rapid decrease in TNT poisoning [1].

RDX intoxication was first seen in 1939 and 1942 when 17 Italian munition workers were reported to have had either convulsions, loss of consciousness, vertigo, confusion, or vomiting [1]. The intoxication had not lead to death until a report by Tsa and Lee discussed the RDX poisoning of eight people who had eaten from bowls which had been previously used to mix RDX with other substances 3 years prior. As a result, one person died and the others experienced symptoms such as vomiting, dizziness, headaches, muscular cramps and nausea. Research to determine the toxicity of RDX has been conducted using animals such as rabbits, guinea pigs and rats. From these studies, the systematic toxicity from RDX poisoning was determined to include bronchopneumonia, pneumonia, degenerative renal lesions, depressed bone marrow activity, pulmonary congestion and mild degenerative myocarditis. Since then, further research has suggested an exposure limit of RDX is $1.5 \mathrm{mg} / \mathrm{m}^{3}$ in humans [1].

Although HMX was used during the World War II era, minimal research has been conducted on the symptoms and systematic toxicity that HMX poisoning produces. Since RDX and HMX are similar in structure, many assume that the 
effects of HMX are the same as RDX [1]. Until further research is performed on the toxicity of HMX, this statement can neither be proven nor disputed.

Tetryl poisoning has been shown to cause fatigue, vertigo, apathy, insomnia, depression, sweating, nervousness and headaches. However, the most common symptom of tetryl exposure is dermatitis. In terms of carcinogenicity, research has shown that tetryl (an analog of the carcinogen, $\mathrm{N}$-methyl-N-nitrosoaniline) has been proven to produce tumors in rats at 10 doses of $40 \mathrm{mg}$ a day for over 30 days. [1].

\subsubsection{Methods of Degradation}

\subsubsection{Thermal Degradation (Pyrolysis)}

Pyrolysis is a process that applies high heat (typically in the range from 500 $800^{\circ} \mathrm{C}$ ) to thermally decompose chemical bonds $[18,19]$. The study of the products produced by pyrolysis, also referred to as pyrolytic products, is known as analytical pyrolysis. Analytical pyrolysis allows for the control of temperature, heating rate, and time in a reproducible manner. This enables researchers to study the fragmentation that is characteristic of the original compound. It is primarily based upon the bond strengths between each atom of a molecule with weaker bonds being broken first. Therefore, if the same pyrolysis conditions are applied, the pyrolytic products should be reproducible $[18,20]$.

Generally, pyrolytic products are formed via free radical degradation mechanisms. The types of fragments that are formed are based upon the types of chemical bonds present in the original molecule $[18,20]$. Common reactions seen in pyrolysis include eliminations, rearrangements, oxidations, reductions, substitutions 
or additions. Of the 6 reactions, eliminations and rearrangements are seen more frequently in pyrolysis [19]. Elimination reactions, which are very common in pyrolysis, involve forming new products from fragments. $E_{2}, E_{1}$ and an elimination reaction involving a free radical mechanism can occur during pyrolysis. Figure 3 shows a generic elimination reaction involving a free radical mechanism that includes an initiation, propagation and termination step. This type of reaction proceeds with the weakest bonds being broken first.

A rearrangement reaction involves an atom or group moving from one place to another on the same molecule. A 1,2 shift is a common rearrangement reaction and is shown in Figure 4. Although this reaction most commonly occurs between the 1 and 2 positions, this shift can also be observed in positions further apart [19]. Additionally, this reaction usually involves a free radical being formed and then free radical rearrangement occurring between the two positions [19]. In general, there are 3 statements that can be made about the products formed by pyrolysis. First, the mechanism behind pyrolysis involves free radical formation with the weakest bonds being broken first. Second, the pyrolytic products are based on the stability of the free radicals. Last, the stability of the free radicals follows the order $3^{\circ}>2^{\circ}>1^{\circ}$ $>\mathrm{CH}_{3}[18]$.

Analytical pyrolysis has been performed on several different types of compounds. Of all the different substances, analytical pyrolysis has primarily been applied to polymers [18- 23]. Forensic samples such as fibers, automobile paints, photocopier toners, chewing gum, and blood stains [18, 24-28] have also been 
Figure 3 - An example of an elimination reaction using a free radical mechanism commonly seen in pyrolysis (bond dissociation energies for $\mathrm{C}-\mathrm{H}$ and $\mathrm{C}-\mathrm{Cl}$ bonds are $338.4 \mathrm{~kJ} / \mathrm{mol}$ and $394.9 \mathrm{~kJ} / \mathrm{mol}[78])$.

Initiation:

$\mathrm{R}_{2} \mathrm{CH}-\mathrm{CH}_{2} \mathrm{Cl} \stackrel{\triangle}{\longrightarrow} \mathrm{R}_{2} \mathrm{CH}-\mathrm{CH}_{2} \cdot+\mathrm{Cl}$.

Propagation:

$$
\begin{aligned}
& \mathrm{R}_{2} \mathrm{CH}-\mathrm{CH}_{2} \mathrm{Cl}+\mathrm{Cl} \cdot \longrightarrow \mathrm{R}_{2} \mathrm{C} \cdot-\mathrm{CH}_{2} \mathrm{Cl}+\mathrm{HCl} \\
& \mathrm{R}_{2} \mathrm{C} \cdot-\mathrm{CH}_{2} \mathrm{Cl} \longrightarrow \mathrm{R}_{2} \mathrm{C}=\mathrm{CH}_{2}+\mathrm{Cl} \cdot
\end{aligned}
$$

Termination: $\quad 2 \mathrm{R}_{2} \mathrm{C} \cdot-\mathrm{CH}_{2} \mathrm{Cl} \longrightarrow \mathrm{R}_{2} \mathrm{C}=\mathrm{CH}_{2}+\mathrm{R}_{2} \mathrm{CCl}-\mathrm{CH}_{2} \mathrm{Cl}$

$2 \mathrm{Cl} \longrightarrow \mathrm{Cl}_{2}$ 
Figure 4 - An example of a 1,2 shift rearrangement reaction.
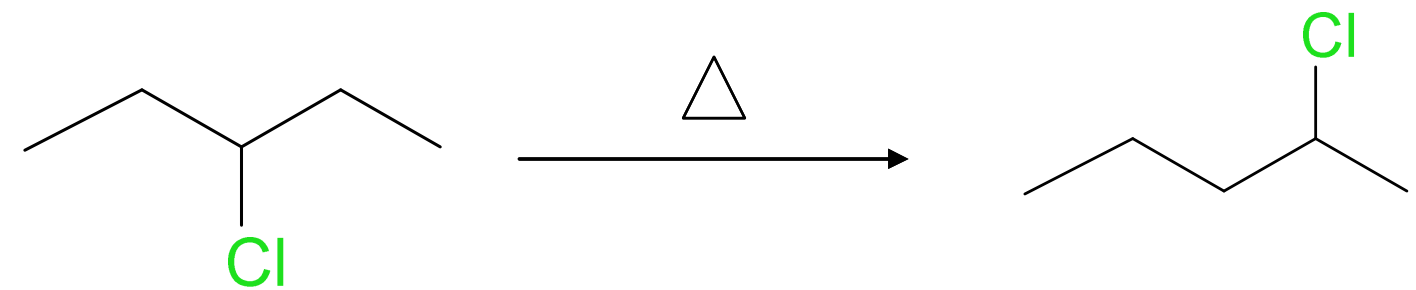
studied. Pyrolysis of abused drugs has also been performed to mimic the high temperatures achieved when these drugs are smoked [29-31]. Since cigarette smoking temperatures can range between $400-830^{\circ} \mathrm{C}$ [32], pyrolysis is useful in this context.

Pyrolytic products have been determined for methamphetamine using different methods. $\mathrm{A} \mathrm{C}_{8}$ cartridge has been used for collecting volatile analytes produced when methamphetamine was mixed with tobacco [30]. In addition, a smoking apparatus that simulates smoking by using a syringe attached to a cigarette mixed with methamphetamine has been used [29]. The syringe acts as a "puffing" device, drawing any volatile compounds through a glass fiber filter paper to be collected and extracted using methanol. For both methods, GC/MS was used for the detection of pyrolytic products. Another method included using a capillary tube containing methamphetamine sealed at one end and sealed with a flame at the other. The tube was wrapped in pyrolysis foil and was held at $220-500^{\circ} \mathrm{C}$ for $1 \mathrm{~min}$. The tube was then broken into 2 parts, immediately submerged in $1 \mathrm{~mL}$ of methanol and sonicated [31]. The main pyrolytic products produced at $445^{\circ} \mathrm{C}$ were amphetamine and dimethylamphetamine, respectively [31]. Other products that have been reported include $\mathrm{N}$-formyl-, $\mathrm{N}$-acetyl-, $\mathrm{N}$-propionyl-, and $\mathrm{N}$-cyanomethylmethamphetamine which were determined from mixtures of methamphetamine and tobacco [29].

Pyrolysis of cocaine has also been carried out using a U-shaped pipe made of glass that has been heated at a constant temperature. One end of the glass pipe was connected to a glass wool filter. The filter was connected to 3 traps containing 
ethanol, sulfuric acid and sodium hydroxide. Vapor from the pipe was drawn by negative pressure through the filter and traps. Cocaine and pyrolytic products were extracted from the glass wool filter using dichloromethane and analyzed using GC/MS [33]. Using this method, AEME and benzoic acid were the only two products formed.

A limitation to performing analytical pyrolysis is that the process can not completely mimic smoking conditions. For example, when smoking a cigarette, the temperature at the burning end is higher than the smoke inhaled, but the heat volatilizes the amines in the tobacco. Thus, short of a smoking machine, the smoking process can not be reproduced. Also, the smoking process contains both aerobic and anaerobic conditions. Pyrolysis systems can only perform one of these conditions at a time, limiting its use as a smoking apparatus. Although these limitations are apparent, the products produced by pyrolysis have been consistent with literature reports of smoked markers [34-36].

This dissertation (and associated publications) represents the first report of adapting a pyroprobe pyrolysis system to study smoked drugs of abuse. This research has led to a publication in the Journal of Forensic Science and has been referenced in literature. Additionally, this work has been adapted by the Bell Research Group to study other smoked drugs, such as fentanyl and ritalin.

\subsubsection{Environmental Degradation of TNT, RDX, HMX and Tetryl}

Environmental degradation of energetic materials can occur via photolytic or other chemical reactions or via metabolic reactions principally in bacteria. The 
environmental degradation of TNT can lead to a number of degradation products. Sunlight exposure transforms aqueous TNT to primarily 1,3,5-trinitrobenzene (TNB); however, 2,4,6-trinitrobenzonitrile, 4,6-dinitroanthranil, 2,4,6-trinitrobenzladehyde, 2,2',6,6'-tetranitro-4,4'-azoxytoluene (4,4'-AZ), 4,4',6,6'-tetranitro-2,2'-azoxytoluene (2,2'-Az), 2',4-dimethyl-3,3',5,5'-tetranitro-ONN-azoxybenzene and 2,4'-dimethyl3,3'5,5'-tetranitro-ONN-azoxybenzene were also detected [37]. Microbial degradation of TNT results in products that differ from photochemical decomposition. Biotransformation products such as 2-amino-4,6-dinitrotoluene (2-ADNT), 4-amino2,6-dinitrotoluene (4-ADNT), 2,4-diamino-6-nitrotoluene (2,4-DANT) and 2,6diamino-4-nitrotoluene (2,6-DANT) are commonly found in contaminated soil [37]. Figure 5 shows a biotransformation pathway leading to the main products mentioned above.

The biodegradation of RDX has been studied under anaerobic and aerobic conditions. The anaerobic studies used anaerobic sewage sludge to transform RDX to hexahydro-1-nitroso-3,5-dinitro-1,3,5-triazine (MNX), hexahydro-1,3--dinitroso-5nitro-1,3,5-triazine (DNX) and hexahydro-1,3,5-trinitroso-1,3,5-triazine (TNX) [38]. Under aerobic conditions using phytosymbiotic Methylobacterium sp. (strain BJ001), RDX was shown to metabolize to MNX and methylenedinitramine (MEDINA) [39]. In groundwater, the main environmental degradation product for RDX has been determined to be 1-acetylhexahydro-3,5-dinitro-1,3,5-triazine (TAX) [1].

Similar to RDX, HMX biodegradation has been studied under both aerobic and anaerobic conditions using different types of bacteria. The aerobic 
Figure 5 - Pathway for the environmental degradation of TNT in compost. Figure adapted from [40].

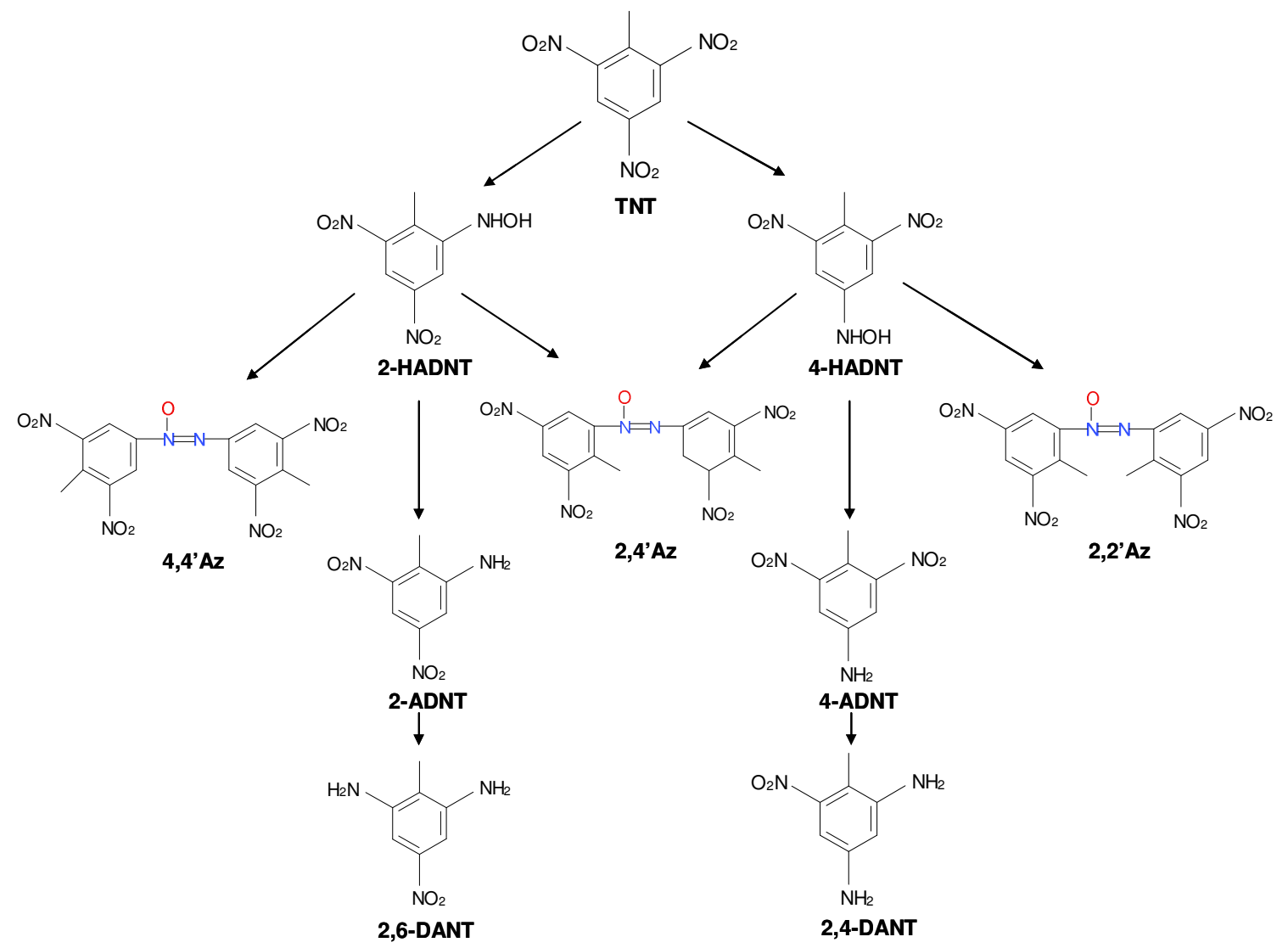


degradation using Phanerochaete chrysosporium generated 4-nitro-2,4-diazabutanal (NDAB), nitrite $\left(\mathrm{NO}_{2}{ }^{-}\right)$, nitrous oxide $\left(\mathrm{N}_{2} \mathrm{O}\right)$, and formaldehyde $(\mathrm{HCHO})$ [41]. A proposed pathway leading to these products is revealed in Figure 6. The anaerobic degradation of $\mathrm{HMX}$ has been studied using municipal sludge [42]. First, HMX degraded to MEDINA and bis(hydroxymethyl)nitramine; however, these products further degraded to nitrous oxide $\left(\mathrm{N}_{2} \mathrm{O}\right)$ and formaldehyde $(\mathrm{HCHO})$ [42].

Tetryl has also been shown to produce several environmental degradation products. The thermal decomposition of tetryl produces its hydrolysis product, $\mathrm{N}$ methyl picramide, which has been detected in water [43]. Photochemical degradation of tetryl forms picrate ion, $\mathrm{N}$-methyl picramide, methyl nitramine, nitrate and nitrite [44]. Additionally, the biodegradation of tetryl has been studied using an aerobic/anoxic soil-slurry reactor [43]. This study was shown to produce trinitro-Nmethylaniline, trinitrobenzeneamine, dinitrobenzenediamine, nitroaniline and aniline [43]. 
Figure 6 - A proposed pathway for the aerobic biotransformation of HMX. Figure adapted from [41].

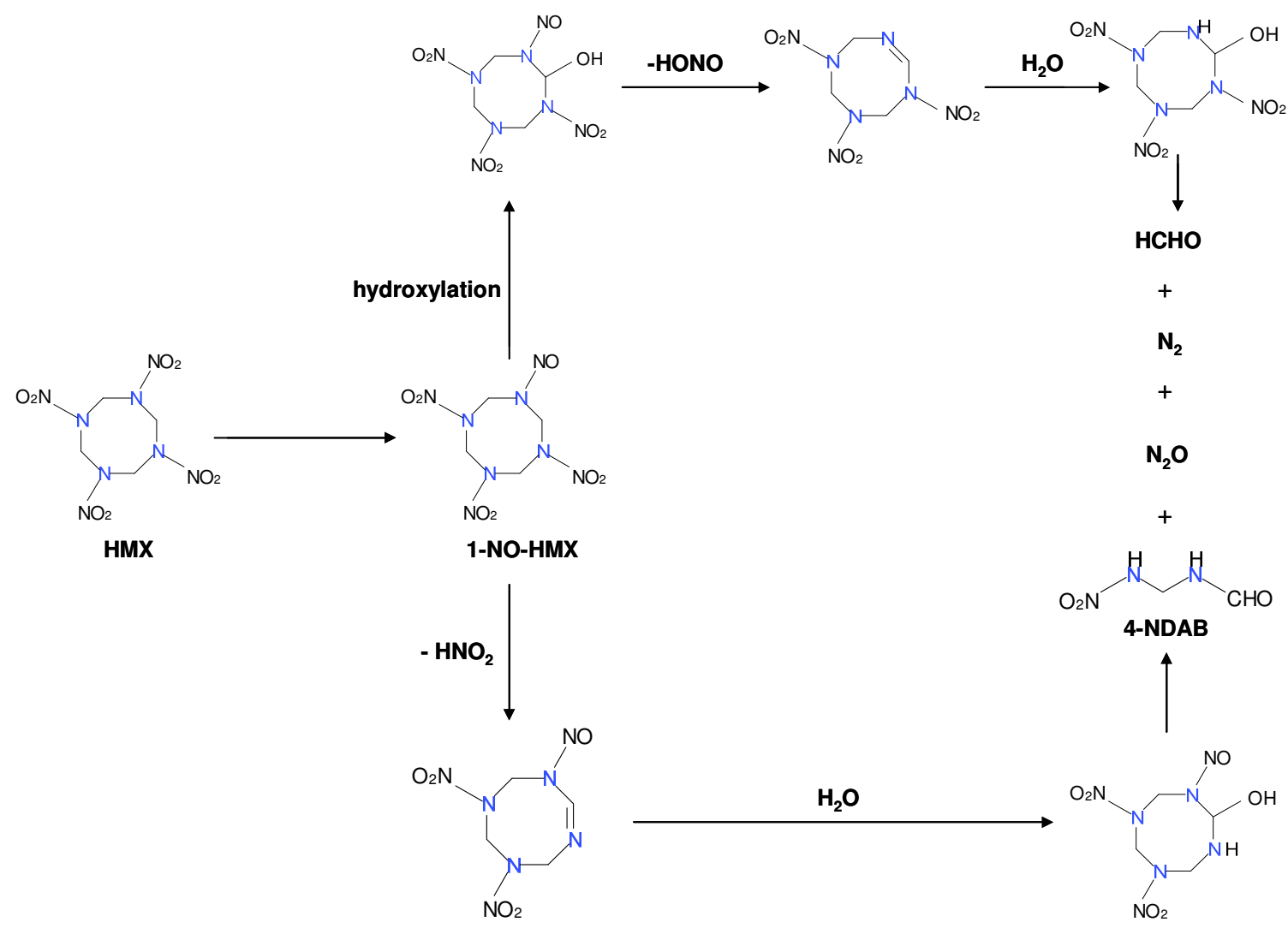




\subsubsection{Human Metabolism of TNT, RDX, HMX and Tetryl}

Table 3 lists reported metabolites of TNT, RDX, HMX and tetryl. Besides what is listed for TNT, most of the metabolites in this table were produced and discovered in animals and bacteria. Although human metabolites have been identified for TNT, little information is provided on human metabolites of RDX, HMX, and tetryl.

Of principal interest in our work is the human metabolism of energetic materials. Energetic materials can be absorbed by the body by means of inhalation, skin adsorption, and/or ingestion. Contributing to the removal of foreign substances in the body are a class of enzymes found on the smooth endoplasmic reticulum known as cytochrome P450 (CYP). These enzymes are utilized in the metabolism of exogenous compounds such as drugs, carcinogens, pesticides and pollutants that enter the body via inhalation, ingestion and absorption [45]. Not only are they involved in removing foreign compounds, but they also play a key role in the biosynthesis of steroid hormones [46]. Since there are many different types of CYPs (57 in the human body alone), each one is given a name based upon the family $(1,2,3, \ldots)$, subfamily $(A, B, C, \ldots)$ and individual $\operatorname{CYP}(1,2,3, \ldots)[47,48]$. Examples of different types of CYPs include 1A2, 2C9, 2C19, 2D6, 2E1 and 3A4 which all contribute to the metabolism of drugs in humans [45]. Cytochrome P450 enzymes are monooxygenases in which NADPH-cytochrome P450 reductase, a flavoprotein 
Table 3 - Summary of Reported Metabolic and Biodegradation Products*.

\begin{tabular}{|c|c|c|}
\hline Explosive & Metabolite & References \\
\hline \multirow[t]{17}{*}{ TNT } & 2-hydroxylamino-4,6-dinitrotoluene & 49 \\
\hline & 4-amino-2,6-dinitrotoluene & 49 \\
\hline & 6-amino-2,4-dinitrotoluene & 49 \\
\hline & 2,2',6,6'-tetranitro-2,2'-azoxytoluene & 49 \\
\hline & 2,2',6,6'-tetranitro-4,4'-azoxytoluene & 57 \\
\hline & 2,2',6,6'-tetranitro-2,4'-azoxytoluene & 57 \\
\hline & 2,4-diamino-6-nitrotoluene & 49 \\
\hline & 1,3-diamino-5-nitrobenzene & 49 \\
\hline & 4-hydroxylamino-4,6-dinitrotoluene & 58 \\
\hline & 4-hydroxylamino-2,6-dinitrotoluene & 58 \\
\hline & 2-nitro-4-hydroxybenzoic acid & 59 \\
\hline & 4-hydroxybenzaldehyde & 59 \\
\hline & 4-hydroxybenzoic acid & 59 \\
\hline & 4-nitroso-2,6-dinitrotoluene & 59 \\
\hline & 2,4,6-trinitrobenzaldehyde & 54 \\
\hline & cyclohexanone & 57 \\
\hline & & \\
\hline \multirow[t]{6}{*}{ Tetryl } & methyl picramide & 43 \\
\hline & picramide & 50 \\
\hline & picric acid & 50 \\
\hline & p-nitroaniline & 50 \\
\hline & trinitroanisole & 50 \\
\hline & & \\
\hline \multirow[t]{11}{*}{$\mathrm{RDX} / \mathrm{HMX}$} & $\begin{array}{l}\text { hexahydro-1,3,5-trinitroso-1,3,5- } \\
\text { triazine (TNX) }\end{array}$ & 38 \\
\hline & $\begin{array}{l}\text { hexahydro-1-nitroso-3,5-dinitro-1,3,5- } \\
\text { triazine (MNX) }\end{array}$ & 38 \\
\hline & $\begin{array}{l}\text { hexahydro-1,3-dinitroso-5-nitro-1,3,5- } \\
\text { triazine (DNX) }\end{array}$ & 38 \\
\hline & formaldehyde & 41 \\
\hline & 4-nitro-2,4-diazabutanal & 60 \\
\hline & formaldehyde & 60 \\
\hline & ammonia & 60 \\
\hline & methylenedinitramine (MEDINA) & 60 \\
\hline & 1-NO-HMX & 60 \\
\hline & bis(hydroxymethyl)-nitramine & 60 \\
\hline & $\mathrm{N}$-nitrosodiethanolamine & 60 \\
\hline
\end{tabular}

$*: \mathrm{CO}_{2}$ and inorganic nitrate and nitrite forms are not included. 
that donates electrons, acts as a redox partner. The P450 catalytic cycle can be described in 8 steps shown in Figure 7 [45]:

1. The substrate $(\mathrm{RH})$ binds to the active site on the enzyme $\left(\mathrm{Fe}^{+3}\right)$.

2. Since Step 1 brings about a conformation change in the enzyme, this creates favorable binding for NADPH-P450 reductase. An electron is transferred from the reductase to the enzyme, thus reducing the heme to $\mathrm{Fe}^{+2}$.

3. Oxygen binds to the $\mathrm{Fe}^{+2}$ part of the enzyme producing $\mathrm{Fe}^{+2}-\mathrm{O}_{2}$.

4. A second electron is transferred from cytochrome b5 (in liver microsomal P450 systems) or direct transfer from NADPH-P450 reductase to produce $\mathrm{Fe}^{+2}-\mathrm{O}_{2}^{-}$.

5. The addition of hydrogen produces $\mathrm{Fe}^{+2}-\mathrm{OOH}$.

6. The addition of another hydrogen removes $\mathrm{OH}$ to form $\mathrm{H}_{2} \mathrm{O}$. This oxidizes the heme to $(\mathrm{FeO})^{+3}$.

7. An unstable $(\mathrm{FeO})^{+3}$ donates its oxygen to the substrate $(\mathrm{RH})$ resulting in $\mathrm{ROH}$.

8. The oxidative product, $\mathrm{ROH}$, is released from the enzyme. The heme is oxidized back to $\mathrm{Fe}^{+3}$. 
Figure 7 - Generalized P450 cycle. Figure adapted from [45].

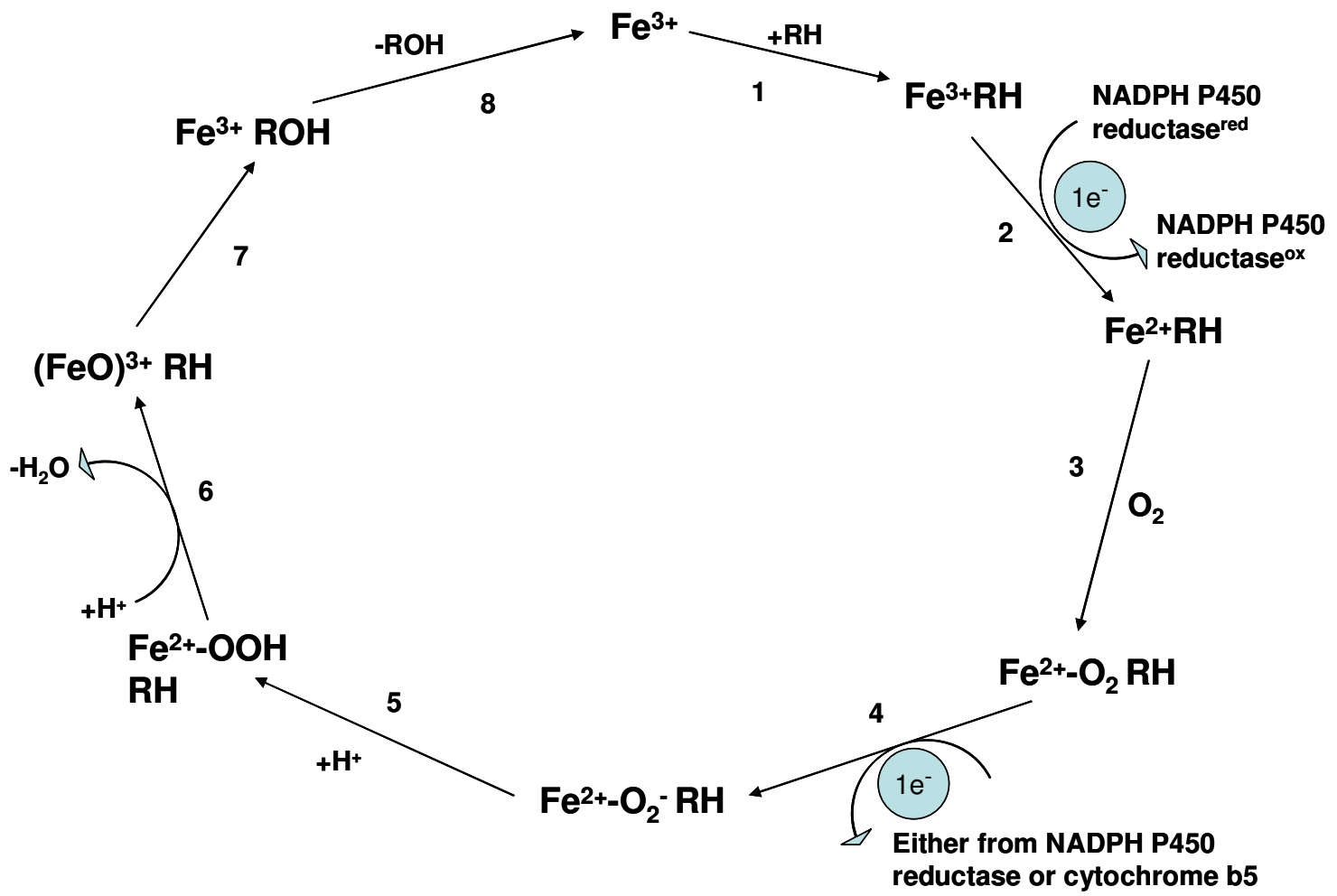


CYP enzymes are found in different parts of the body such as the lungs, liver and other tissues. The liver is thought to contain the majority of CYPs, except for $1 \mathrm{~A} 1$ and 1B1 [47]. Common reactions catalyzed by these enzymes include dehalogenation, epoxidation, hydroxylation of aromatic and aliphatic compounds, dealkylation of nitrogen, oxygen, and sulfur, and the oxidation of phosphorus, sulfur and nitrogen [51].

The experimental use of CYPs with explosives has been performed utilizing bacterial, human and non-human CYP enzymes [16, 52-56]. An in vitro metabolism of TNT was performed utilizing purified rat liver NADPH- cytochrome P450 reductase and CYPs [53]. The reduced metabolite resulting from NADPHcytochrome P450 reductase was 4-hydroxylamino-2,6-dinitrotoluene (4HA). With the addition of CYPs, the metabolites, 4-amino-2,6-dinitrotoluene (4-ADNT) and 2amino-4,6-dinitrotoluene (2-ADNT) were detected. The interpretation of these results suggest that NADPH- cytochrome P450 reductase is responsible for catalyzing the reduction of the nitro group to yield the hydroxylamine. However, CYPs are the key factor that reduces the hydroxylamine to an amine [53]. Alternatively, human biomarkers for TNT have been determined in biological fluids [62]. These biomarkers include 4-ADNT bound to hemoglobin $(\mathrm{Hb})$ in blood, and 4ADNT and 2-ADNT found in urine. The median concentration levels of these biomarkers found in Chinese ammunition factory workers were $0.21 \mu \mathrm{g} / \mathrm{mL}$ in urine and $59 \mathrm{ng} / \mathrm{g} \mathrm{Hb}$ in blood [62]. The same metabolites were also detected in people working at munition waste site in Germany. For workers that dismantled old munition, 4-ADNT was found at levels between $230-710 \mathrm{ng} / \mathrm{ml}$ in urine using gas 
chromatography/mass spectrometry (negative chemical ionization) [63]. Hemoglobin adducts with 4-ADNT were detected at a median concentration of 0.22 $\mathrm{ng} / \mathrm{g}[63]$

RDX metabolites have been identified using both bacterial and animal enzymes [15, 60, 63, 64]; however, no studies have been reported involving human CYPs. Although human metabolites of TNT have been studied [61], more research is needed for RDX, HMX and tetryl. The detection of multiple human metabolites can increase the possibility of finding a unique biomarker for RDX, HMX and tetryl.

A primary goal that emerged in this dissertation was the ability to identify biomarkers of TNT, RDX, HMX, and tetryl. Biomarkers are used as a forensic tool similar to the way metabolites are used for drugs in that they reveal evidence of ingestion. Finding biomarkers of energetic materials is important not only because they reveal evidence of ingestion, but exposure as well.

\subsubsection{Instrumentation}

The instruments used in this dissertation included gas chromatography/mass spectrometry (GC/MS) (quadrupole) and liquid chromatography/tandem mass spectrometry (LC/MS/MS) (triple quadrupole including a linear ion trap). Three types of ionization sources were used including electron ionization (EI), atmospheric pressure chemical ionization (APCI), and electrospray ionization (ESI). Additional instrument details and conditions are provided in the relevant chapter.

El is commonly coupled to GC because analytes must be thermally stabile and volatile. Since GC and El require samples to be volatile, coupling both methods 
is ideal. The process of El begins with bombarding a volatile sample with an electron beam at pressures around $10^{-5}-10^{-6}$ torr. A molecular ion or radical cation is produced when an electron from the target molecule is released due to the collision. This reaction will occur only if the kinetic energy of the colliding electrons is greater than the ionization energy (IE) of the analyte. Generally, a $70 \mathrm{eV}$ beam is utilized for ionization since this amount usually exceeds the IE of most organic molecules. As a result, the molecule will fragment into smaller molecules.

Fragmentation will continually occur if there is a sufficient amount of electron energy. Therefore, the mass spectrum produced can provide structural information pertaining to the original molecule. There are several advantages to using this type of ionization source compared to other types of sources. As mentioned above, El can provide the molecular mass and structural information of a molecule since it is a harsh ionization technique. Also, given that a large number of organic molecules (less than $600 \mathrm{Da}$ ) can be ionized using $\mathrm{El}$, over 100,000 spectral libraries have been developed and can be accessed through most GC/MS software and the internet. The limitations to using EI stem from the volatility and stability of the sample. Only volatile molecules can be ionized using this source. Also, unstable compounds may fragment to the point that the molecular ion can not be determined in the mass spectrum. In addition, the fragments produced in this high energy environment may produce small fragmented molecules, thus providing no structural information [65].

ESI is used to ionize liquid-phase samples and is useful for analyzing polar compounds and large biomolecules. The process of ESI begins after HPLC 
separation where the analytes mixed with the HPLC mobile phase (usually a water and organic mix) passes through a stainless steel capillary. The tip of this capillary is held at a potential around $3-4 \mathrm{kV}$ which produces an electrostatic field with a counter-electrode positioned at the walls of the atmospheric pressure region [65]. The analytes are in the form of ions and are present at the end of this capillary tip. In positive mode ESI, cations are present at the capillary edge and because like charges repel each other, the analytes are pushed out of the capillary end. As the charged droplets migrate towards the counter electrode, this process is counterbalanced by the surface tension of the liquid. As a result, a Taylor cone is formed (Figure 8). The solution surrounding the charged ions is evaporated by a flow of hot nitrogen gas. As the solvent evaporates, charged ions to come closer together. The charge density on the surface increases until the point of the Rayleigh instability limit. When the repulsive coulombic forces are greater than the surface tension of the droplet, coulombic explosion occurs and smaller droplets are produced [65]. This cycle is repeated until the drop size consists of one solute molecule. Ions present are then transported into the mass analyzer for detection. ESI libraries can be made in-house; however, international libraries, like those for EI, are not available. 
Figure 8 - A schematic of positive mode electrospray ionization (ESI). Figure adapted from [66].

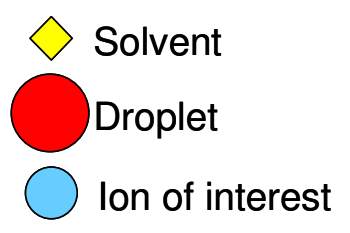

\section{Oxidation}

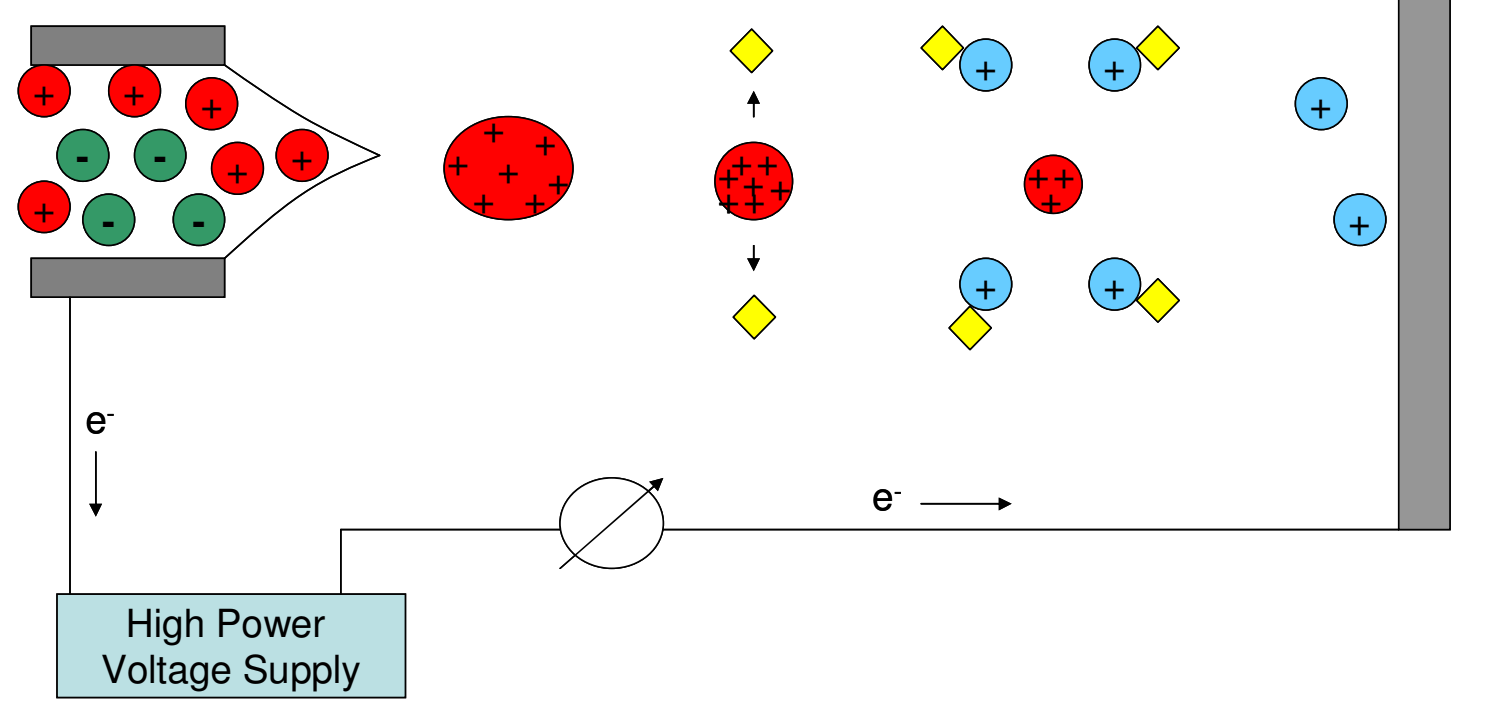


$\mathrm{APCl}$ is also an ionization method utilized for liquid phase samples and ionizes molecules in a manner similar to that of chemical ionization. Compared to ESI, APCI can be applied to less polar molecules. As the LC eluent enters the ionization source through a fused-silica capillary, it meets nebulizing and sheath gases (both are $\left.\mathrm{N}_{2}\right)$. The LC eluent is heated $\left(350-500^{\circ} \mathrm{C}\right.$ ) and in conjunction with the high flows of nitrogen, an aerosol mist is produced (Figure 9). Ionization occurs by utilizing a discharge electrode (corona pin) that is held between $2-3 \mathrm{kV}$ with respect to the counter-electrode. As the aerosol mist comes in contact with the discharge electrode, $\mathrm{N}_{2}{ }^{+\cdot}$ and $\mathrm{O}_{2}{ }^{+}$ions produced and collide with the droplets. Charge transfers from these ions to the methanol, acetonitrile or $\mathrm{H}_{2} \mathrm{O}$ that is present in the droplets. Another charge transfer occurs from the recently charged droplets to the molecules within producing $[\mathrm{M}+\mathrm{H}]^{+}$in the positive mode. The $[\mathrm{M}-\mathrm{H}]^{-}$is produced in the negative mode caused by interactions with solvated oxygen anions. Generally, APCI can ionize molecules with an upper mass range of $1500 \mathrm{Da}$ and is preferred over ESI for non-polar compounds [65].

Both $\mathrm{ESI}$ and $\mathrm{APCl}$ were utilized in an LC/MS/MS system similar to a triple quadrupole instrument with one quadrupole acting as a linear ion trap (LIT) (Figure 10). A single quadrupole consists of 4 parallel metal rods (electrodes) positioned in a square array with applied direct-current (DC) and a radio-frequency (RF) [65]. One pair of electrodes have a positive DC potential $(U)$ and a timedependent RF potential (Vcoswt) where $V$ is the amplitude, $\omega$ is the angular frequency of the RF voltage and $t$ is time [65]. The other pair of electrodes 
Figure 9 - A schematic of atmospheric pressure chemical ionization (APCI). Figure adapted from [65].

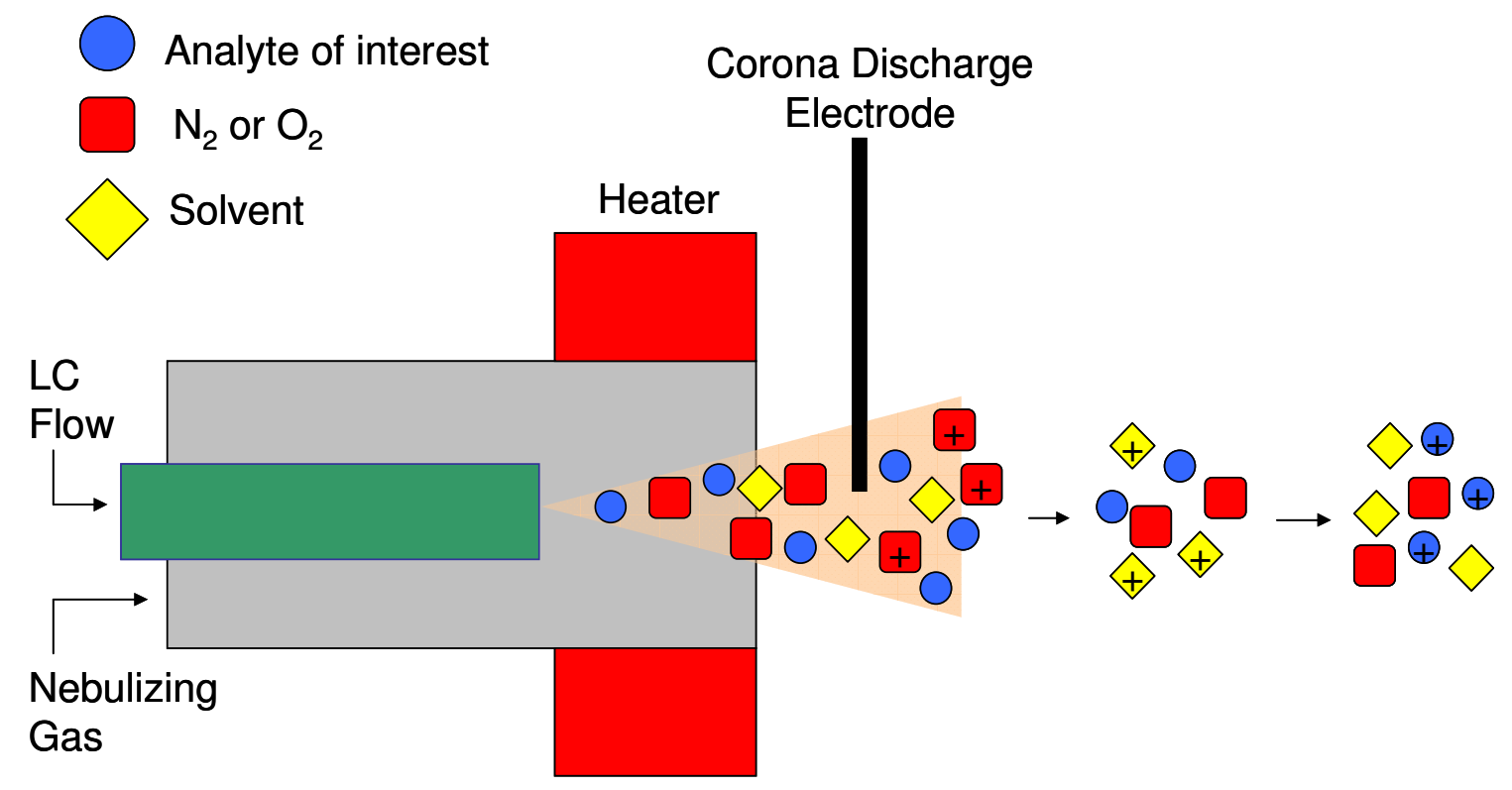


have a negative $U$ value and an $R F$ potential that is $180^{\circ}$ out of phase with the other electrode. At certain DC and RF potentials, an ion of a specific $\mathrm{m} / \mathrm{z}$ will pass through the quadrupoles due to its stable motion in this electric field. All other ions present will be ejected out of the quadrupoles because of their unstable trajectories [65].

In this LC/MS/MS system, two quadrupoles are used in series with a third that is in RF only mode (Figure 10). The first quadrupole (Q1) is used to either select ions of a certain $\mathrm{m} / \mathrm{z}$ or to allow a specified broad range of ions through to the second quadrupole (Q2). At Q2, the ion or ions are injected into an rf-only electric field. Therefore, this region acts as a wideband mass filter, allowing all ions to pass through. It is also here that a collision activated dissociation (CAD) gas (ex. $\mathrm{N}_{2}, \mathrm{Ar}$ ) may be used to collide with the ions to cause fragmentation. As fragments are formed, they migrate to the third quadrupole (Q3) which is similar to Q1. Ions can be passed through or destabilized in Q3 before reaching the detector [65]. In this particular instrument, Q3 also acts as the LIT. The LIT employs an RF potential for trapping ions in the axial and radial positions [67]. After trapping, the ions are expelled axially into the detector.

Several general scans can be performed using this type of mass analyzer. A Q1 MS scan allows a set $\mathrm{m} / \mathrm{z}$ range through $\mathrm{Q} 1, \mathrm{Q} 2$ and through Q3. A Q3 scan is similar to Q1 except all ions are passed through Q1 and Q2 but are filtered to a set range in Q3. Both $\mathrm{Q} 1$ and Q3 MS scans are general and commonly used for an unknown sample. Also, the collision cell (Q2) is not utilized for either scan. Scans 
Figure 10 - A schematic of a quadrupole linear ion trap. Figure obtained with permission from Applied Biosystems, Inc.

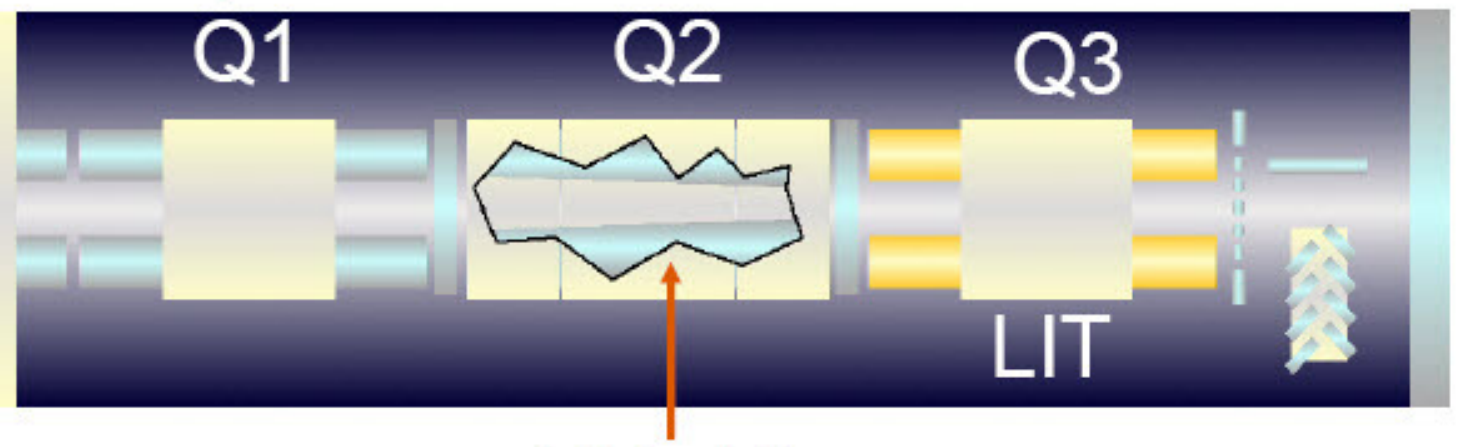

Collision Cell 
where Q2 is utilized include a product ion scan (Prod), precursor ion scan (Prec) and multiple reaction monitoring (MRM). A product ion scan allows for a selected molecule (precursor molecule) to be passed through Q1. The precursor is fragmented in Q2 and the products are scanned in Q3. This scan is typically performed to determine the most abundant fragments to be used for MRM scans. The precursor ion scan is performed by allowing a broad range of $\mathrm{m} / \mathrm{z}$ to pas through Q1 which are fragmented in Q2. A selected $\mathrm{m} / \mathrm{z}$ fragment resulting from Q2 is selected to be filtered in Q3. The mass spectrum provides information revealing which precursor ion or ions provided the specified fragment.

MRM is the most sensitive scan performed using this instrument. It can provide lower limits of detection compared to the scan discussed previously due to the trapping capabilities in Q3. In MRM, a selected precursor ion is filtered and passed through Q1. After fragmentation occurs in Q2, the most abundant fragment is collected and trapped in Q3. All other ions are ejected out of the Q3 cell. After being trapped, the ions are expelled into the detector.

The high specificity and high sensitivity that LC/MS/MS provides makes it ideal for determining explosives in different matrices. For forensic purposes, a method for detecting explosives in hand-swabs has been developed utilizing an ESI/triple quadrupole MS system [63]. The limit of detection (LOD) for the explosives ranged from $1-800 \mathrm{pg}$ injected. Additionally, a LC/tandem mass spectrometry system has also been used to identify explosives in contaminated groundwater [67]. 
Explosives metabolites have also been determined and detected using LC/MS/MS. In terms of environmental degradation, RDX and RDX transformation products in groundwater, MNX, DNX, TNX, and MEDINA, have been detected using an ESI/triple quadrupole MS system [65]. LODs for these analytes ranged from 0.1 $-0.6 \mu \mathrm{g} / \mathrm{l}$ in groundwater. In addition, RDX metabolites in Yucatan miniature pigs have been determined [66]. In this study, a quadrupole linear ion trap system was used with ESI to determine metabolites extracted from blood. In all the literature discussed above, MRM transitions were used for the identification and quantitation of explosives. 


\section{Chapter 2: Application of a Pyroprobe to Simulate Smoking of Abused Drugs through Analytical Pyrolysis}

\subsubsection{Introduction}

The goal of this project was to simulate smoking utilizing a pyroprobe for the analysis of smoked drugs of abuse, particularly cocaine and methamphetamine. At of the time this research was published, a pyroprobe, which provides simple and rapid pyrolysis, had not been used for the thermal degradation of drugs. This research laid the groundwork for the analysis of other smoked drugs such as fentanyl which is currently being studied in our laboratory.

Cocaine was highly abused during the 1980's and 1990's and although the number of cocaine abusers has declined within the last decade, there is still a large amount of cocaine being distributed in America [8]. Unlike cocaine, methamphetamine use has increased due to small clandestine laboratories synthesizing amphetamine and methamphetamine [73]. Methamphetamine is commonly abused by drinking it dissolved in alcohol, snorting it through the nose, injection by needles and smoking [73]. Cocaine can be abused the same ways; however, the freebase form of cocaine known as "crack" is the commonly smoked form [8]. Cocaine and methamphetamine are commonly smoked because this route of administration produces a quick "high" [4]. The thermal degradation products of cocaine and methamphetamine have been previously reported and summarized in Table 4.

Analytical pyrolysis can be employed to mimic the smoking process and conditions. The pyrolytic products are important because these compounds may be 
toxic and could contribute to drug-related deaths in an unknown way. Also, pyrolytic products could be exploited for use as a marker of smoking versus other modes of ingestion.

Information pertaining to pyrolysis and how it thermally degrades compounds is discussed in Section 1.3.1 of this dissertation. The pyrolytic products of cocaine and methamphetamine have already been determined using various methods. Some previous methods of pyrolyzing abused drugs include using an apparatus to simulate smoking of a tobacco cigarette laced with the drug [29, 74], heating an aluminum boat containing the drug [75] or using drug filled capillaries heated with a flame [31]. Further discussion of these methods is presented in Section 1.3.1. Disadvantages to these methods include analytical complexity and poor reproducibility due to imprecise temperature control.

An analytical pyrolysis instrument, such as a pyroprobe, addresses the issue of analytical complexity by heating samples in a controlled environment. Additional advantages are rapid sample analysis (approximately 30 minutes including the GC run) and minimal sample preparation. Pyroprobes have been used in forensic science for the pyrolysis of fibers, paints, photocopier toners, and polymeric materials [21, 24-26], but to date, pyroprobes have not been widely used in forensic toxicology or solid dose drug analysis.

One major disadvantage is that the technique is incapable of providing quantitative information. The design of the instrument includes a wire coil which is wrapped around a quartz tube containing the sample. Since the pyrolysis temperature is achieved by the wire coil, the exact temperature applied to the 
Table 4 - Reported pyrolytic products of cocaine and methamphetamine (pyrolysis temperatures ranged from $250-650^{\circ} \mathrm{C}$ ).

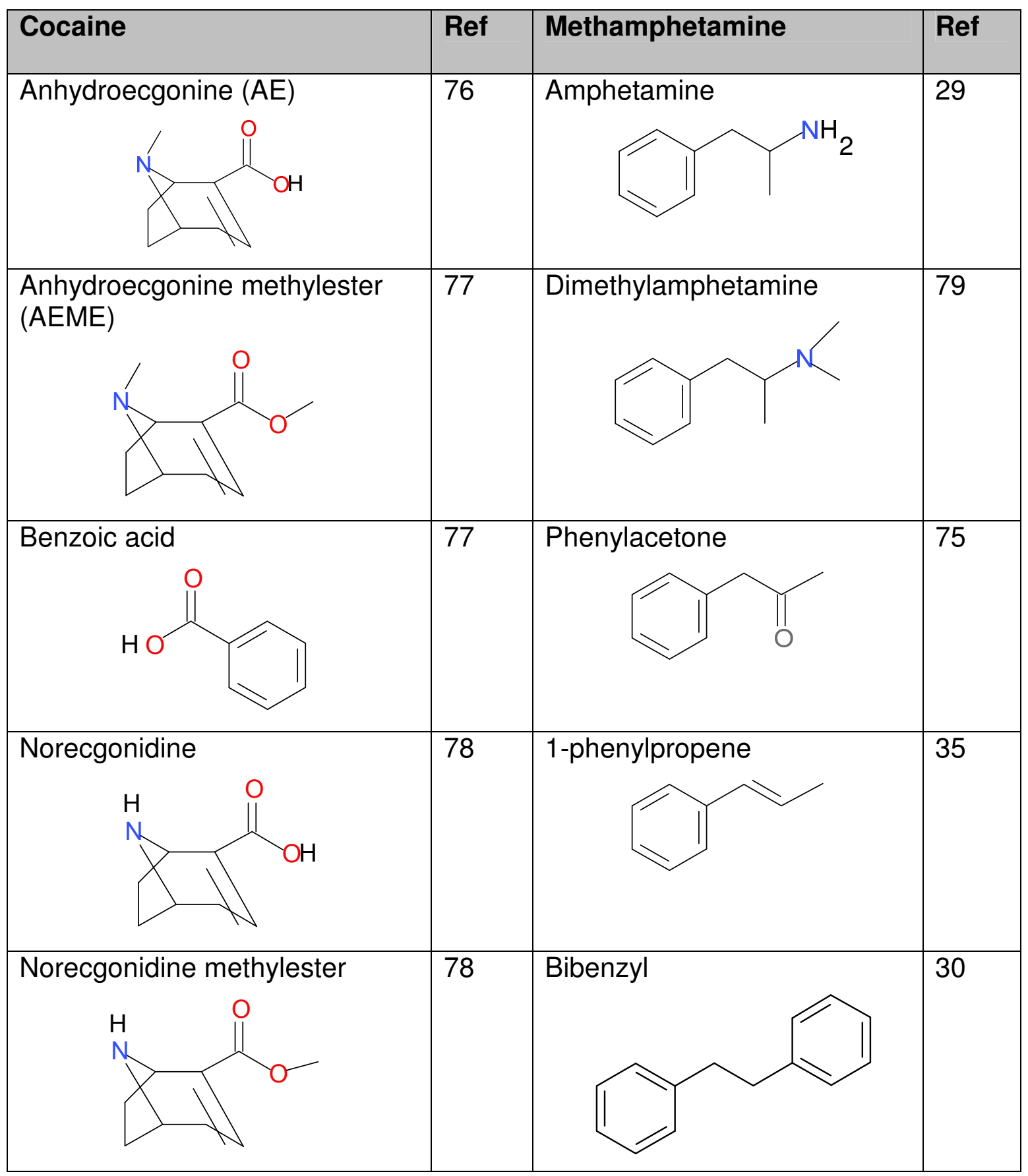


sample can not be determined. The part of the sample closest to the wire coil will receive higher temperatures, thus, uniform distribution is not achievable. Because of this issue, pyrolysis is rarely used quantitatively.

Another limitation of using a pyroprobe is that in the case of smoking, the process does not exactly reproduce the smoking event. Smoking temperatures range from $400-830^{\circ} \mathrm{C}$ [32]. Using a pyroprobe can provide conditions similar to smoking because of its ability to reach high temperatures (up to $1400^{\circ} \mathrm{C}$ ); however, the environment in pyrolysis is primarily anaerobic. In the case of tobacco smoking, the burning (pyrolysis) region of a cigarette or cigar is oxygen-deficient (anaerobic) [80]. However, it becomes an oxidative process when air is drawn in during "puffing". It was shown by Baker and Bishop that varying the oxygen levels between $2-20 \%$ showed no differences in the pyrolytic products obtained [80]. Therefore, smoking is expected to produce both anaerobic and aerobic conditions. Furthermore, reactant gas pyrolysis may better mimic conditions of smoking since oxygen is present during pyrolysis. This chapter will compare the differences between reductive (no oxygen) and oxidative (with oxygen) pyrolysis.

The present work employed the utilization of a pyroprobe device coupled to a GC/MS for the pyrolysis of cocaine and methamphetamine. The primary goal of this project was to detect smoked markers using this method. Products were tentatively identified using a NIST MS library. The pyrolytic products obtained during the study were compared to products noted in the literature (Table 4); the reported smoked 
marker of cocaine is anhydroecgonine methylester (AEME) [76] while that of methamphetamine is 1-phenylpropene [36].

Different ratios of drug and typical diluent such as lidocaine, benzocaine and caffeine were analyzed given that many street drugs contain diluents such as these. In addition, the difference between reductive and oxidative pyrolysis was also studied. This required using 2 different pyroprobe units. The first pyroprobe unit performed reductive pyrolysis under anaerobic conditions (helium). The second unit used air as a reactant gas during thermal degradation and a trap to collect the pyrolytic products. By adding air during pyrolysis, this provided conditions suitable for oxidative pyrolysis.

\subsubsection{Materials and Methods}

Cocaine and methamphetamine as hydrochloride salts, HPLC grade ethanol, benzocaine, lidocaine and caffeine were all purchased from Sigma Chemical Co. (St. Louis, MO, USA). HPLC grade methanol was purchased from Fisher Science (Fair Lawn, NJ, USA).

\subsubsection{Pyrolysis/GC/MS Instrumentation and Conditions}

Pyrolysis was performed utilizing a CDS Analytical 5150 pyroprobe (CDS Analytical, Inc., Oxford, PA). The pyroprobe consisted of four components: the pyroprobe, accessory, valve oven and transfer line (Figure 11). The sample was placed on a plug of quartz wool positioned inside a quartz tube. This can be achieved by spiking the wool with a liquid standard of the analyte or by placing the 
solid analyte directly on the wool. The quartz tube was placed inside the wire coil of the pyroprobe and inserted inside the accessory region of the pyrolysis unit. The accessory region was used to evaporate any volatile solvents present in the sample. Helium was used to purge volatile components present at temperatures below the volatile temperature of the drugs. The pyrolysis temperatures were achieved in the probe itself which was positioned inside an accessory region. The accessory and pyrolysis temperatures occurred via a controlled ramp rate (Figure 12). Helium was used to carry the volatile pyrolytic products through the transfer line into a Clarus $500 \mathrm{GC} / \mathrm{MS}$ (PerkinElmer. Waltham, MA). Pyrolysis and GC conditions for cocaine and methamphetamine are presented in Table 5. The MS consisted of an electron ionization/quadrupole with a 1 min solvent delay and a MS scan range of 50 to 600 $\mathrm{m} / \mathrm{z}$. The pyrolysis valve oven, transfer line and $\mathrm{GC}$ injection port were set to $325^{\circ} \mathrm{C}$ to eliminate any cold spots. Optimization of pyrolysis conditions was performed by pyrolyzing cocaine and methamphetamine at different temperatures ranging from $400-900^{\circ} \mathrm{C}$. The conditions providing the most pyrolytic products at the highest abundances were chosen for each drug. The pyrolysis temperature for cocaine was $750^{\circ} \mathrm{C}$ and $800^{\circ} \mathrm{C}$ for methamphetamine. 
Figure 11 - Schematic of a pyroprobe unit used for pyrolysis. The sample is placed in a quartz tube which is inserted into a wire coil that is attached to the probe. The probe is inserted into a heated accessory region where pyrolysis occurs by the rapid heating of the wire coil. The pyrolytic products are swept into the valve oven by $\mathrm{N}_{2}$ and through the transfer line to the injector port of the GC. The transfer lines and valve oven were set to $325^{\circ} \mathrm{C}$.

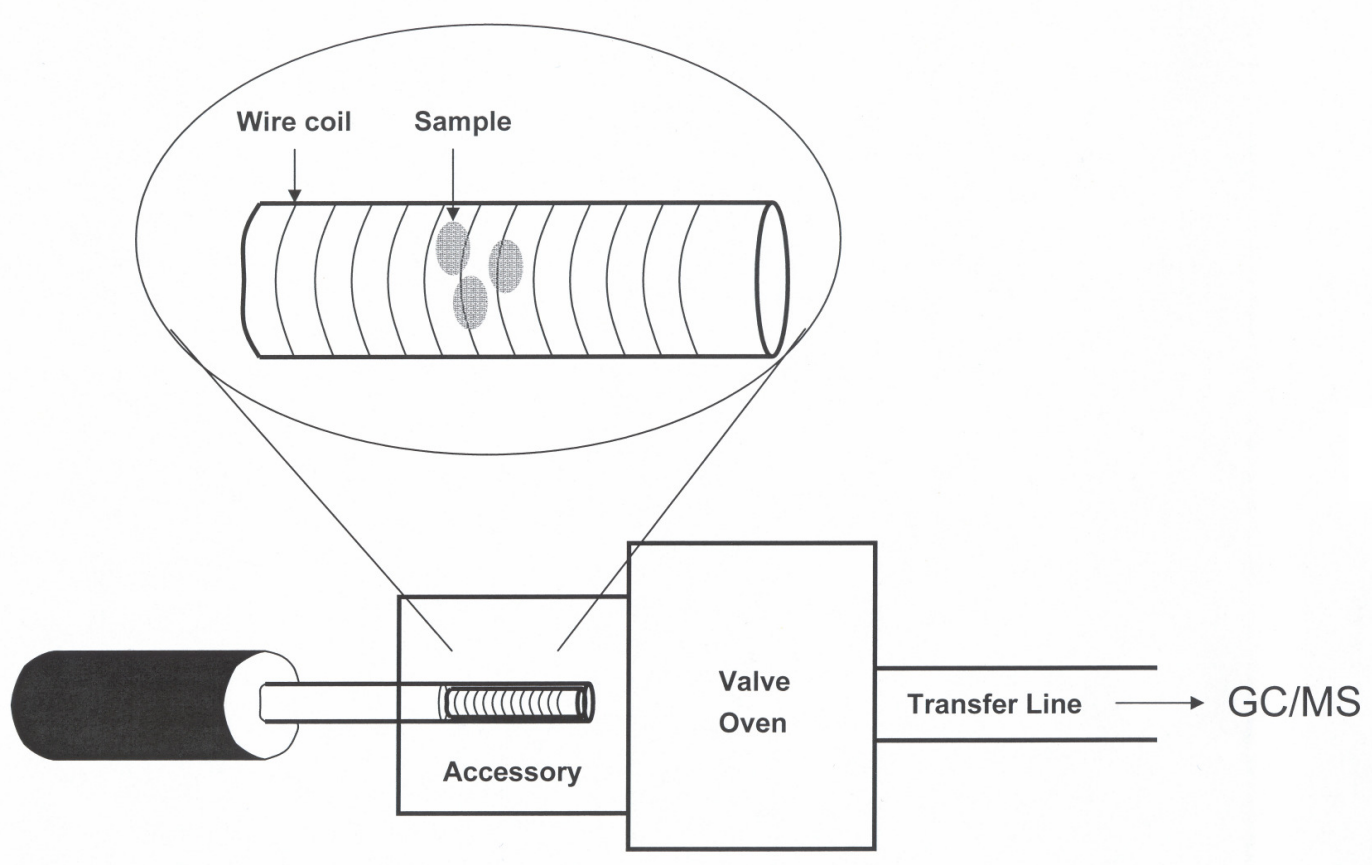


Figure 12 - Pyroprobe temperature program with no reactant gas or trapping.

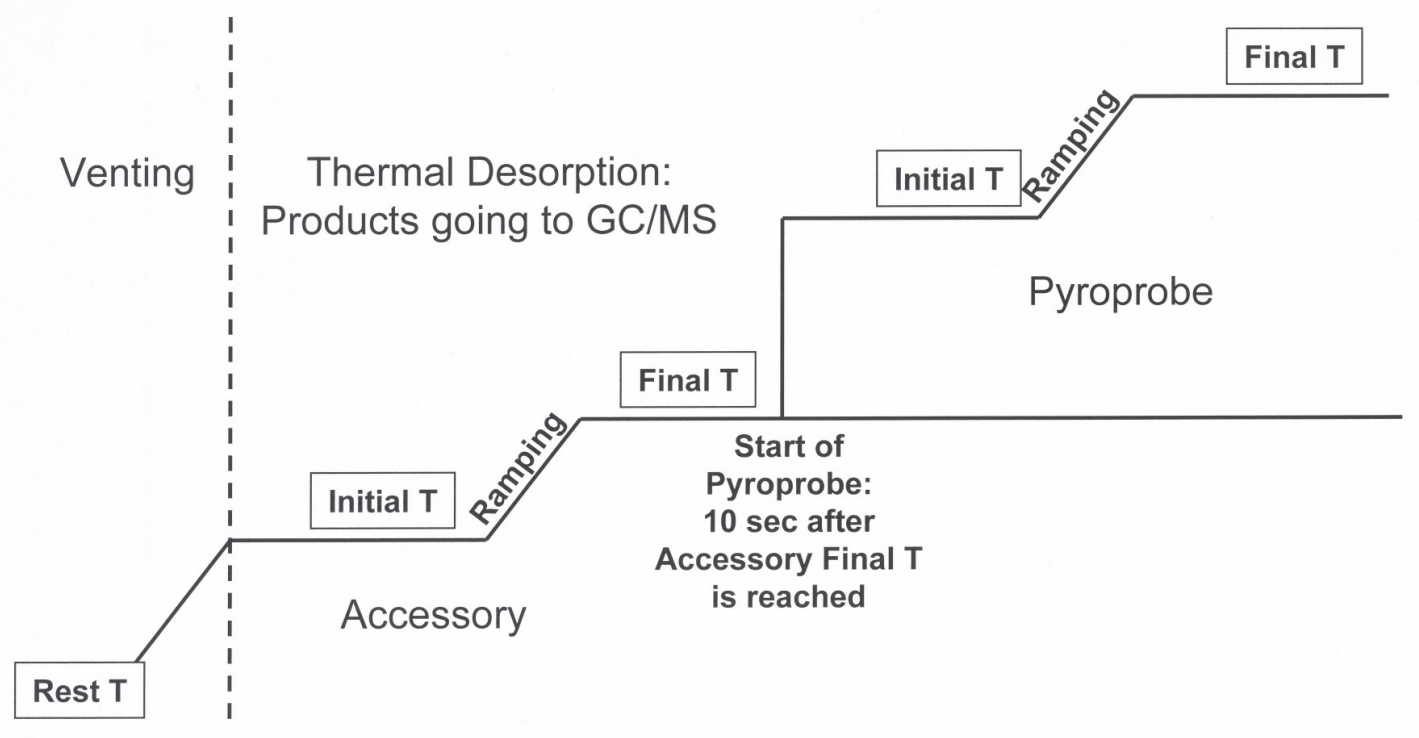


Table 5 - Pyrolysis and GC conditions.

Pyrolysis Conditions

\begin{tabular}{|l|l|l|}
\hline & Cocaine & Methamphetamine \\
\hline $\begin{array}{l}\text { Accessory } \\
\text { Temperatures }\end{array}$ & $50^{\circ} \mathrm{C}$ & \\
\hline Rest & $90^{\circ} \mathrm{C} 1 \mathrm{~min}$ & $50^{\circ} \mathrm{C}$ \\
\hline Initial & $100^{\circ} \mathrm{C} / \mathrm{min}$ & $50^{\circ} \mathrm{C} 1 \mathrm{~min}$ \\
\hline Ramp Rate & $350^{\circ} \mathrm{C} 15 \mathrm{~min}$ & $100^{\circ} \mathrm{C} / \mathrm{min}$ \\
\hline Final & & $100^{\circ} \mathrm{C} 2 \mathrm{~min}$ \\
\hline $\begin{array}{l}\text { Pyroprobe } \\
\text { Temperatures }\end{array}$ & $50^{\circ} \mathrm{C} 1 \mathrm{sec}$ & $100^{\circ} \mathrm{C} 1 \mathrm{sec}$ \\
\hline Initial & $20^{\circ} \mathrm{C} / \mathrm{sec}$ & $20^{\circ} \mathrm{C} / \mathrm{sec}$ \\
\hline Ramp rate & $750^{\circ} \mathrm{C} 10 \mathrm{sec}$ & $800^{\circ} \mathrm{C} 10 \mathrm{sec}$ \\
\hline Final & &
\end{tabular}

GC Conditions

\begin{tabular}{|l|l|l|}
\hline GC Column & \multicolumn{2}{|l|}{$\begin{array}{l}\text { PerkinElmer Elite-5 (5\% diphenyl) capillary column } \\
(30 \mathrm{~m} \times 0.25 \mathrm{~mm} \text { ID with a film thickness of } 0.25 \mathrm{~mm})\end{array}$} \\
\hline & Cocaine & \multicolumn{2}{l|}{ Methamphetamine } \\
\hline Initial Temp & $70^{\circ} \mathrm{C}$ & $50^{\circ} \mathrm{C}(1 \mathrm{~min})$ \\
\hline Ramp rate 1 & $15^{\circ} \mathrm{C} / \mathrm{min}$ & $20^{\circ} \mathrm{C} / \mathrm{min}$ \\
\hline Temp 2 & $130^{\circ} \mathrm{C}$ & $150^{\circ} \mathrm{C}(5 \mathrm{~min})$ \\
\hline Ramp rate 2 & $8^{\circ} \mathrm{C} / \mathrm{min}$ & $30^{\circ} \mathrm{C} / \mathrm{min}$ \\
\hline Temp 3 & $210^{\circ} \mathrm{C}$ & $250^{\circ} \mathrm{C}(2 \mathrm{~min})$ \\
\hline Ramp rate 3 & $10^{\circ} \mathrm{C} / \mathrm{min}$ & \\
\hline Temp 4 & $290^{\circ} \mathrm{C}$ & \\
\hline
\end{tabular}




\subsubsection{Reactant Gas Pyrolysis/GC/MS Instrumentation and Conditions}

Reactant gas pyrolysis was accomplished using a CDS Analytical 5200 pyroprobe (Figure 13). This model is similar to the 5150 used in section 2.2.1; however, it includes a second heated zone that contains trapping sorbent material. Tenax (2,6-diphenylene oxide polymer resin) is commonly used in the second heated zone because it provides good trapping for volatile and semi-volatile organic compounds. Tenax traps collect analytes with boiling points higher than $35^{\circ} \mathrm{C}$ [81]. Thus, most compounds of interest may be trapped using Tenax. There are several advantages to using the trap. This method can allow for low molecular weight and highly volatile compounds to be trapped. As a result, this pre-concentration can lead to lower detection limits. Additionally, trapping analytes can improve the chromatography of volatiles. The disadvantage is cross contamination of residual analytes that are not properly desorbed off the trap.

Additionally, a reactant gas, such as air, can be introduced into the first heated zone that contains the pyroprobe unit. The air sweeps the pyroprobe filament, transporting any volatile compounds into the Tenax trap for preconcentration. Figure 14 shows a picture of both heated zones. A detailed schematic shown in Figure 15 illustrates the gas flows with or without the trap. The non-trapping unit allows helium to sweep the volatile analytes from the pyroprobe to the GC/MS. The trapping unit sweeps the analytes using a reactant gas (air) to the sorbent trap. Once the analytes are collected onto the trap, a desorbing temperature is reached which allows the volatile analytes to leave the 
Figure 13 - Photo of the CDS Analytical 5200 model (trapping + reactant gas).

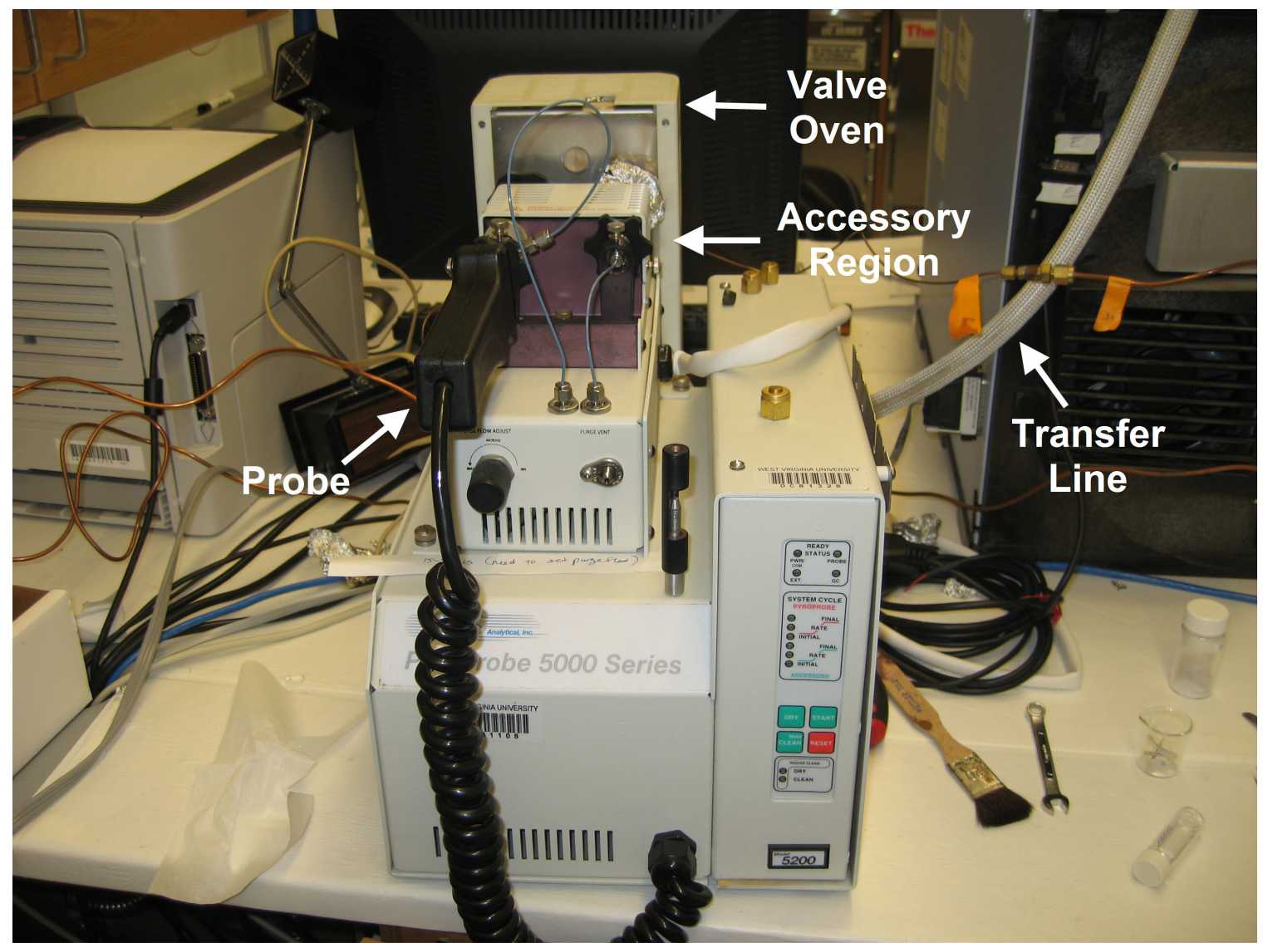


Figure 14 - Picture of the two heated zones in the 5200 model (foil was used for insulation and to reduce cold spots).

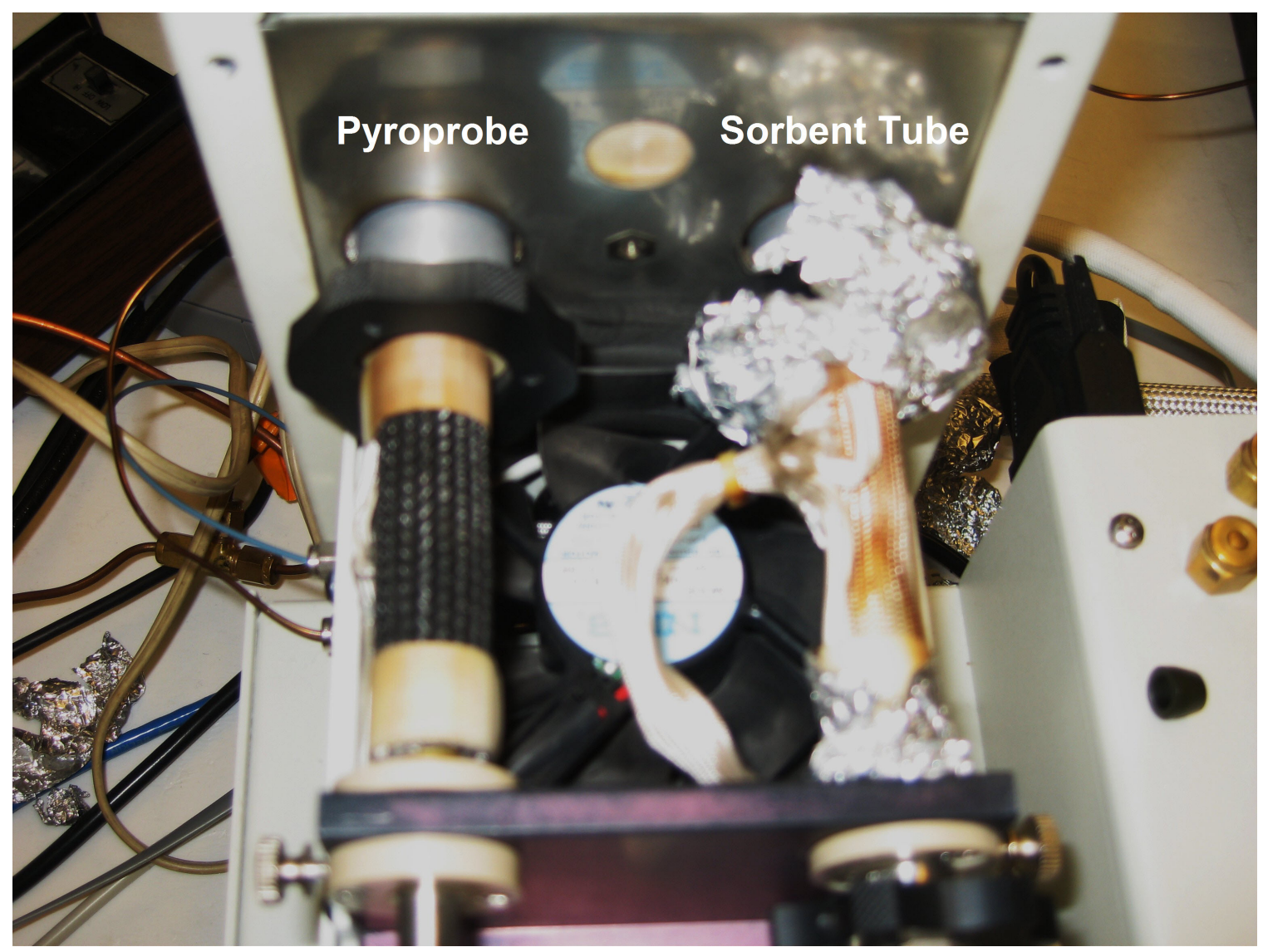


Figure 15 - Gas flow with and without trapping.

Pyrolysis (no trapping)

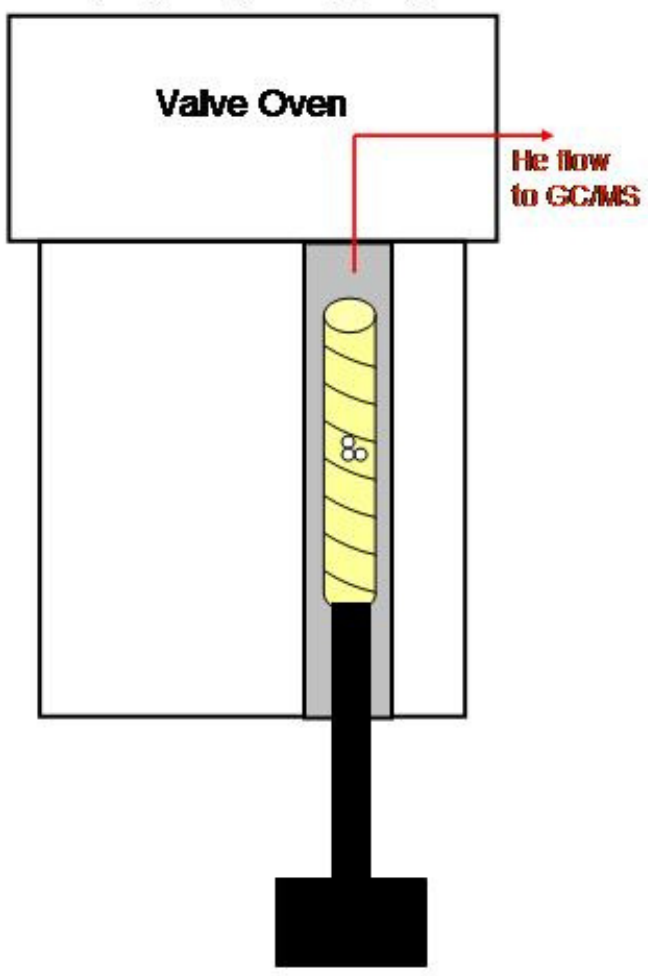

Trapping and

Reactant Gas Pyrolysis

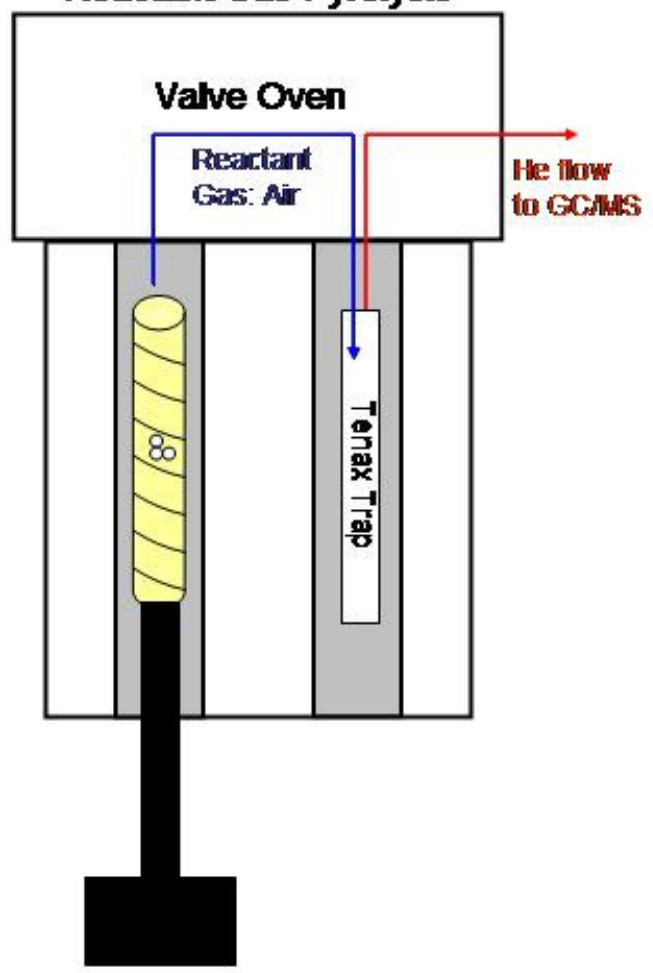


trap and be carried to the GC/MS using helium. The temperature ramp is shown in Figure 16.

The same GC/MS was used for reductive and oxidative (with trapping) pyrolysis. Additionally, the reductive pyrolysis/GC/MS conditions stated in Table 5 applied to the oxidative analysis as well. A temperature and time of $325^{\circ} \mathrm{C}$ for 2 min was set to desorb the Tenax trap.

\subsubsection{Drug Sample Preparation}

As configured, the probe can accommodate solids or liquids. In the present case, a liquid stock solution was used to insure that the same amount of drug was accurately placed in the probe for each run. This facilitated comparison of reproducibility of pyrolytic products. A 10,000. ppm stock solution of cocaine and methamphetamine prepared from solid drug were made in methanol. A $1.0 \mu \mathrm{L}$ $(10 \mu \mathrm{g})$ sample of the stock solution was injected inside the quartz tube using a syringe and pyrolyzed. A comparison of pyrolysis of liquid standard and direct pyrolysis of solid cocaine was also undertaken. The solid sample was pyrolyzed by placing between $10-80 \mu \mathrm{g}$ of the drug inside the quartz tube.

\subsubsection{Cutting Agent/Drug Mixture Control}

Stock solutions of 10,000. ppm lidocaine, benzocaine and caffeine were prepared separately. Lidocaine and benzocaine were dissolved in methanol. Because caffeine is only partially soluble in methanol, it was prepared in deionized water. A 1:1 mixture of the cutting agent with the drug was prepared to yield a 
total concentration of $5000 \mathrm{ppm}$ of each substituent. For lidocaine and benzocaine, $1.0 \mu \mathrm{L}$ was injected into the quartz tube allowing for $5 \mu \mathrm{g}$ of each substituent to be analyzed. $2.0 \mu \mathrm{L}$ was used for the caffeine/drug analysis to yield $10 \mu \mathrm{g}$ for analysis. 
Figure 16 - Pyroprobe temperature program with the reactant gas and trapping.

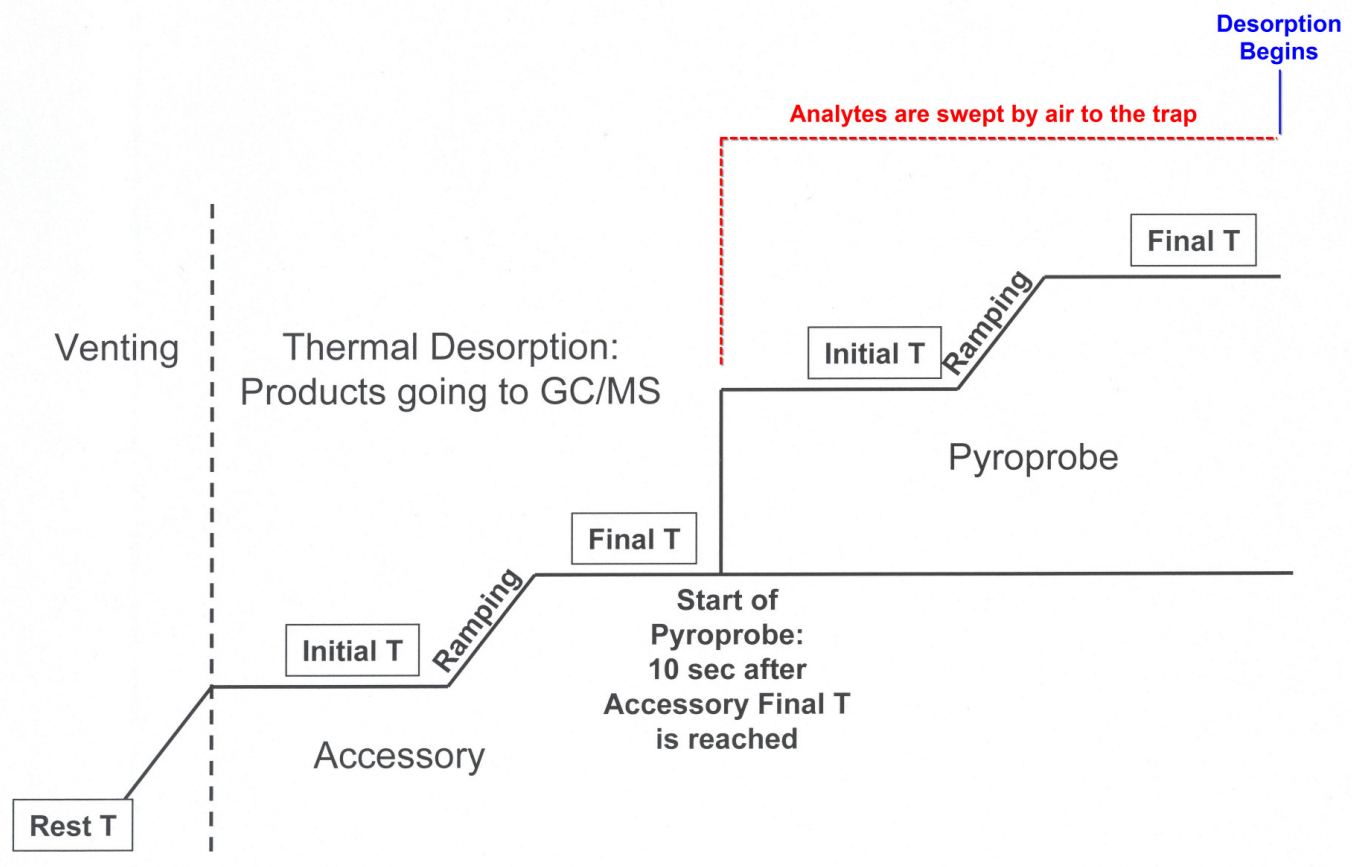




\subsubsection{Results}

\subsubsection{Analytical Pyrolysis of Drugs}

As discussed in Chapter 1, the prediction of pyrolytic products is based primarily upon bond strength. Types of measurements of the bond strength in a chemical bond include bond energy and bond dissociation energy (BDE). Figure 17 shows the relevant BDEs for both analytes [82]. Based on these energies in a thermal degradation situation, the bonds with the lowest BDE would break first.

Examples of this are witnessed in the pyrolysis of methamphetamine. The tentative identification of the pyrolytic products produced (all simple molecules) was made using a NIST MS library search. The pyrolytic products produced in reductive conditions (in order of abundance) were ephedrine, ethylbenzene, toluene, styrene, and 1-phenylpropene (Figure 18). Also, the parent compound was present at the highest level in both the solid sample and the liquid standard. Correlating with BDEs, one of the weakest bonds in methamphetamine is the C-N bond.

Ethylbenzene, toluene, styrene, and 1-phenylpropene are products formed from C-N bond breakage. The pyrolytic product, 1-phenylpropene, has been reported to be a potential marker for smoked methamphetamine and has been detected in real cases $[35,36]$. 
Figure 17 - Bond dissociation energies $(\mathrm{kJ} / \mathrm{mol})$ for cocaine and methamphetamine.

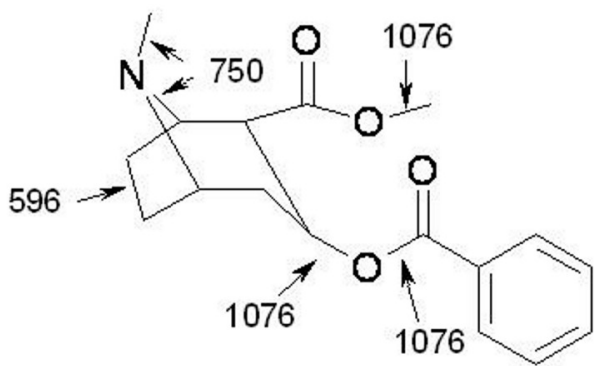

Cocaine

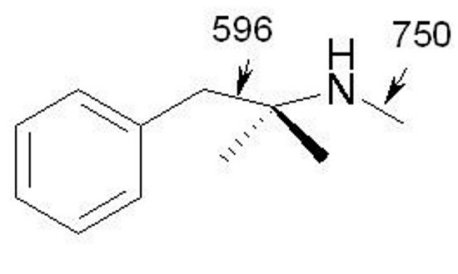

Methamphetamine 
Figure 18 - Pyrolysis results of methamphetamine utilizing a pyroprobe (pyrolysis temperature obtained was $800^{\circ} \mathrm{C}$ ). Products were tentatively identified using GC/MS and a NIST MS library.

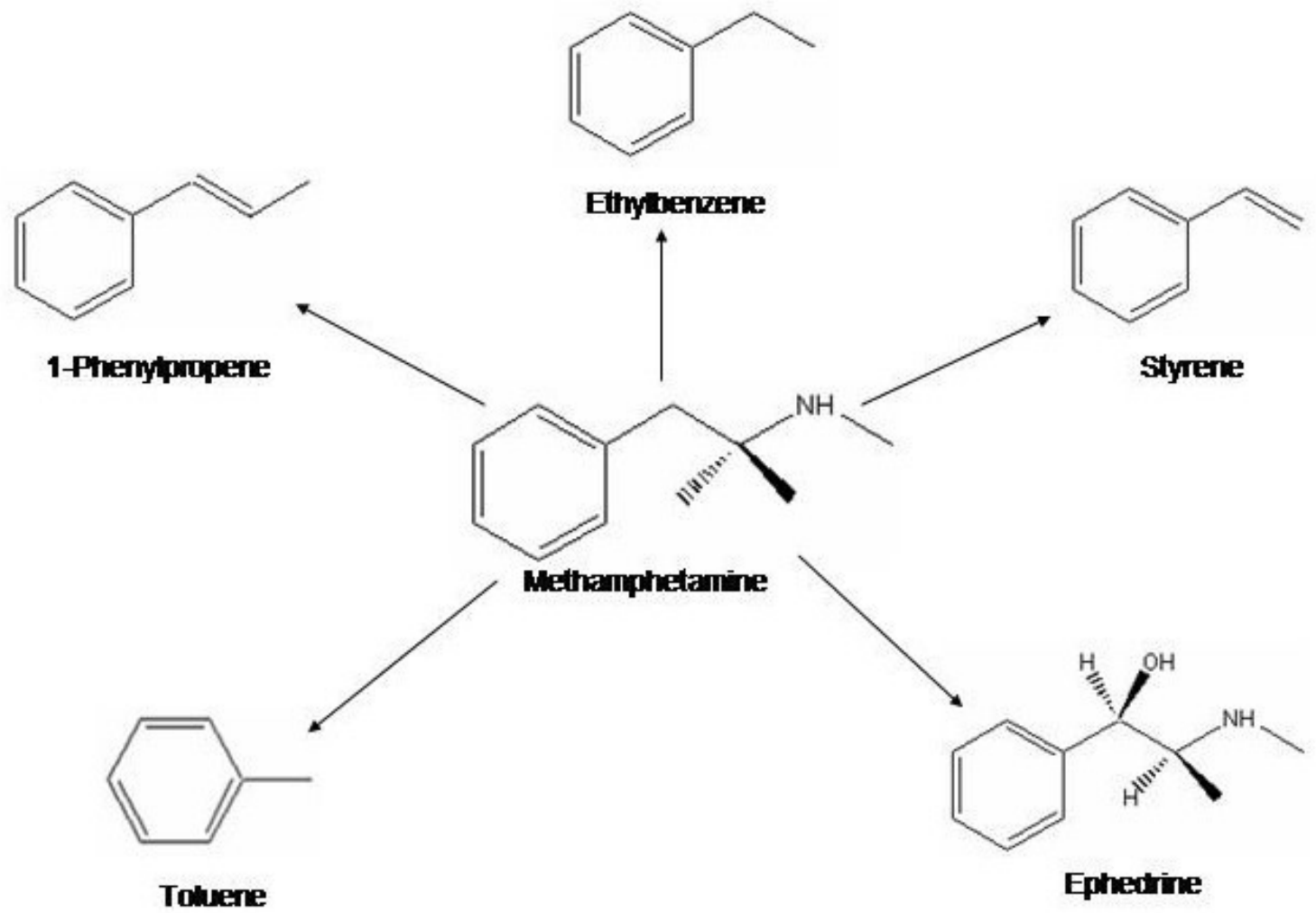


Although the weakest bonds are typically broken first in pyrolysis, this was not seen in cocaine. The pyrolytic products produced by this method are shown in Figure 19. In order of abundance, the products were benzoic acid, AEME, cocaethylene, and norcocaine. Cocaine was also detected at a level higher than the pyrolytic products. The two main pyrolytic products, benzoic acid and AEME, were a result of the $\mathrm{C}-\mathrm{O}$ bond breaking. This is surprising because the $\mathrm{C}-\mathrm{O}$ bond is stronger than the $\mathrm{C}-\mathrm{C}$ and $\mathrm{C}-\mathrm{N}$ bonds.

Cocaethylene and norcocaine were detected using this method but are also known metabolites of cocaine [76]. Cocaethylene, a cocaine transesterification product, is commonly found as a human metabolite when alcohol is mixed with cocaine [83]. Such products can not be used as smoked markers because they are produced by both pyrolysis and metabolism. In a real biological sample, it would be difficult to evaluate the mode of exposure if these products were detected.

Ratios of 1:1, 1:2 and 2:1 (wt: wt) cocaine: methamphetamine were analyzed for any additional products produced by the possible interaction between the drugs. For the $1: 1$ mixture, $5 \mu \mathrm{g}$ of each drug was pyrolyzed while in the other cases, $10 \mu \mathrm{g}$ and $5 \mu \mathrm{g}$ for the 2:1 and 1:2 were used respectively. No additional pyrolytic products were produced other than what was detected from single drug analysis. Similarly, the products from a 1:1 ratio of drug: cutting agent (lidocaine, benzocaine and caffeine) is shown in Table 6. Pyrolysis of lidocaine, benzocaine, and caffeine did not produce pyrolytic products. 
Figure 19 - Pyrolysis results of cocaine utilizing a pyroprobe. The products, norcocaine and Cocaethylene, are also known metabolites (pyrolytic products obtained by a pyroprobe $(P)$ and metabolites $(M)$ ). Products were tentatively identified using a NIST MS library.

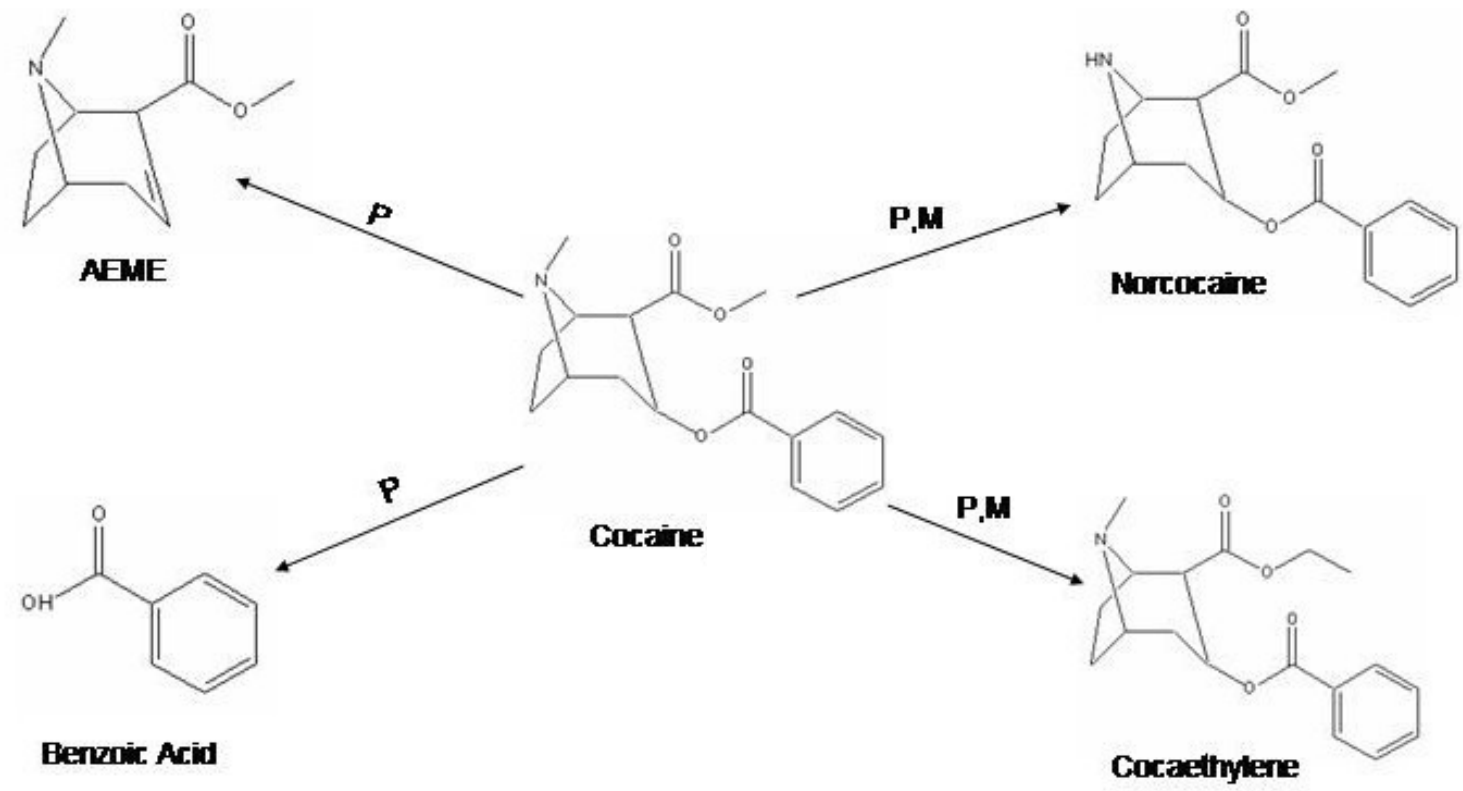


Table 6 - Pyrolytic products of the diluents, and diluents with cocaine and methamphetamine. Products were tentatively identified using a NIST MS library.

\begin{tabular}{|c|c|c|}
\hline Sample & $\begin{array}{l}\text { Pyrolytic } \\
\text { products }\end{array}$ & $\begin{array}{l}\text { Structure of Pyrolytic } \\
\text { Product }\end{array}$ \\
\hline lidocaine & $\mathrm{N} / \mathrm{A}$ & \\
\hline lidocaine + cocaine & $\mathrm{N} / \mathrm{A}$ & \\
\hline lidocaine + methamphetamine & ethylbenzene & \\
\hline & styrene & \\
\hline & bibenzyl & \\
\hline Benzocaine & $\mathrm{N} / \mathrm{A}$ & \\
\hline benzocaine + cocaine & $\mathrm{N} / \mathrm{A}$ & \\
\hline benzocaine + methamphetamine & ethylbenzene & \\
\hline & styrene & \\
\hline & bibenzyl & \\
\hline
\end{tabular}


Table 6 - continued.

\begin{tabular}{|l|l|}
\hline caffeine & AEME \\
\hline caffeine + cocaine & ethylbenzene \\
methamphetamine + & styrene \\
\hline bibenzyl
\end{tabular}




\subsubsection{Results of Analytical Pyrolysis with Trap and Reactant Gas (Air)}

Because smoking occurs under both anaerobic and aerobic conditions, oxidative pyrolysis was performed on cocaine and methamphetamine to compare the products with those obtained via anaerobic conditions. The presence of oxygen and water during thermal degradation may provide better conditions for producing other pyrolytic products. The pyrolysis of cocaine and methamphetamine using the reactant gas, air, tentatively produced benzoic acid, AEME, and benzoic acid methyl ester for cocaine and toluene and benzaldehyde for methamphetamine. As in reductive pyrolysis, benzoic acid was the most abundant product followed by AEME for cocaine. The oxidative conditions did produce a new product, benzoic acid methyl ester. For methamphetamine, toluene was the most abundant, followed by the new product, benzaldehyde. The new products, benzoic acid methyl ester and benzaldehyde (Figure 20), are not found in the literature and are not recognized as smoked products of cocaine and methamphetamine.

The reactant gas system was shown to produce fewer pyrolysis products than normal pyrolysis of cocaine and methamphetamine. The smoked marker, 1phenylpropene was not detected using this method. Comparing the trapping versus non-trapping procedures may help explain why minimal products were detected. The non-trapping pyrolysis unit allows the pyrolytic products to be directly swept into the GC/MS following pyrolysis. This allows for the least amount of analyte loss in the system. One plausible explanation for not detecting as many pyrolytic products is that the analytes may be irreversibly retained. Also, there are more possibilities for the analytes to be lost in the instrument. Fentanyl is commonly pyrolyzed using 
this system in our laboratory. After pyrolyzing fentanyl at $750^{\circ} \mathrm{C}$, it is necessary to run multiple blanks (using the same pyrolysis temperature) between analytical samples to purge residual fentanyl. When running fentanyl under the pyrolysis only mode with no trap, this problem was not as severe. 
Figure 20 - Structures of benzaldehyde and benzoic acid methyl ester.

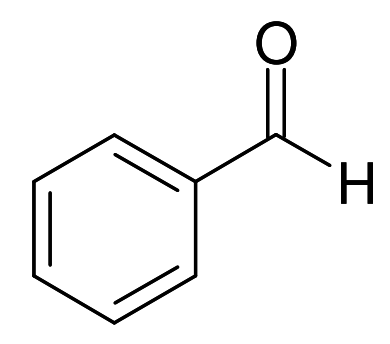

Benzaldehyde

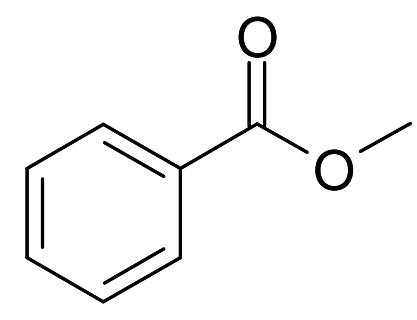

Benzoic acid methylester 


\subsubsection{Conclusions}

The identification of smoked markers can help determine if the route of drug abuse was via smoking. This research incorporated a pyroprobe unit to produce these smoked markers by pyrolysis. This was demonstrated by producing known smoked markers of cocaine and methamphetamine using the pyroprobe under reductive conditions. The reported smoked marker, AEME, was detected using both anaerobic and aerobic conditions; however, the methamphetamine smoked marker, 1-phenylpropene, was only detected under anaerobic conditions. These results show 1-phenylpropene as a product of smoked methamphetamine in an anoxic environment. In addition, this study has laid the groundwork for the analysis of the pyrolytic products of other smoked drugs of abuse. Since publication, this simple and rapid method has been applied to the pyrolysis of smoked fentanyl and smoked fentanyl patches in our laboratory. Future research also involves applying this method to smoked Ritalin. 


\section{Chapter 3: Application of LC/MS/MS and Adapted Sampling to UXO and Related Compounds}

\subsubsection{Introduction}

The objective of this research was to detect explosive residue resulting from the detonation of unexploded ordnance in the soils within sections of the West Virginia Maneuvers Area using EPA 8330b and LC/MS/MS. The primary goal was to determine if contamination was present in the selected areas and, if so, whether remediation was needed. A secondary goal was to evaluate potential alternatives to blow-in-place. The third goal was to adapt the sampling procedure discussed in EPA $8330 \mathrm{~b}$ to a heavily vegetated, rocky, and mountainous terrain.

Unexploded ordnance (UXO) are, "military munitions that have been primed, fuzed, armed, or otherwise prepared for action, and have been fired, dropped, launched, projected or placed in such a manner as to constitute a hazard to operations, installation, personnel, or material and remain unexploded either by malfunction, design, or any other cause [84]." The removal of UXO by detonation has become an issue of concern from an environmental perspective. UXO is commonly found at military firing ranges and test sites where explosive residue can contaminate the surrounding soil. Groundwater contamination is a concern because these explosives can migrate through soil and into groundwater. Thus, soil sampling is critical to determining possible future contamination.

The types of explosives commonly found in the soil and water from UXO include the military explosives, TNT, RDX, HMX, 2,4-DNT, and tetryl. Extraction of these explosives from soil has been studied using different techniques such as 
supercritical fluid extraction (SFE) [85, 86], liquid-liquid extraction [87], and solidphase extraction (SPE) [88]. In 1987, Jenkins and Grant published a paper comparing the kinetics and recovery of TNT, TNB, RDX, and HMX using various extraction techniques [89]. These techniques included a Soxhlet, mechanical shaker, ultrasonic bath, and homogenizer-sonicator. The results showed that the ultrasonic bath was the best method. A disadvantage to using the ultrasonic bath is that the extraction efficiency depends upon the vigor of agitation, which is different for various sonic devices [89]. Heat can be produced during an ultrasonic bath extraction without the use of a water cooling system which can cause degradation of explosives. Additionally, environmental conditions must be kept constant during the extraction for this procedure and since doing so can be difficult, Jenkins and Grant suggested using a mechanical shaker as a reasonable alternative. Advantages to using this method include high sample throughput, no heat production, and the conditions can easily be kept constant throughout the procedure. In addition to comparing the different extraction techniques, this research evaluated methanol and acetonitrile as the extraction solvent. Results showed that methanol extracted TNT and TNB well; however, acetonitrile worked best with RDX and HMX. Because of this research, ACN has become generally accepted as the solvent for soil extractions $[89,90]$.

The results of this study led to the development of a protocol for sampling soil at these military ranges, extracting the soil for explosives and detecting them using liquid chromatography/ultraviolet spectroscopy (LC/UV). This work was steered by Dr. Thomas Jenkins (mentioned above) who worked for the US Army Cold Regions 
Research and Engineering Laboratory (CRREL) in Hanover, NH. His work resulted in this protocol which was adapted by the US EPA (Environmental Protection Agency) [91, 92].

In 1994, the EPA titled this procedure, "Method 8330, Nitroaromatics and Nitramines by High Performance Liquid Chromatography (HPLC)." Explosives listed in the EPA 8330 are the most common explosives found at these military sites. Table 7 provides chemical, physical, and structural information for the 4 main explosives, TNT, RDX, HMX, and tetryl. Other explosives and TNT degradation products listed in the method are NB, 2-NT, 3-NT, 4-NT, 1,3,5-TNB, 1,3-DNB, 4ADNT, 2-ADNT, 2,4-DNT, and 2,6-DNT. A table of these remaining components are shown in Table 8.

EPA 8330 uses the ultrasonic or mechanical shaking methods with acetonitrile for the extraction of explosives from soil. The method discusses using 2 columns for the LC/UV $(254 \mathrm{~nm})$ analysis for definitive identification. First, the extracts are run on a $\mathrm{C}-18$ column for initial identification of any explosives present and then on a $\mathrm{CN}$ (cyano) column for confirmation. Such dual column methods are commonly used in environmental and forensic analyses such as blood alcohol and pesticides $[93,94]$. The explosives that cannot be separated using the $\mathrm{C}-18$ column can be separated using the $\mathrm{CN}$ column and vice versa.

As with all EPA methods, the protocols are proscribed in detail and extensive QA/QC requirements are specified. The method requires a calibration curve (between $2.5-1,000 \mu \mathrm{g} / \mathrm{l}$ or $0.02-8 \mu \mathrm{g} / \mathrm{g}$ soil) to be constructed and the midpoint calibration standard to be run everyday. This standard must agree within $\pm 15 \%$ of 
the response factor of the curve. A surrogate is a compound similar to the analyte of interest but should not be found in the extract. The surrogate is spiked into the matrix (ex: soil, groundwater) prior to extraction. The resulting concentration post extraction helps determine the recovery from the extraction procedure. Although a surrogate is mentioned, the method provides no examples or detailed information about how the surrogate is prepared and spiked. This issue will be discussed later in this Chapter.

In 2006, an updated version of EPA 8330, EPA 8330b, was released which included several additions to the original method. Three new target analytes were added: nitroglycerin (NG), pentaerythritol tetranitrate (PETN), and 3,5-dinitroaniline (3,5-DNA). Although these explosives are not present in munitions found at the location discussed in this Chapter, they were added to the EPA method because they are found in some UXO. The other main additions include the multi-increment sampling method and the use of a mechanical grinder to reduce the soil particle size prior to extraction. These techniques aid in the reduction of sampling error and improvement in reproducibility and reliability of sample data. The multi-increment method is a procedure for sampling areas where UXO was blown-in-place. It takes into account the random distribution and particulate nature of the explosives in their post detonation. This sampling method was designed by CRREL to work in environments that are flat with no physical obstacles, an issue that drove much of 
Table 7 - Physical, Chemical and Structural information of TNT, RDX, HMX and Tetryl.

\begin{tabular}{|c|c|c|c|c|}
\hline & TNT & RDX & HMX & Tetryl \\
\hline Structure & $\aleph^{\mathrm{NC}}$ & 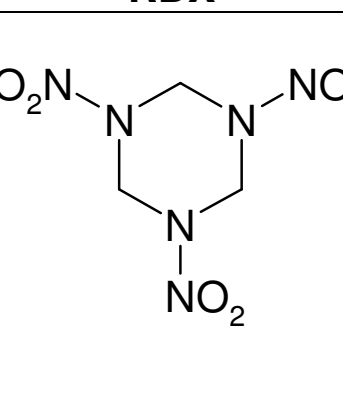 & $\mathrm{O}_{2} \mathrm{~N}_{\mathrm{O}_{2} \mathrm{~N}^{\prime}}^{\mathrm{NO}_{2}}$ & $\mathrm{O}_{2} \mathrm{O}_{1}^{\prime}$ \\
\hline Physical Appearance & $\begin{array}{c}\text { Pale yellow } \\
\text { crystalline solid }\end{array}$ & $\begin{array}{l}\text { White crystalline } \\
\text { solid }\end{array}$ & $\begin{array}{l}\text { White crystalline } \\
\text { solid }\end{array}$ & $\begin{array}{l}\text { Light yellow } \\
\text { crystalline solid }\end{array}$ \\
\hline Molecular Weight $(\mathrm{g} / \mathrm{mol})$ & 227.1 & 222.1 & 296.2 & 287.1 \\
\hline Molecular Formula & $\mathrm{C}_{7} \mathrm{H}_{5} \mathrm{~N}_{3} \mathrm{O}_{6}$ & $\mathrm{C}_{3} \mathrm{H}_{6} \mathrm{~N}_{6} \mathrm{O}_{6}$ & $\mathrm{C}_{4} \mathrm{H}_{8} \mathrm{~N}_{8} \mathrm{O}_{8}$ & $\mathrm{C}_{7} \mathrm{H}_{5} \mathrm{~N}_{5} \mathrm{O}_{8}$ \\
\hline Melting Temperature $\left({ }^{\circ} \mathrm{C}\right)$ & 80.8 & $202-204$ & 275 & 129.5 \\
\hline Density $\left(\mathrm{g} / \mathrm{cm}^{3}\right)$ & 1.654 & 1.82 & 1.96 & 1.73 \\
\hline $\begin{array}{l}\text { Thermal Ignition } \\
\text { Temperature }\left({ }^{\circ} \mathrm{C}\right)\end{array}$ & 300 & 260 & 335 & 185 \\
\hline $\begin{array}{l}\text { Water Solubility } \\
(\mathrm{g} / \mathbf{1 0 0 g})\end{array}$ & 0.01 & 0.006 & 0.00066 & 0.008 \\
\hline $\begin{array}{l}\text { Vapor Pressure } \\
\left(\mathrm{mmHg} \text { at } 25^{\circ} \mathrm{C}\right)\end{array}$ & $5.5 \times 10^{-6}$ & $4.6 \times 10^{-9}$ & $3 \times 10^{-9}$ & $5.7 \times 10^{-9}$ \\
\hline $\begin{array}{l}\text { Velocity of Detonation } \\
\text { (VOD) }(\mathrm{m} / \mathrm{s})\end{array}$ & $\sim 6940$ & $\sim 8440$ & $\sim 9110$ & $\sim 7920$ \\
\hline
\end{tabular}

Information was obtained from $[37,12]$ 
Table 8 - Remaining EPA 8330 explosives and transformation products.

\begin{tabular}{|c|c|c|c|}
\hline Compound & Structure & $\begin{array}{l}\text { Molecular } \\
\text { Weight }(\mathrm{g} / \mathrm{mol})\end{array}$ & $\begin{array}{l}\text { Molecular } \\
\text { Formula }\end{array}$ \\
\hline Nitrobenzene (NB) & & 123.1 & $\mathrm{C}_{6} \mathrm{H}_{5} \mathrm{NO}_{2}$ \\
\hline 2-Nitrotoluene (2-NT) & & 137.1 & $\mathrm{C}_{7} \mathrm{H}_{7} \mathrm{NO}_{2}$ \\
\hline 3-Nitrotoluene (3-NT) & & 137.1 & $\mathrm{C}_{7} \mathrm{H}_{7} \mathrm{NO}_{2}$ \\
\hline 4-Nitrotoluene (4-NT) & & 137.1 & $\mathrm{C}_{7} \mathrm{H}_{7} \mathrm{NO}_{2}$ \\
\hline $\begin{array}{l}\text { 1,3,5-Trinitrobenzene }(1,3,5- \\
\text { TNB) }\end{array}$ & & 213.1 & $\mathrm{C}_{6} \mathrm{H}_{3} \mathrm{~N}_{3} \mathrm{O}_{6}$ \\
\hline 1,3-Dinitrobenzene (1,3-DNB) & & 168.1 & $\mathrm{C}_{6} \mathrm{H}_{4} \mathrm{~N}_{2} \mathrm{O}_{4}$ \\
\hline $\begin{array}{l}\text { 4-Amino-2,6-dinitrotoluene } \\
\text { (4-ADNT) }\end{array}$ & & 197.2 & $\mathrm{C}_{7} \mathrm{H}_{7} \mathrm{~N}_{3} \mathrm{O}_{4}$ \\
\hline $\begin{array}{l}\text { 2-Amino-4,6-dinitrotoluene (2- } \\
\text { ADNT) }\end{array}$ & & 197.2 & $\mathrm{C}_{7} \mathrm{H}_{7} \mathrm{~N}_{3} \mathrm{O}_{4}$ \\
\hline 2,4-Dinitrotoluene (2,4-DNT) & & 182.1 & $\mathrm{C}_{7} \mathrm{H}_{6} \mathrm{~N}_{2} \mathrm{O}_{4}$ \\
\hline 2,6-Dinitrotoluene (2,6-DNT) & & 182.1 & $\mathrm{C}_{7} \mathrm{H}_{6} \mathrm{~N}_{2} \mathrm{O}_{4}$ \\
\hline
\end{tabular}


the research conducted here. More information pertaining to multi-increment sampling is discussed in Sections 3.2.3.

Detection of explosives in soil has been performed with various types of instruments including HPLC/UV, HPLC/PDA, HPLC/MS, and CEC/UV [95-98]. HPLC/UV is most common because of the development of EPA 8330 which has been used for 15 years. One drawback to using HPLC/UV is the resolving power. Because of the similar polarities of the explosives in EPA 8330, co-eluting peaks are commonly seen. Use of 2 columns for definitive identification (as performed in 8330) essentially doubles analysis time and solvent used. One of the first reports of using LC/tandem MS for explosives analysis was in 1994 [99]. Since then, LC/MS/MS has been employed to detect explosives in groundwater and soil $[69,70,100]$. LC/MS/MS provides higher sensitivity than LC/UV with limits of detection as low as $25 \mathrm{ng} / \mathrm{l}$ [64]. Additionally, LC/MS/MS is highly selective and only requires the use of one column for confirmation since single ions can be monitored simultaneously. For identification purposes, LC/MS/MS can use a quantifying and qualifying MRM transition simultaneously, reducing analysis time.

The research discussed in this Chapter focused on the determination of explosives and explosive transformation products present at the West Virginia Maneuver Area (WVMA), including the Dolly Sods Wilderness Area, the Canaan Valley National Wildlife Refuge (NWLR), and the Canaan Valley Institute (CVI) (Figure 25).

The Dolly Sods Wilderness Area is a mountainous region located between Seneca Rocks and Canaan Valley and is part of the Monongahela National Forest. 
The area stretches across 18,500 acres and consists of elevations between 2,600 4,100 feet. During World War II from 1943-1944, this area was employed by the military for artillery training for the purpose of training the troops for the mountains in France, Germany, and Italy. Ordnance used at this location included high explosive rockets, mortars, and howitzer rounds. Since the rockets and mortars contained TNT, this explosive along with its degradation products are anticipated at this location. Additionally, the howitzer rounds contained TNT and the propellant, 2,4DNT $[101,102]$.

In 1992, this land was sold to the United States Government so that it could be added to the Wilderness Area of the National Forest. Since it was once used as a military firing range, WVMA is considered to be a Formerly Used Defense Site (FUDS). Today, the US Army Corps of Engineers (USACE), Huntington District, has jurisdiction over this area. In July 1995, the USACE performed site inspections to evaluate the ordnance and explosives (OE) at this site. In 1997 and 1998, 22 live and 19 inert mortar rounds and $1151 \mathrm{lbs}$ of OE scrap which was uncovered from the top $70 \mathrm{~cm}$ (24 in.) of soil from over 23,000 excavations were removed and disposed. As a result, the USACE was able to remove UXO $\sim 6 \mathrm{~m}(20 \mathrm{ft})$ on each side of the hiking trails located in the Dolly Sods Wilderness Area. During our first visit to the area, one of the members of our field team found a live mortar $7.6 \mathrm{~m}$ from the one of the trails, indicating that UXO detonations and accompanying issues will be an on going concern. 
Figure 21 - Location of the West Virginia Maneuver Area. Image obtained from [103].

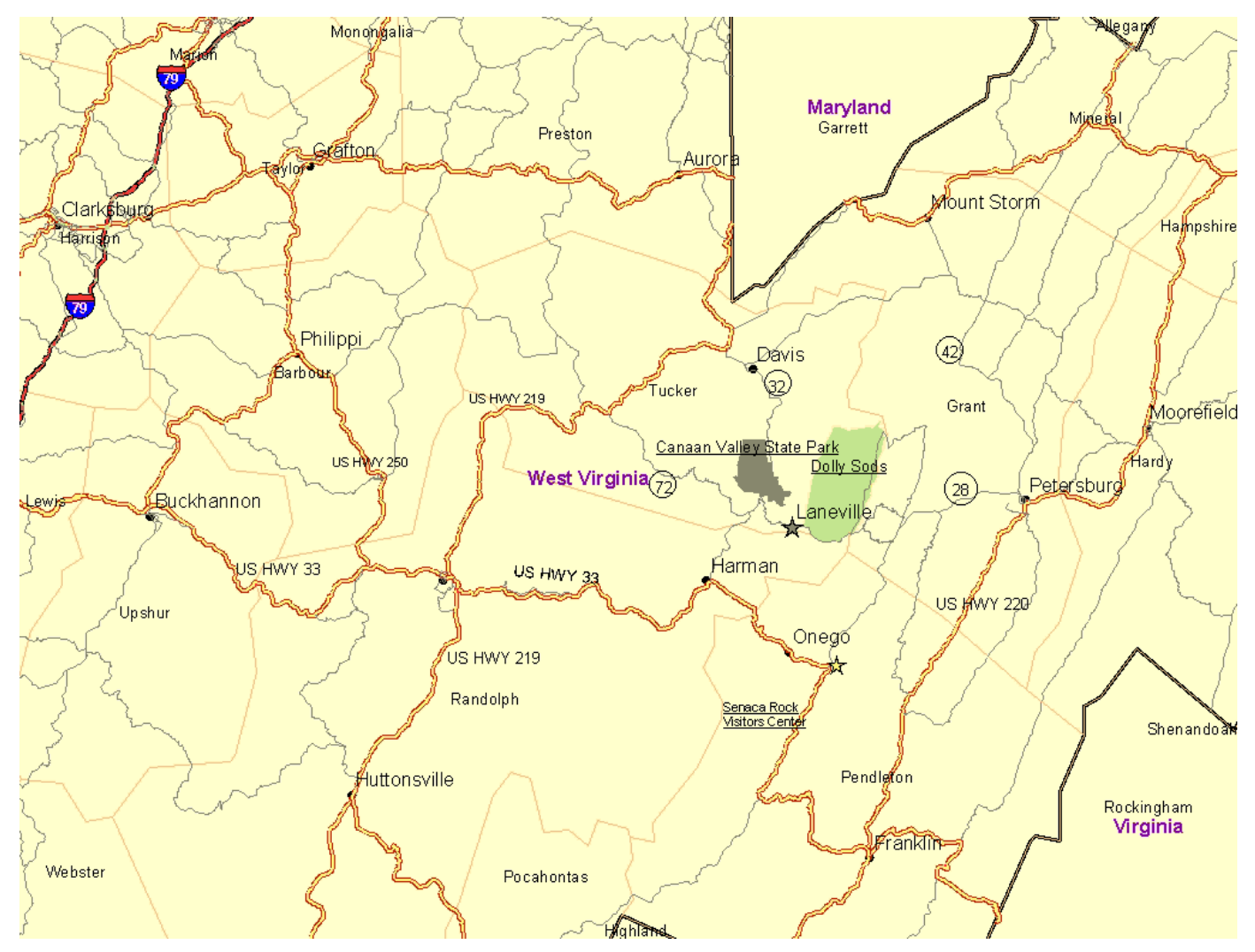


In 2006, funding was obtained by Drs. Bell and Quaranta (WV Water Research Institute) from the USACE. There were two questions to be investigated. The USACE wanted to know if there were any residual explosives present in the soil at areas where blown-in-place had occurred in the WVMA. In addition, if explosives were present, did this present an ecological or human toxicity threat?

The types of explosives anticipated in this location depended upon the original munitions and what was used for the blow-in-place detonation. The mortars fired in this area were filled with TNT and the $105 \mathrm{~mm}$ Howitzer round contained TNT and 2,4-DNT [101]. The type of charge used for the blow-in-place detonation depended upon the location. In the Dolly Sods Wilderness Area and the Canaan Valley NWLR, the WV State Police fired UXO using TNT. In places considered private property like CVI, the army detonated UXO using Composition C4 (C4) [104]. C4 is a plastic explosive that consists of $91 \%$ RDX, $2.1 \%$ polyisobutylene, $1.6 \%$ motor oil, and $5.3 \%$ di(2 ethyl-hexyl)sebacate [1]. The impurity of $\mathrm{HMX}$ is about $10 \%$ [102], a factor that became of interest during this research. Blocks of $C 4$ are frequently used to detonate UXO and if a low-order detonation occurs, white chunks of C4 are often visible after detonation [102]. 


\subsubsection{Materials and Methods}

\subsubsection{Site Locations}

Areas for soil sampling were determined from previous UXO blown-in-place locations provided by the USACE Huntington district. Site locations were located using a Trimble GPS Pathfinder ProXH receiver (Sunnyvale, CA) for field coordinate locations. As requested by the USACE, GPS site coordinates will not be identified in this dissertation. For the safety of the researchers, a UXO Ordnance \& Explosives Safety Specialist provided by the USACE Engineering and Support Center, Huntsville, AL dictated off-trail activities. He used a Schonstedt metal detector to scan the areas for any possible undiscovered UXO (anomaly). After scanning the area, he would use red flags or safety ribbon to designate the site location before field sampling. This was done to mark the "safe" zone so that researchers would not take samples outside of this area. Red flags were also used in areas where anomalies were detected by the metal detector. Researchers were not allowed to walk or sample within $3 \mathrm{ft}$ of these flags. His expertise became abundantly clear when he discovered a live UXO during the first sampling trip in June 2007 which was detonated 3 days later by the WV State Police.

\subsubsection{Soil Sampling Materials}

Prior to field sampling, a detailed sampling plan was developed based on EPA 8330b. Three types of soil samples were obtained for extraction: composite grab, core, and multi-increment. Each method is described in detail below. 
Composite grab samples involved taking soil from random areas within the crater of a blown-in-place UXO. The soil was combined in one plastic bag to create a composite. These samples were gathered using a stainless steel shovel where the top layer of soil and debris were collected. A multi-increment sample was collected using 2 different step soil probes (Figure 22). A device developed by CRREL took samples to a depth of $5.1 \mathrm{~cm}$ with a diameter of $3.2 \mathrm{~cm}$. This probe was easier to use because of its quick soil release capabilities. However, areas that were extremely rocky and vegetated made it difficult to use this probe because of its large dimensions. Therefore, the step soil probe was used at these locations which took samples to a depth of $25.4 \mathrm{~cm}$ with a diameter of $1.90 \mathrm{~cm}$. In addition, this device was used for all core samples. To clean the probes between each grid site, a series of water-acetone-water rinse steps were carried out. 
Figure 22 - (A) Soil Step Probe developed by CRREL, (B) Commercially available step soil probe.

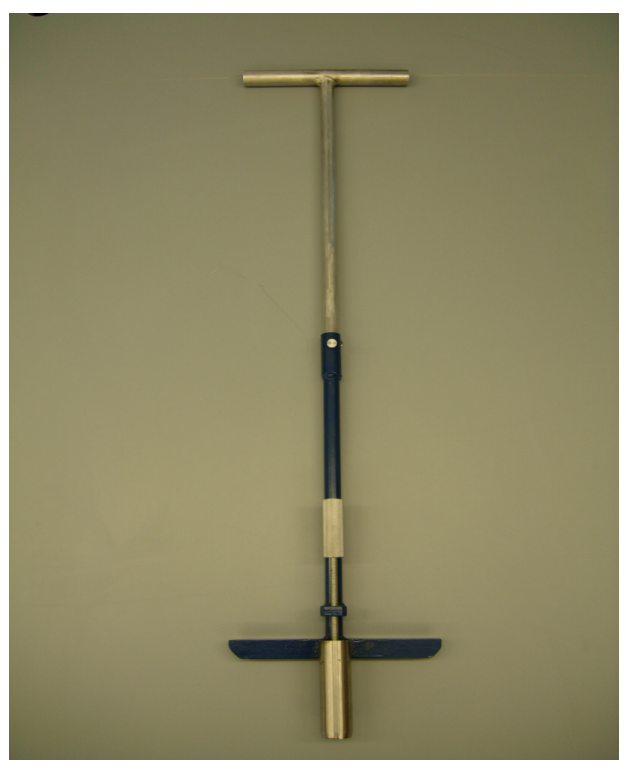

A.

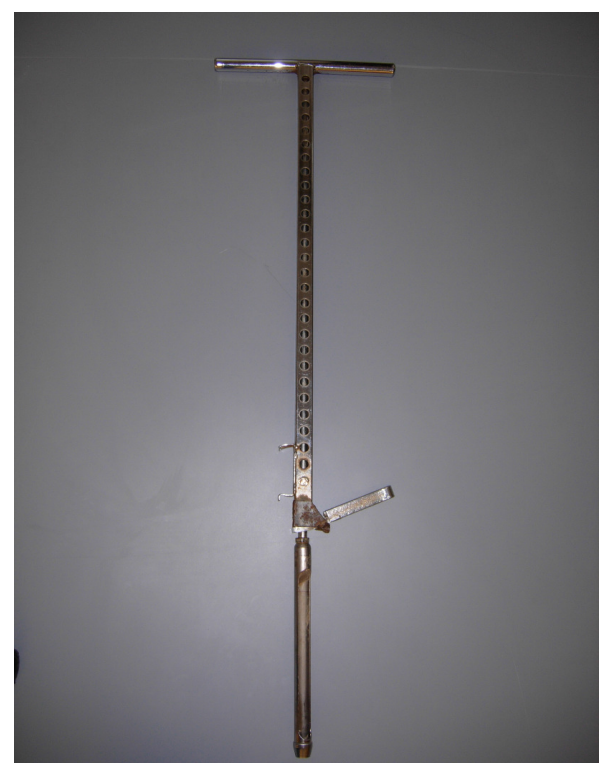

B. 


\subsubsection{Multi-Increment Sampling}

In any analytical procedure, error can be categorized in several ways. Of interest here is error associated with sampling versus error associated with the analytical procedure. In turn, errors are a significant contributor to uncertainty. In modern validated analytical methods, laboratory errors are typically minimized and sampling error dominates. In this project, this is a central issue. Prior to EPA Method 8330b, soil samples were commonly collected using a discrete sampling strategy [101]. This consisted of taking distinct soil samples within areas most likely contaminated. These sampling decisions by nature were subjective. More commonly, these discrete samples would be combined and then separated into smaller portions for easier transport before lab analysis. The fundamental problem with this strategy in UXO applications is that it does not take into consideration the random distribution or particulate nature of explosive residues post detonation. Inevitably, error is introduced due to the non-uniform distribution of particles. Samples cannot be representative since by definition the distribution of target analytes is in 3 dimensions. Using a small number of subjectively selected samples contributes to decision uncertainty in a way that is difficult if not impossible to quantify.

In recognition of this, EPA 8330 was updated in 2006 (EPA 8330b) and included a new procedure for collecting unbiased soil samples for explosives analysis. The multi-increment method was developed by CRREL and adapted to EPA 8330 to decrease the error associated with soil collection and sampling. The method addresses the random distribution and particulate nature of the explosives at 
a blown-in-place site. It has since been used with results published in the literature [105].

Essentially, the multi-increment method described above is combined with elements of compositing in an attempt to insure homogeneity. When dealing with particulates, fundamental error $(\mathrm{FE})$ is a function of particle size and sample mass $[106,107] . F E$ is inversely proportional to sample mass, thus, the number of increments taken is important. A $1 \mathrm{~kg}$ soil sample should be collected from at least 30 evenly spaced increments using a serpentine pattern as shown in Figure 23. A $50 \mathrm{~m}$ X $50 \mathrm{~m}$ "decision unit" (grid) was recommended by CRREL for the type of mortars found in the Dolly Sods Wilderness Area. However, it was immediately obvious in the field that the sampling plan had to be modified. Due to the heavily vegetated, mountainous, and rocky terrain found at Dolly Sods, a $10 \mathrm{~m} \times 10 \mathrm{~m}$ decision unit was commonly used with 30-100 incremented soil samples collected. Decision units and number of increments for each site location will be further addressed in the results and discussion section. 
Figure 23 - The serpentine pattern used in multi-increment sampling. Figure below represents a $10 \mathrm{~m} \times 10 \mathrm{~m}$ decision unit.

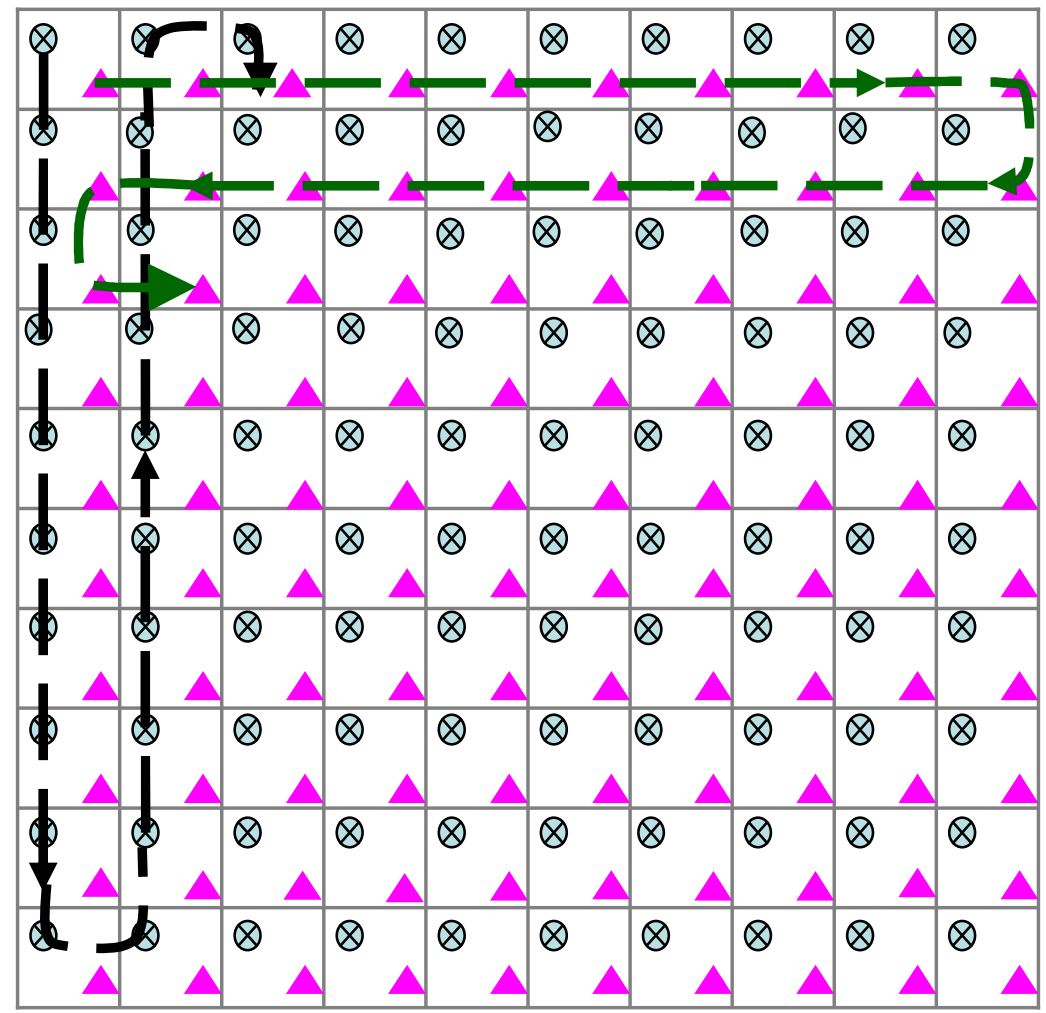

$\bigotimes$ - location of sample taken from first multi-increment sample

$\triangle$ - location of sample taken from second multi-increment sample 


\subsubsection{Soil Extraction}

A flow chart of the extraction procedure is shown in Figure 24. The sample extraction procedure carried out was based upon EPA 8330b. Collected soil stored in $3 \mathrm{~mm}$ thick bags was carefully removed and placed on large cookie sheets covered with foil to allow for drying. In addition, soil was separated by hand to smaller pieces to speed up the drying process. After drying, debris was removed by pushing the soil sample through a $2 \mathrm{~mm}$ sieve using a spoon. Cross contamination was prevented by rinsing the spoon and sieve with water, soap and methanol between each sample. The sieved samples were ground to a particle size of about

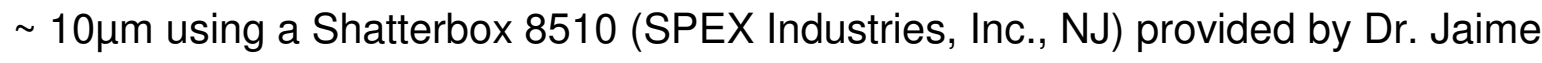
Toro at the WVU Department of Geology (Figure 25). Because significant heat is generated by this process, the Shatterbox operated at $60 \mathrm{sec}$ intervals to prevent thermal degradation of explosives present in the soil. The recommended particle size stated in EPA $8330 \mathrm{~b}$ is $75 \mu \mathrm{m}$; however, fundamental error is reduced at smaller particle sizes. Blank soil and a negative and positive control sample were also ground. All ground samples were stored in clean plastic bags prior to extraction.

To further reduce the uncertainty between sub-samples, EPA $8330 \mathrm{~b}$ requires a miniature multi-increment sampling procedure be performed on the powdered soil. Ground soil was first mixed inside the plastic bag and then spread out evenly at a thickness of $2.5 \mathrm{~cm}$ onto a piece of foil. To achieve a $10 \mathrm{~g}$ soil sample, 30 evenly spaced multi-increments of about $3.3 \mathrm{~g}$ were taken using a spatula. The soil was weighed directly into a $60 \mathrm{~mL}$ glass jar and sealed using a PTFE-lined cap. Soil 
was extracted using 20. $\mathrm{mL}$ of acetonitrile. The jars were vortexed and placed on a platform shaker table (VWR Mini Orbital Shaker) at a speed of $150 \mathrm{rpm}$ for $18 \mathrm{hrs}$. Extracted soil samples were removed from the shaker table and allowed to sit for 30 minutes. As a result, the soil settled to the bottom and the liquid extract remained at the top. The liquid extract was pipetted into a glass syringe with a PTFE filter ( 0.5 $\mu \mathrm{m}$ pore size). Extracts were filtered and stored in the dark at $-20^{\circ} \mathrm{C}$ until use. Prior to LC/MS and LC/UV analysis, liquid extracts were diluted 1:4 in the appropriate mobile phase. 
Figure 24 - The extraction procedure represented by photos. (1) Soil is spread out on an aluminum foil covered baking sheet and dried for 24 hours. (2) Soil is sieved using a \#10 sieve to remove the oversized $(>2 \mathrm{~mm})$ fraction. Soil is gently passed through the mesh using a spoon to break up clumps. (3) Soil is ground to approximately $10 \mu \mathrm{m}$ particle diameter using a mechanical grinder. (4) Onto a sheet of aluminum foil, ground soil is spread out and 30 increments are collected from the complete depth (approximately $0.3 \mathrm{~g}$ each) to form a $10 \mathrm{~g}$ composite sub-sample for extraction. (5) $20 \mathrm{~mL}$ of acetonitrile is added to each sample and placed on a platform shaker table to be mixed for $18 \mathrm{hrs}$ at $150 \mathrm{rpm}$. (6) Supernatant is collected from each sample.

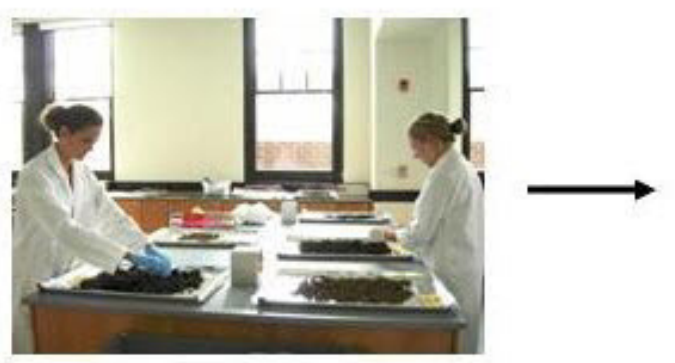

(1)

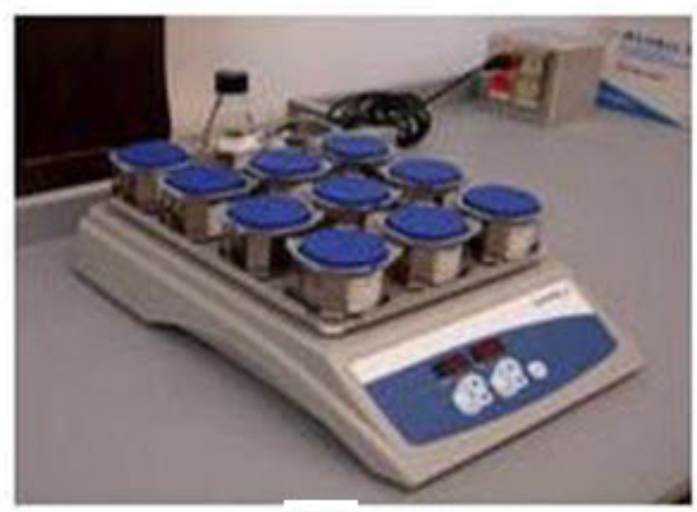

(5)

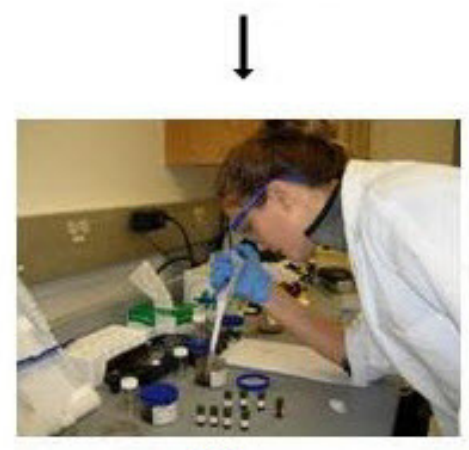

(6)

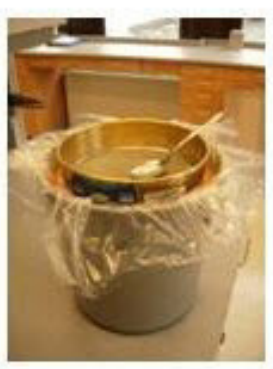

(2)

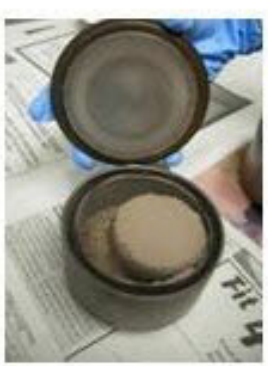

(3)

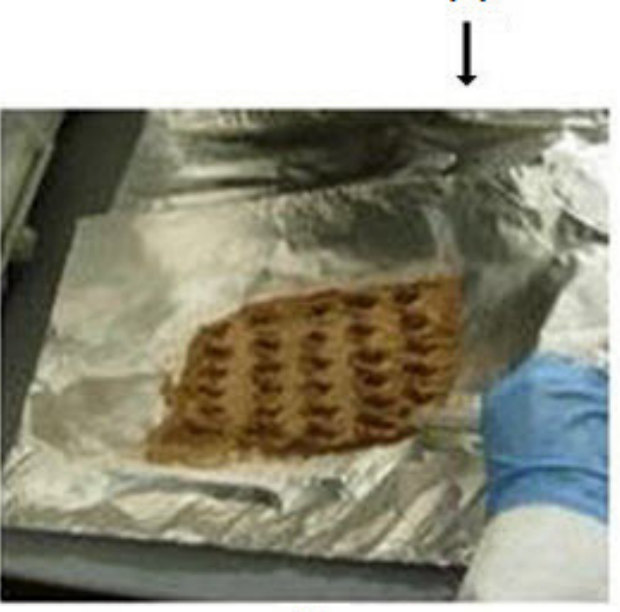

(4) 
Figure 25 - Photo of the grinding process: a) Only $<2 \mathrm{~mm}$ soil is used, b) soil is divided into small portions and put into the grinding dish with a puck, c) 3 dishes are placed into the Shatterbox and set to $60 \mathrm{~s}$ intervals for a total of 5 minutes, and d) soil is ground to $\sim 10 \mu \mathrm{m}$ particle size.
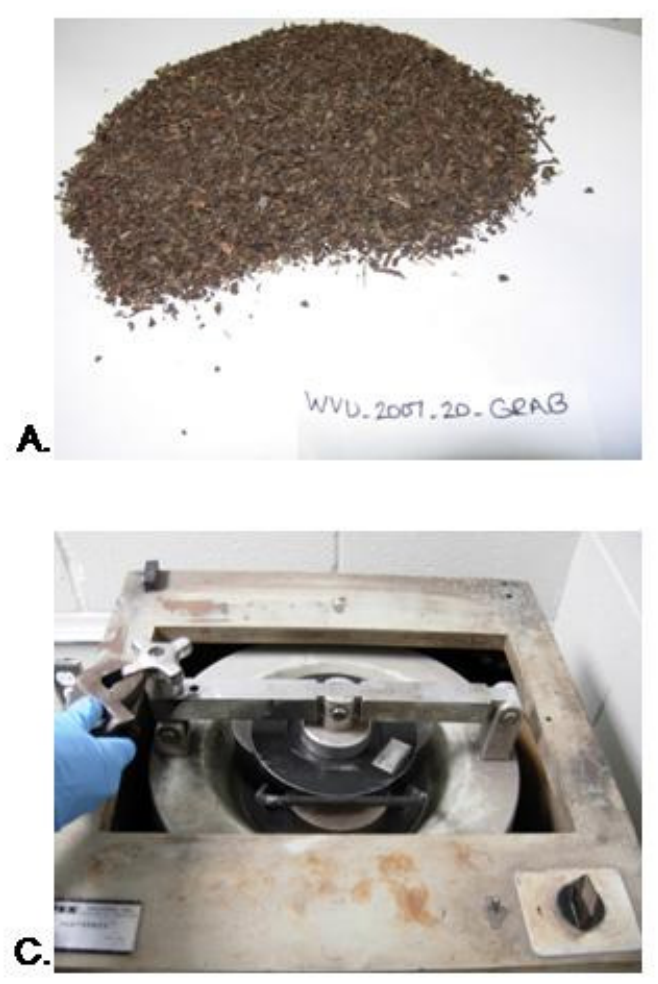
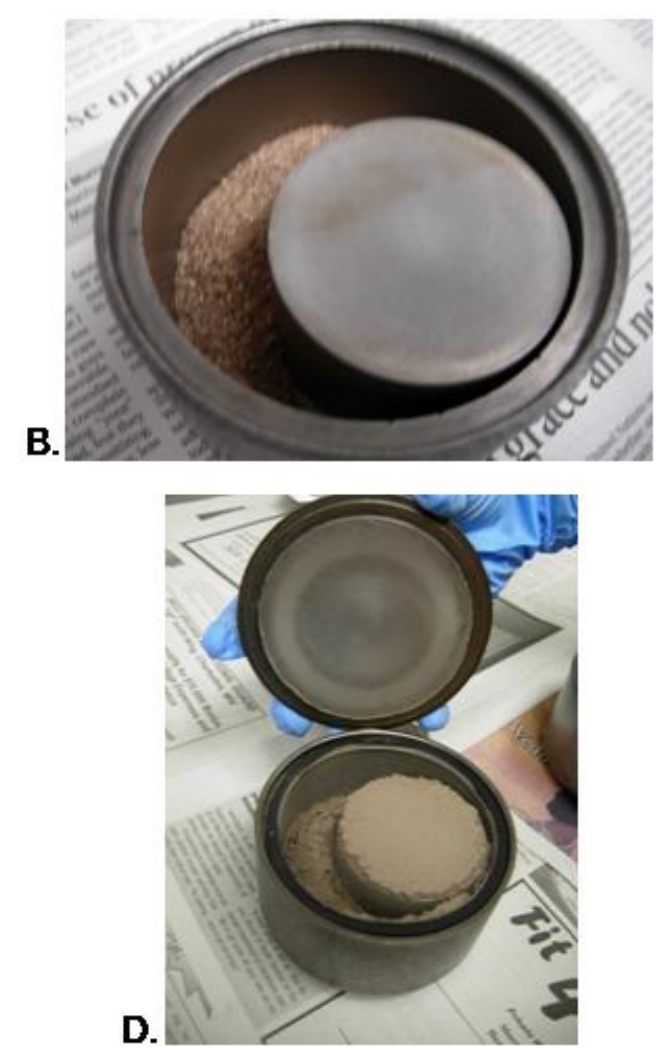


\subsubsection{LC/MS/MS Analysis}

A Shimadzu Prominence HPLC system was used for the chromatographic separation of the explosives listed in EPA 8330. A $200.0 \pm 11 \mu \mathrm{g} / \mathrm{ml}$ standard mixture of all 14 components listed in the EPA 8330 method was purchased in acetonitrile from Cerilliant (Round Rock, TX). HPLC grade acetonitrile, methanol with $0.1 \%$ ammonium acetate for LC/MS, and water with $0.1 \%$ ammonium acetate for LC/MS were purchased from Sigma Aldrich (St. Louis, MO) and used for the extraction and LC/MS/MS analysis. An Acclaim E2 column (combination of C-18 and CN phase) $3 \times 150 \mathrm{~mm}, 3 \mu \mathrm{m}$ particle size, was purchased from Dionex (Sunnyvale, CA) and used for the LC separation. Eluent A consisted of $\mathrm{H}_{2} \mathrm{O}$ with $0.1 \%$ ammonium acetate and Eluent $B$ was methanol with $0.1 \%$ ammonium acetate. Separation was achieved using $43 \%$ Eluent $A$ and $57 \%$ Eluent $B$ at $1 \mathrm{ml} / \mathrm{min}$ flow rate and the column oven was set to $30^{\circ} \mathrm{C}$ with $30 \mu$ injections. For $\mathrm{QA} / \mathrm{QC}$ purposes, a blank, mid-point calibration standard followed by another blank were first run on the HPLC system at the beginning of each day prior to running extracts. The extracts were run in the same order as they were ground.

An Applied Biosystems 3200 QTrap MS System (Foster City, CA) using Atmospheric Pressure Chemical Ionization (APCI) in the negative mode was used for the detection of explosives. MS conditions are summarized in Table 9. All other MS parameters were optimized for each analyte by infusion and iterative adjustment. Table 10 lists 10 of the 14 components with a quantitative and qualitative multiple reaction monitoring (MRM) transitions for each analyte. It should be noted that NB would not ionize using APCI or ESI. This was not surprising since other studies have 
shown that nitrobenzene is difficult to ionize $[108,109,69]$. The lack of ionization could be due to the absence of acidic protons which assist in deprotonation [68]. In addition, 2,6-DNT had the same MRM transition as 2,4-DNT but the intensity was much lower. Therefore, the peak detected at 14.85 min using the $181 \rightarrow 46 \mathrm{~m} / \mathrm{z}$ MRM transition is primarily 2,4-DNT. This problem was recognized as a limitation to the method. A similar problem occurred with 2-NT, 3-NT, and 4-NT in that all 3 analytes ionized poorly and elute as one peak at $18.8 \mathrm{~min}$. Since ionization was poor, NT only has a quantifier MRM and no qualifier MRM transition. All samples were run under these MRM transitions and the concentrations of any detected explosives were determined using the quantifier MRM. Retention times, linear ranges, $R^{2}$ values and LODs are listed in Table 11. External calibration curves were created for each analyte with $R^{2}$ values exceeding 0.99 .

Method 8330b (HPLC/UV instrument), as with all EPA methods, utilizes several levels of $Q A / Q C$ to insure reliability. However, when compared to other EPA methods (for example, EPA 8260 which detects volatile organic compounds using GC/MS), several analytical compromises are made. An internal standard was not initially discussed in the original EPA 8330 method due to the difficulty of finding a similar compound that would not co-elute with one of the other 14 components. 
Table 9 -MS conditions used for explosives detection.

\begin{tabular}{|l|l|}
\hline Curtain Gas $\left(\mathrm{N}_{2}\right)$ & $20 \mathrm{psi}$ \\
\hline CAD Gas $\left(\mathrm{N}_{2}\right)$ & $3.0 \times 10^{-5}$ torr (medium) \\
\hline Gas 1 (air) & $40 \mathrm{psi}$ \\
\hline Desolvation Temp & $350^{\circ} \mathrm{C}$ \\
\hline Dwell Time & $50 \mathrm{~ms}$ \\
\hline Ionspray voltage & $-4500 \mathrm{~V}$ \\
\hline
\end{tabular}


Table 10 - Monitored MRM transitions of explosives.

\begin{tabular}{|l|l|l|l|l|}
\hline Compound & $\mathbf{M W}(\mathbf{g} / \mathbf{m o l})$ & Quantifier MRM & $\begin{array}{l}\text { Observed } \\
\text { precursor ion }\end{array}$ & $\begin{array}{l}\text { Observed } \\
\text { product }\end{array}$ \\
\hline $\mathrm{HMX}$ & 296 & $355 / 46$ & $\mathrm{M}+\mathrm{CH}_{3} \mathrm{COO}^{-}$ & $\mathrm{NO}_{2}^{-}$ \\
\hline RDX & 222 & $281 / 46$ & $\mathrm{M}+\mathrm{CH}_{3} \mathrm{COO}^{-}$ & $\mathrm{NO}_{2}^{-}$ \\
\hline $1,3,5-\mathrm{TNB}$ & 213 & $213 / 183$ & $\mathrm{M}^{-}$ & $\mathrm{C}_{6} \mathrm{H}_{5} \mathrm{~N}_{3} \mathrm{O}_{4}^{-}$ \\
\hline $1,3-\mathrm{DNB}$ & 168 & $168 / 46$ & $\mathrm{M}^{-}$ & $\mathrm{NO}_{2}^{-}$ \\
\hline Tetryl & 287 & $241 / 213$ & $\mathrm{M}-\mathrm{NO}_{2}$ & $\mathrm{C}_{6} \mathrm{H}_{3} \mathrm{~N}_{3} \mathrm{O}_{6}^{-}$ \\
\hline TNT & 227 & $226 / 46$ & $\mathrm{M}-\mathrm{H}$ & $\mathrm{NO}_{2}^{-}$ \\
\hline 4-ADNT & 197 & $196 / 46$ & $\mathrm{M}-\mathrm{H}$ & $\mathrm{NO}_{2}^{-}$ \\
\hline 2-ADNT & 197 & $196 / 136$ & $\mathrm{M}-\mathrm{H}$ & $\mathrm{C}_{6} \mathrm{H}_{4} \mathrm{~N}_{2} \mathrm{O}_{2}^{-}$ \\
\hline $2,4-\mathrm{DNT}$ & 182 & $181 / 46$ & $\mathrm{M}-\mathrm{H}$ & $\mathrm{NO}_{2}^{-}$ \\
\hline NT & 137 & $137 / 46$ & $\mathrm{M}^{-}$ & $\mathrm{NO}_{2}^{-}$ \\
\hline
\end{tabular}


Although this is less of a concern in MS and $\mathrm{MS}^{n}$ methodology, the internal standard remains problematic. The recommended internal standards, 1,2-DNB or 3,4-DNT, have the same MRM transitions as their sister compounds, making it difficult to differentiate between the internal standard and the actual component. This can be corrected by using an isotope modified standard of an explosive.

Additionally, a surrogate should be used to test the efficiency of the sample preparation and extraction. As an added QA/QC measure, most EPA methods use surrogate spikes. Some examples include EPA 526 which detects semi-volatiles in drinking water and EPA 3541 which detects organic analytes from soil, sediment, sludges and waste solids using an automated Soxhlet extraction. However, the explosives found at firing ranges are in the particulate form post detonation. Thus, a representative surrogate would be particulate as well. This creates several problems for explosives analysis including cost, availability, and safety. Also, it is difficult to analytically spike a soil sample with micrograms of solid explosive.

CRREL, the original developers of EPA 8330 and EPA 8330b, are also aware of this problem. They are currently working on developing new standards [110]. 
Table 11 - Quantitation parameters of each explosive. LOD's were achieved using MS noise.

\begin{tabular}{|l|l|l|l|l|}
\hline Explosive & $\begin{array}{l}\text { Retention } \\
\text { Time }(\min )\end{array}$ & Calibration Curve & $\mathbf{R}^{2}$ value & $\begin{array}{l}\text { LOD } \\
(\mathbf{S} / \mathrm{N}=3)\end{array}$ \\
\hline HMX & 4.96 & $1-1000 \mu \mathrm{g} / \mathrm{L}$ & 0.9998 & $500 \mathrm{ng} / \mathrm{L}$ \\
\hline RDX & 7.44 & $1-1000 \mu \mathrm{g} / \mathrm{L}$ & 0.9996 & $500 \mathrm{ng} / \mathrm{L}$ \\
\hline $1,3,5-T N B$ & 8.49 & $50-1000 \mu \mathrm{g} / \mathrm{L}$ & 0.9998 & $6 \mu \mathrm{g} / \mathrm{L}$ \\
\hline $1,3-D N B$ & 10.0 & $100-1000 \mu \mathrm{g} / \mathrm{L}$ & 0.9914 & $50 \mu \mathrm{g} / \mathrm{L}$ \\
\hline Tetryl & 11.83 & $50-1000 \mu \mathrm{g} / \mathrm{L}$ & 0.9999 & $25 \mu \mathrm{g} / \mathrm{L}$ \\
\hline TNT & 12.69 & $50-1000 \mu \mathrm{g} / \mathrm{L}$ & 0.9994 & $6 \mu \mathrm{g} / \mathrm{L}$ \\
\hline $4-A D N T$ & 17.59 & $50-1000 \mu \mathrm{g} / \mathrm{L}$ & 0.9999 & $6 \mu \mathrm{g} / \mathrm{L}$ \\
\hline $2-A D N T$ & 18.75 & $50-1000 \mu \mathrm{g} / \mathrm{L}$ & 0.9999 & $12 \mu \mathrm{g} / \mathrm{L}$ \\
\hline $2,4-D N T$ & 14.85 & $50-1000 \mu \mathrm{g} / \mathrm{L}$ & 0.9998 & $6 \mu \mathrm{g} / \mathrm{L}$ \\
\hline NT & 18.8 & $100-1000 \mu \mathrm{g} / \mathrm{L}$ & 0.9993 & $50 \mu \mathrm{g} / \mathrm{L}$ \\
\hline
\end{tabular}




\subsubsection{LC/UV Conditions}

For comparative analysis with LC/MS, LC/UV detection was carried out using a PerkinElmer HPLC/UV system running EPA $8330 \mathrm{~b}$ as proscribed. An external calibration was performed by preparing calibration standards of $50,200,500,700$, and $1000 \mu \mathrm{g} / \mathrm{L}$ containing all the explosives in EPA 8330. Calibration curves of each component were created with correlation coefficients greater than 0.99 . The same LC column used for LC/MS (Acclaims E2) was used for LC/UV analysis thatincluded $100 \mu \mathrm{L}$ injections, a mobile phase of $43 / 57$ organic free water/methanol at a flow rate of $1 \mathrm{ml} / \mathrm{min}$, and a column temperature of $30^{\circ} \mathrm{C}$. The UV-vis detector was set at 254 $\mathrm{nm}$.

\subsubsection{Results and Conclusion}

\subsubsection{Quality Assurance Data}

A reference soil standard was purchased from ERA (Environmental Resource Associates) that included TNT, RDX, HMX, tetryl, 4-ADNT, 2-ADNT, 1,3-DNB, 2,4DNT, 2,6-DNT, NB, 2-NT, 3-NT, 4-NT, and 1,3,5-TNB. It is important to note that this soil was spiked with explosives from liquid standards and not particulates. These soil standards underwent the same extraction procedure as the Dolly Sods and Canaan Valley samples except for the sieving process. Sieving was not performed because the reference soil was already less than $2 \mathrm{~mm}$ in diameter. Samples were analyzed on both LC/UV and LC/MS/MS to test the extraction efficiency, precision, and estimate accuracy. Of the 14 compounds listed in the EPA 8330 method, 13 were present in the ERA soil standard. Table 12 lists the QC 
Performance Acceptance Limits (QC PALs) and the results from LC/UV and LC/MS/MS. The QC PALs are based upon past data that reflects any biases towards different extraction techniques. ERA estimates a 95\% confidence limit that experienced laboratories should achieve.

A comparison of the reproducibility between LC/MS/MS and LC/UV was conducted. A calibration mix containing all components was run in triplicate on the LC/MS and LC/UV in order to calculate the \%RSD of each analyte. Table 13 shows the \%RSDs for each component from both methods. The overall average of 3.3\% RSD was determined for LC/UV and a lower \%RSD of 1.6 was determined for LC/MS. Using the t-test of means, the differences between the means are statistically significant.

\subsubsection{Example field sites: Grid 14}

Grid 14 was located in the Dolly Sods Wilderness Area where an $81 \mathrm{~mm}$ mortar was found in 1997 . The steep, rocky and heavily vegetated terrain made it difficult to take soil samples as shown in Figure 26. Additionally, the rain that had passed the night before left the soil wet. As per CRREL methodology, a decision unit of $10 \mathrm{~m} \times 10 \mathrm{~m}$ was to be sampled; however, the steepness of some areas made it unsafe to take samples. Thus, a modified decision unit of $10 \mathrm{~m}$ wide $\times 5 \mathrm{~m}$ long over the crater was used to define the grid. The CRREL coring device was utilized for this decision unit. Out of 100, 76 multi-increment samples were taken. The 24 samples that were missed could not be obtained due to rocks and tree roots. Results revealed no detectable explosives present in this grid using LC/MS/MS. 
Table 12 - Results for ERA soil standard using LC/UV and LC/MS/MS. All concentrations are in units of $\mu \mathrm{g} / \mathrm{kg}$.

\begin{tabular}{|c|c|c|c|c|}
\hline \multicolumn{5}{|c|}{ LC/UV Data } \\
\hline \multirow[t]{2}{*}{ Component } & \multicolumn{2}{|c|}{$\begin{array}{c}\text { QC Performance Acceptance } \\
\text { Limits }\end{array}$} & \multirow{2}{*}{$\begin{array}{c}\text { Experimentally } \\
\text { Determined } \\
\text { Concentration* }\end{array}$} & \multirow[t]{2}{*}{ Within Range } \\
\hline & Lower Limit & Upper Limit & & \\
\hline $\mathrm{HMX}$ & 420 & 916 & 1100 & No \\
\hline RDX & 557 & 1100 & 780 & Yes \\
\hline 1,3,5-TNB & 7150 & 15600 & 8400 & Yes \\
\hline 1,3-DNB & 5680 & 10100 & 5800 & Yes \\
\hline NB & 1640 & 3700 & 800 & No \\
\hline TNT & 1860 & 3090 & 1700 & No \\
\hline 2,6-DNT & 3030 & 6390 & 3200 & Yes \\
\hline 2,4-DNT & 2300 & 4420 & 2400 & Yes \\
\hline $2-N T$ & 2930 & 5160 & 1500 & No \\
\hline 4-NT & 2790 & 5500 & 2100 & No \\
\hline 3-NT & 2800 & 5270 & 1800 & No \\
\hline 4-ADNT & 776 & 1890 & 1000 & Yes \\
\hline 2-ADNT & 1530 & 2960 & 1600 & Yes \\
\hline
\end{tabular}

\begin{tabular}{|c|c|c|c|c|}
\hline \multicolumn{5}{|c|}{ LC/MS/MS Data } \\
\hline \multirow[t]{2}{*}{ Component } & \multicolumn{2}{|c|}{$\begin{array}{c}\text { QC Performance Acceptance } \\
\text { Limits }\end{array}$} & \multirow{2}{*}{$\begin{array}{l}\text { Experimentally } \\
\text { Determined } \\
\text { Concentration }\end{array}$} & \multirow[t]{2}{*}{ Within Range } \\
\hline & Lower Limit & Upper Limit & & \\
\hline $\mathrm{HMX}$ & 420 & 916 & 561 & Yes \\
\hline RDX & 557 & 1100 & 839 & Yes \\
\hline 1,3,5-TNB & 7150 & 15600 & 12482 & Yes \\
\hline 1,3-DNB & 5680 & 10100 & 9238 & Yes \\
\hline TNT & 1860 & 3090 & 2140. & Yes \\
\hline 2,4-DNT & 2300 & 4420 & 3408 & Yes \\
\hline NT & 2790 & 5500 & 494 & No \\
\hline 4-ADNT & 776 & 1890 & 1075 & Yes \\
\hline 2-ADNT & 1530 & 2960 & 2248 & Yes \\
\hline
\end{tabular}


Table 13 - Reproducibility results using LC/UV and LC/MS/MS, $n=3$ (the same extraction preparation and LC conditions were used).

\begin{tabular}{|c|c|c|}
\hline Component & LC/UV: \%RSD & LC/MS/MS: \%RSD \\
\hline HMX & 5.4 & 1.6 \\
\hline RDX & 2.7 & 0.8 \\
\hline 1,3,5-TNB & 3.0 & 0.5 \\
\hline $1,3-$ DNB & 3.4 & 3.6 \\
\hline NB & 3.0 & -- \\
\hline TNT & 3.3 & 1.2 \\
\hline Tetryl & 3.1 & 3.3 \\
\hline 2,6-DNT & 3.4 & -- \\
\hline 2,4-DNT & 3.1 & 2.4 \\
\hline 2-NT & 3.3 & $0.9(\mathrm{NT})^{\star}$ \\
\hline 4-NT & 3.0 & -- \\
\hline 3-NT & 2.6 & -- \\
\hline 4-ADNT & 4.0 & 1.0 \\
\hline 2-ADNT & 3.2 & 0.8 \\
\hline AVERAGE & 3.3 & 1.6 \\
\hline
\end{tabular}

* This value is of all 3 nitrotoluenes combined. 
Figure 26 - Photograph of researchers staking the decision unit for Grid 14. The steep, rocky and heavily vegetated terrain presented challenges during sampling.

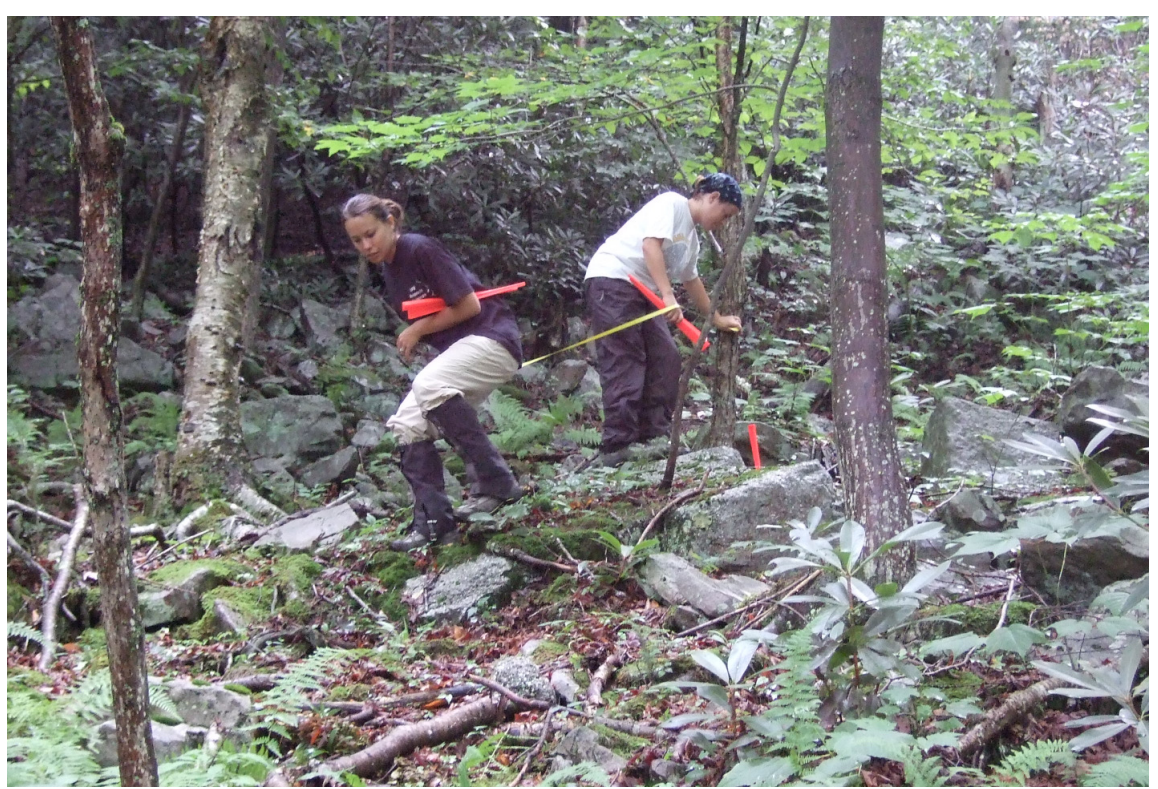




\subsubsection{Example field sites: Grid 15}

Grid 15 consisted of a densely wooded and vegetated terrain located on a slight incline in the Dolly Sods Wilderness area (Figure 27). An $81 \mathrm{~mm}$ mortar was also found and detonated at this site. During the initial scan of this grid by the Safety Specialist, the metal detector responded to something at one corner of the grid. Due to this anomaly and the dense vegetation, only a $3 \mathrm{~m} \times 3 \mathrm{~m}$ decision unit was obtainable. Using the CRREL coring device, 84 out of 100 multi-increments were taken from this location. The LC/MS/MS results showed no detectable explosives present in the soil at this location.

\subsubsection{Example field sites: Grid 16}

Grid 16 was positioned in the Canaan Valley National Wildlife Reserve (NWLR) where a 105 mm Howitzer round was found and blown-in-place in 2007. This location contained many large rocks, trees and vegetation (Figure 28). Sampling this environment became difficult and dangerous due to the wet soil and rocks from rainy weather. The step soil probe was used to achieve 2 multiincrement replicates for a $10 \mathrm{~m} \times 10 \mathrm{~m}$ decision unit. The first replicate took 82 out of 100 multi-increments and the second took 84 out of 100 . Within the $10 \mathrm{~m} \times 10 \mathrm{~m}$ decision unit, a miniature $2 \mathrm{~m} \times 2 \mathrm{~m}$ decision unit was centered around the visible crater (Figure 29). Out of 36, 32 multi-increments were collected using the CRREL coring device. In addition, a composite grab sample was taken from the large $10 \mathrm{~m}$ x 10 m decision unit. No explosives were detected in either the $10 \times 10 \mathrm{~m}$ or $2 \times 2 \mathrm{~m}$ grids. In addition, no detectable explosives were found in the random grab sample. 
Figure 27 - Photograph of a research group member staking out the decision unit for Grid 15.

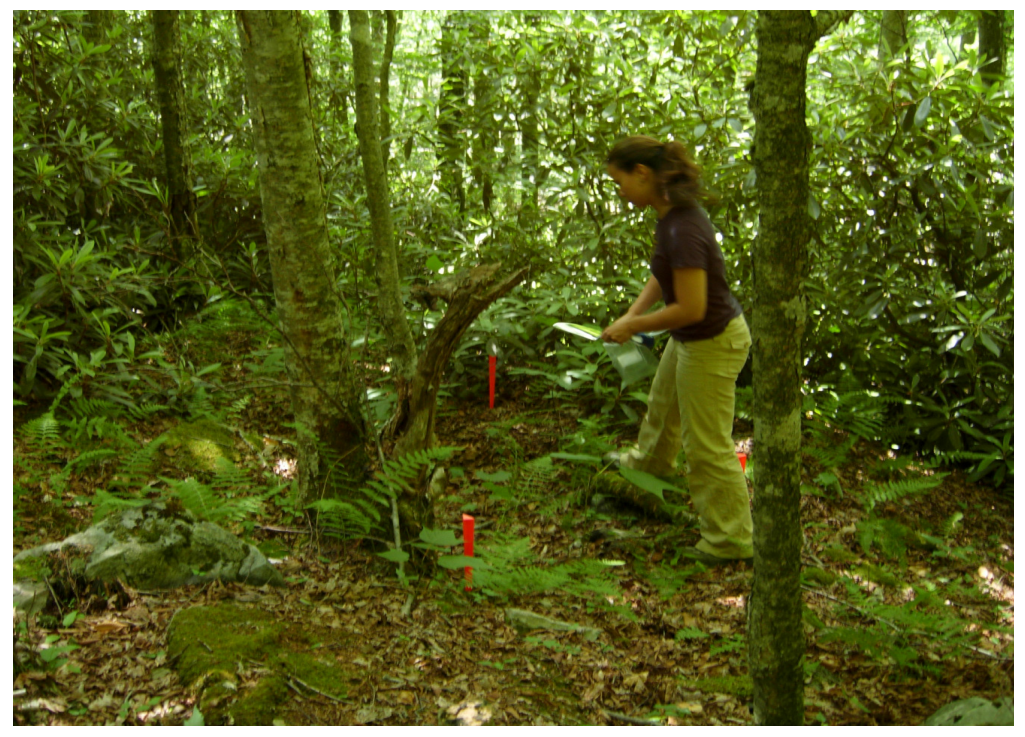


Figure 28 - Photograph showing researchers navigating the rocky and vegetated terrain to collect samples for Grid 16.

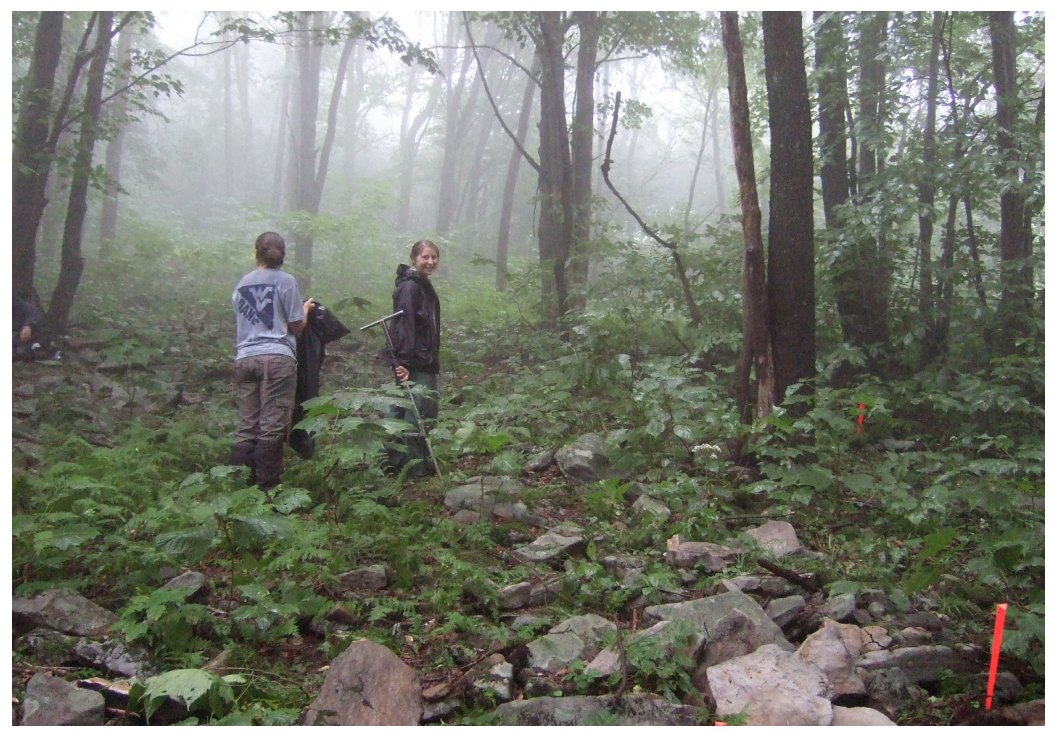


Figure 29 - Photograph showing the $2 \mathrm{~m} \times 2 \mathrm{~m}$ decision unit surrounding the crater found within Grid 16.

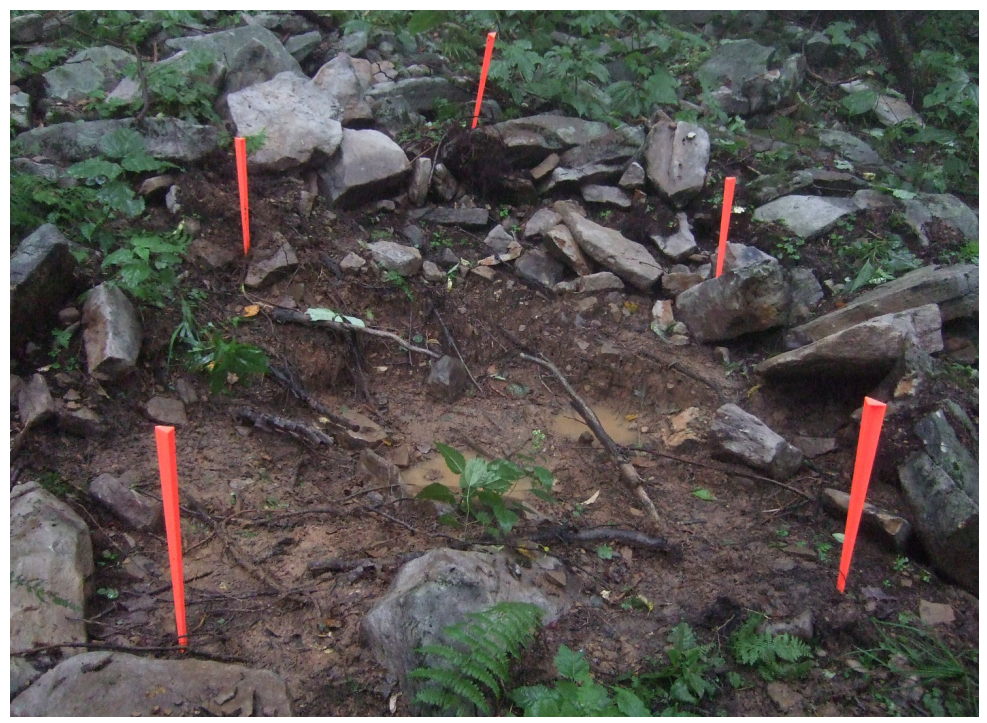




\subsubsection{Example field sites: Grid 19}

Grid 19 was located within the Canaan Valley Institute where an $80 \mathrm{~mm}$ rocket was found and detonated in 2006. Figure 30 shows that this site was flat but wooded with large rocks. Since the soil was very firm, the soil step probe was used to take soil samples. Although a $10 \mathrm{~m} \times 10 \mathrm{~m}$ decision unit was staked out, only 58 out of 100 multi-increments could be sampled. The wooded environment made it difficult to take samples and the Safety Specialist had located 6 anomalies with his metal detector during his initial scan of the grid. The anomalies were found in various locations of the grid, making it difficult to maneuver around the grid. Additionally, a composite grab sample was taken from within the crater.

The results from the multi-increment sample showed no detectable explosives; however, the composite grab sample revealed both RDX and HMX present. The concentration of RDX found was $44.5 \mu \mathrm{g} / \mathrm{kg}$ of soil and HMX was 215 $\mu \mathrm{g} / \mathrm{kg}$ of soil. 
Figure 30 - Photograph showing Grid 19. The crater was nestled in the cluster of rocks shown in the center of the image.

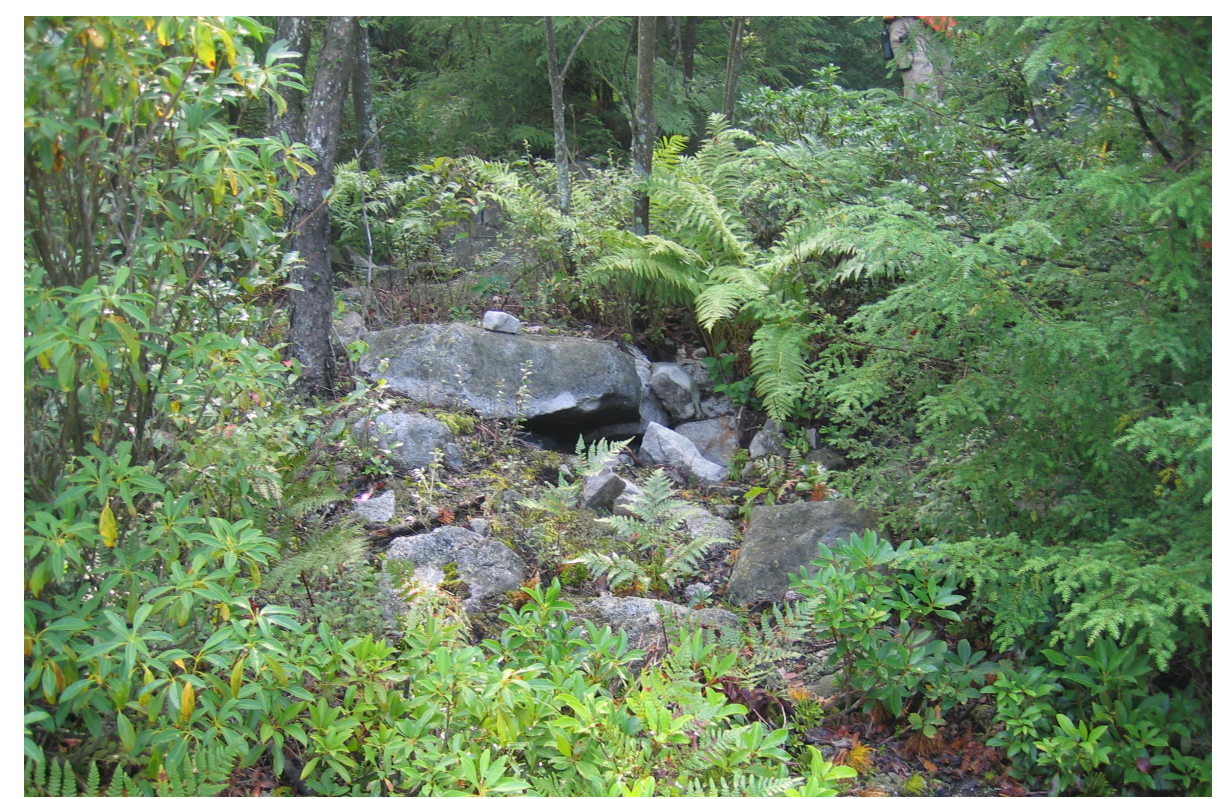




\subsubsection{Example field sites: Grid 20}

Like Grid 19, Grid 20 was located within the Canaan Valley Institute where an $80 \mathrm{~mm}$ rocket had been found and detonated in 2006. Half of the grid included a heavily vegetated area and the other half was flat and less vegetated (Figure 31). The half that was vegetated included several anomalies; therefore, this portion of the grid was not sampled. Consequently, a $10 \mathrm{~m} \times 5 \mathrm{~m}$ decision unit was used and 3 multi-increment replicates were achieved. Using the CRREL coring device, 48 out of 50,45 out of 50 , and 44 out of 50 multi-increments were taken from this grid.

Composite grab samples were also obtained from the crater of this grid. A chunky white substance was found and assumed to be unexploded C4 remaining from the detonation. Some of the chunky white substance was taken with the composite grab sample. A depth profile sample was also gathered across a $1 \mathrm{~m} \mathrm{x}$ $1 \mathrm{~m}$ area, encompassing the crater. This area was sampled in five locations to a depth of at least $12.7 \mathrm{~cm}$. The 5 portions obtained from soil above $12.7 \mathrm{~cm}$ deep were combined to form a composite sample labeled core_1. The 5 portions obtained from soil $12.7 \mathrm{~cm}$ deep and deeper were combined to form a composite sample, labeled core_2. Results from the multi-increment, grab sample and cored samples are shown in Table 14. An example of the total ion chromatogram (TIC) of the $2^{\text {nd }}$ multi-increment sample (WVU_2007_20_Ml_2) taken from Grid 20 is shown in Figure 32. 
Figure 31 - Photograph showing members of the research team gathering soil samples from Grid 20 using the CRREL coring devise.

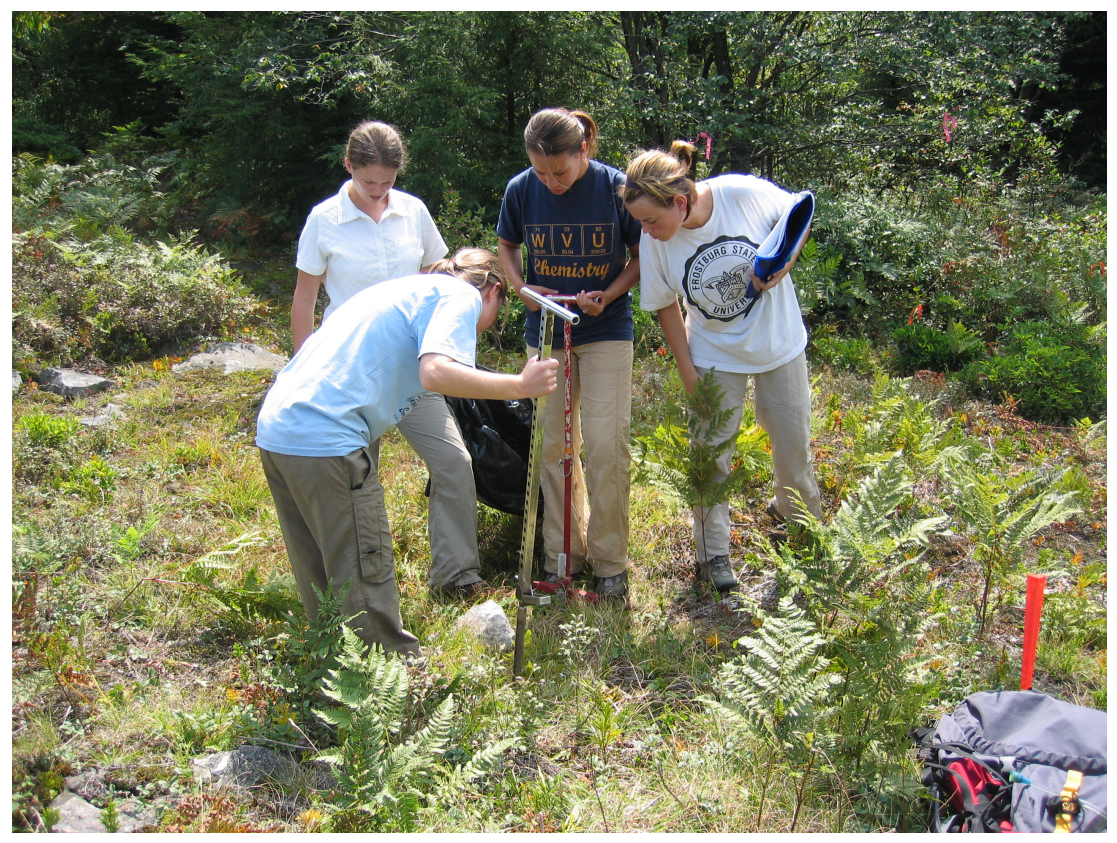


Figure 32 - Example of the total ion chromatogram (TIC) of the $2^{\text {nd }}$ multi-increment sample (WVU_2007_20_MI_2) taken from Grid 20. Explosives were detected and identified using MS in MRM mode.

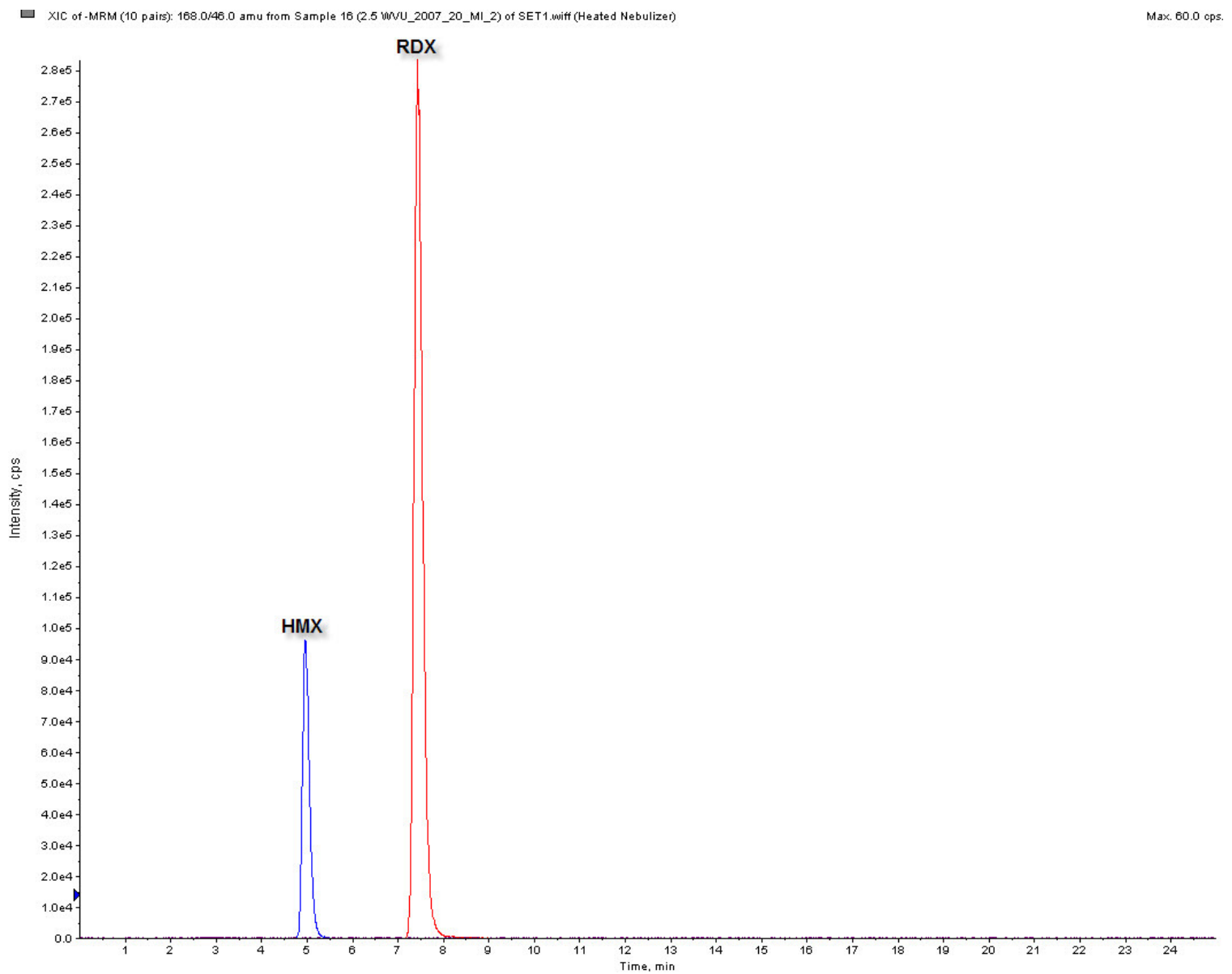


Table 14 - Results for multi-increment, random grab, and cored soil samples from Grid 20.

\begin{tabular}{|l|c|c|c|c|}
\hline & $\begin{array}{c}\text { Number } \\
\text { of } \\
\text { samples }\end{array}$ & $\begin{array}{c}\text { Number of } \\
\text { increments }\end{array}$ & \multicolumn{2}{|c|}{ Concentration (mg/kg) } \\
\cline { 4 - 5 } analyzed & per sample & RDX & HMX \\
\hline WVU_2007_20_MI_1 & 1 & 48 & 1.63 & 0.779 \\
\hline WVU_2007_20_MI_2 & 1 & 45 & 2.92 & 9.43 \\
\hline WVU_2007_20_MI_3 & 1 & 43 & 0.917 & 0.158 \\
\hline WVU_2007_20_GRAB & 1 & - & $1.04 \times 10^{3}$ & 163 \\
\hline WVU_2007_20_CORE_1 & 1 & - & 5.28 & 1.81 \\
\hline WVU_2007_20_CORE_2 & 1 & - & 5.72 & 0.753 \\
\hline
\end{tabular}




\subsubsection{Example field sites: Site XD}

During a trip to the Dolly Sods Wilderness Area 2 months prior, the UXO expert and Safety Specialist discovered an unexploded $60 \mathrm{~mm}$ mortar about $25 \mathrm{ft}$ from one of the trails. The mortar was blown-in-place with TNT 2 days later by the WV State Police and sampled during the trip in August. Due to several anomalies found, only one researcher was allowed to go to the location to take grab samples; a decision unit model was unfeasible due to safety issues and the steep terrain. A photo of the crater is shown in Figure 33. Five composite grab samples were taken at different areas of the crater. Sample XD_1 was taken from the detonation center, sample XD_2 was taken from the left side of the detonation center, sample XD_3a and XD_3b were taken from the back of the detonation crater (up-slope) and sample XD_4 was taken from the area below the detonation crater (down-slope).

Results for Site XD are shown in Table 15. TNT, 2-ADNT, and 4-ADNT were found in all 5 samples at concentrations ranging from $0.239-27.8 \mathrm{mg} / \mathrm{kg}$ of soil. An example TIC of sample XD_1 is seen in Figure 34, where all 3 compounds were detected. In addition, 2,4-DNT was detected in samples XD_2, XD_3a and XD_4 and NT was detected in samples XD_1, XD_2 and XD_3a. These results agree with the fact that TNT was used to detonate this UXO. 
Figure 33 - Photograph showing the crater in the area where a $60 \mathrm{~mm}$ mortar was found and detonated during the first trip to Dolly Sods (June 2007). The area was sampled as site XD during the August 2007 Field Campaign.

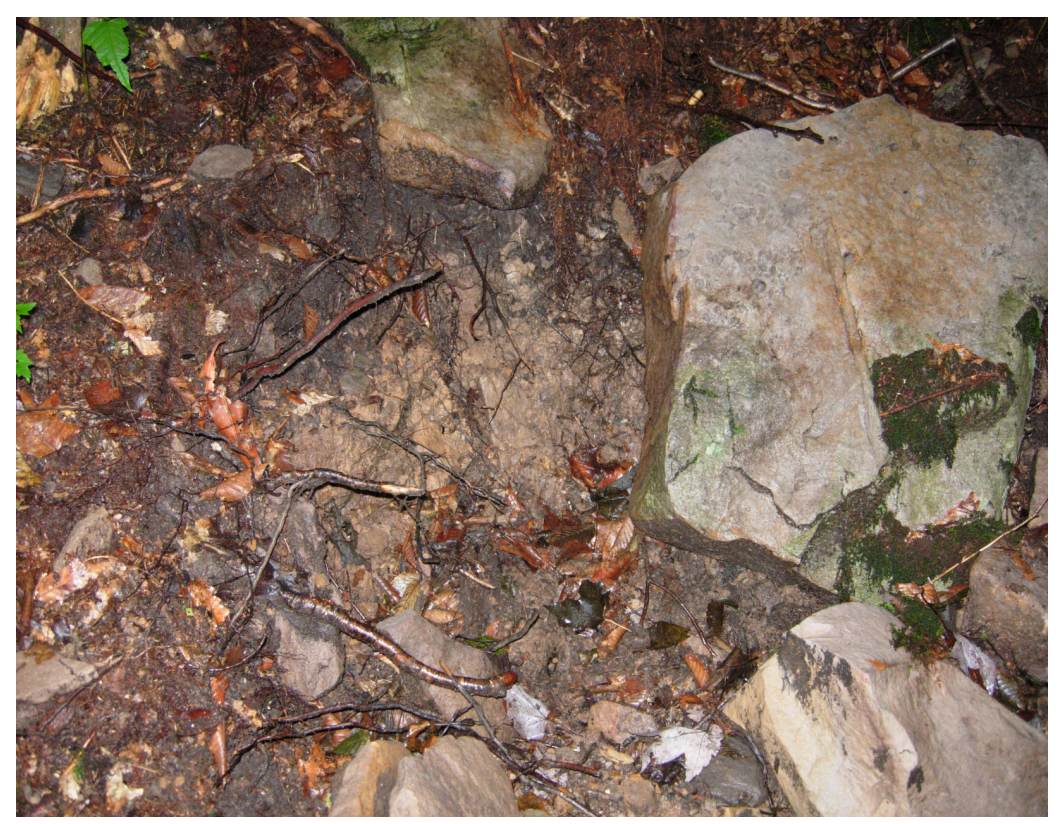


Table 15 - Results for random grab samples from Grid XD.

\begin{tabular}{|c|c|c|c|c|c|c|c|c|c|c|}
\hline \multirow[b]{2}{*}{ Sample ID } & \multirow{2}{*}{$\begin{array}{l}\text { Number } \\
\text { of } \\
\text { samples } \\
\text { analyzed }\end{array}$} & \multirow{2}{*}{$\begin{array}{c}\text { Location } \\
\text { of sample } \\
\text { within } \\
\text { crater }\end{array}$} & \multicolumn{8}{|c|}{ Concentration (mg/kg) } \\
\hline & & & TNT & 2,4-DNT & 2-ADNT & 4-ADNT & NT & $1,3,5-T N B$ & 1,3-DNB & Tetryl \\
\hline WVU_2007_XD_1 & 1 & $\begin{array}{l}\text { Inside } \\
\text { crater }\end{array}$ & 27.8 & ND & 8.55 & 1.56 & 1.59 & ND & ND & ND \\
\hline WVU_2007_XD_2 & 1 & $\begin{array}{c}\text { left side of } \\
\text { crater }\end{array}$ & 7.22 & 0.00550 & 2.51 & 1.43 & 0.355 & ND & ND & ND \\
\hline WVU_2007_XD_3a & 1 & $\begin{array}{l}\text { back side } \\
\text { of crater }\end{array}$ & 6.78 & 0.0295 & 2.14 & 5.64 & 0.197 & ND & ND & ND \\
\hline WVU_2007_XD_3b & 1 & $\begin{array}{l}\text { back side } \\
\text { of crater }\end{array}$ & 0.239 & ND & 0.440 & 0.271 & ND & ND & ND & ND \\
\hline WVU_2007_XD_4 & 1 & $\begin{array}{l}\text { below } \\
\text { crater }\end{array}$ & 5.36 & 0.00160 & 1.35 & 1.35 & ND & ND & ND & ND \\
\hline
\end{tabular}


Figure 34 - TIC of the sample taken from the detonation crater of Site XD (XD_1). Explosives were detected and identified using MS in MRM mode.

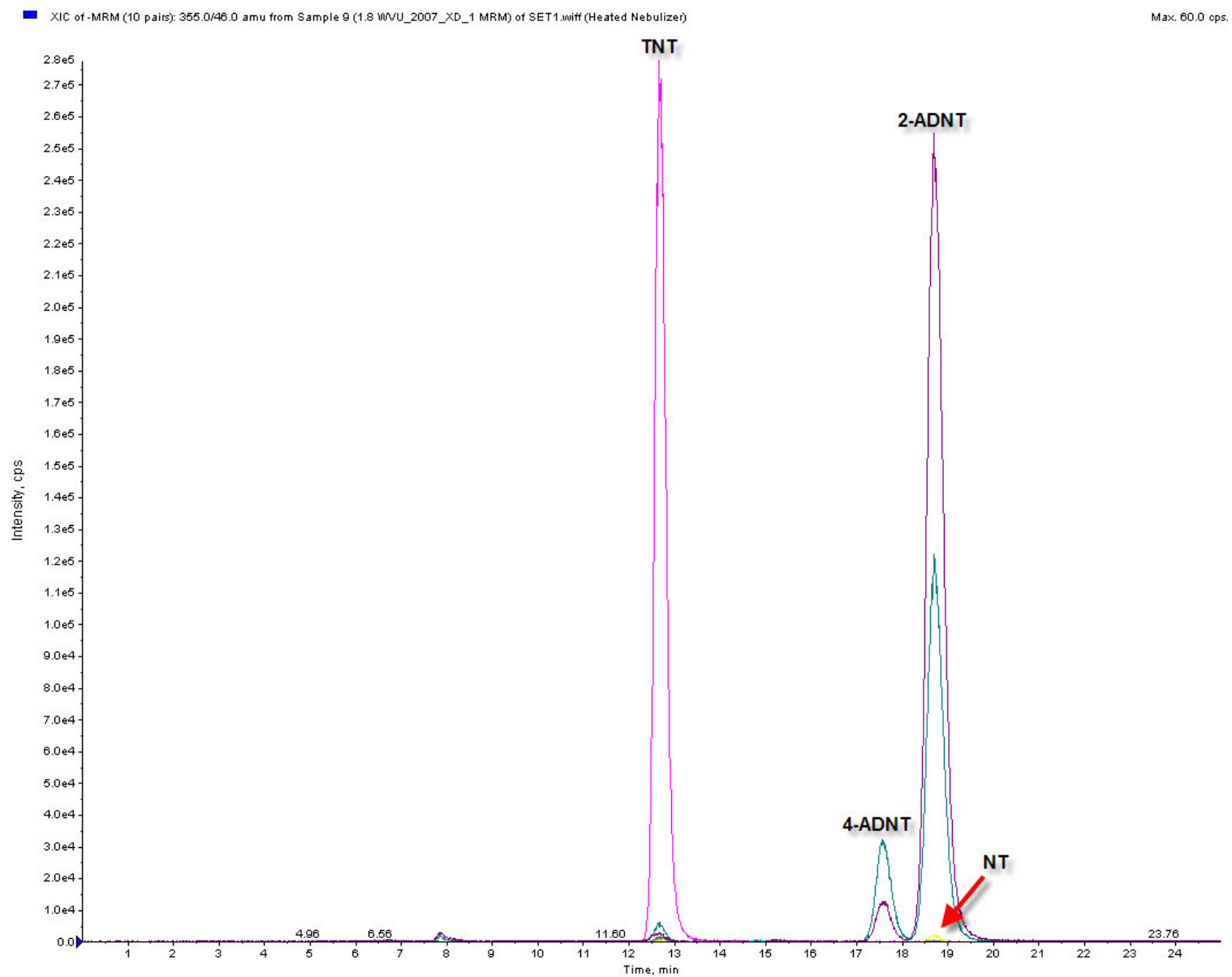




\subsubsection{Discussion}

The first goal of this project was to determine if explosives were present in the soil at areas where UXO had been blown-in-place. No explosives were detected in Grids 14,15 , or 16 using this method. Grids 14 and 15 were located within the Dolly Sods Wilderness Area where $81 \mathrm{~mm}$ mortars were found and detonated by the WV State Police. Since the mortars and detonating charge only contained TNT, this is the only explosive along with its transformation products that were expected to be present. Grid 16 was located at the WV NWLR where a $105 \mathrm{~mm}$ Howitzer round was found. Despite the extensive sampling procedures and replicate analysis performed on Grid 16, no detectable concentrations of explosives residues were found in the recovered soil. Upon further research into how the $105 \mathrm{~mm}$ Howitzer round was fired, it was noted by the USACE that the WV State police had used too much TNT charge. An explanation for not detecting any explosives in this grid is the possibility that a high order detonation occured. High order detonations produce particulates in the submicron particulate size [102], making it difficult to detect using this type of method.

The two grids that did contain residual explosives were 19 and $20.80 \mathrm{~mm}$ rockets were found at both grids which were located in the Canaan Valley Institute. Since this area is considered private property, the US Army detonated the rockets with C4 in 2006. Therefore, TNT, RDX and HMX were expected to be detected at these sites. As expected, the results for Grid 19 revealed that the grab sample taken from the crater contained RDX and HMX at $44.5 \mu \mathrm{g} / \mathrm{kg}$ and $215 \mu \mathrm{g} / \mathrm{kg}$. The multi-increment sample which represents the grid as a whole, showed no detectable 
traces of any explosives. Results for Grid 20 showed RDX and HMX present in every soil sample. All 3 multi-increment samples, grab samples and cored samples contained high levels of these explosives. Although RDX and HMX were present in both grids, TNT was not detectable although this explosive was expected since the $80 \mathrm{~mm}$ rockets contained TNT. One plausible explanation can be due to the halflives of TNT, RDX and HMX. A study conducted by the Los Alamos National Laboratory in 1991 revealed the half-lives of various explosives in soil. The halflives of TNT, RDX and HMX were shown to be 1 year, 36 years, and 39 years [111]. TNT has a considerable lower half-life compared to RDX and HMX, thus, explaining why TNT is no longer present in Grids 14-20.

TNT and TNT transformation products were found in Site XD since this site was detonated only 2 months prior. Site XD was the best example of how sampling, analysis and interpretation can be integrated to improve existing methods for explosives detection. By taking soil samples recently after detonation, these results can be compared to soil taken from this same site one year later. Monitoring TNT degradation in the environment can provide useful information to the USACE pertaining to when remediation is needed.

The depth profile samples showed RDX and HMX existing at least $20.3 \mathrm{~cm}$ below the surface. This presents an environmental concern because RDX and HMX can migrate to groundwater. An example of this can be seen at the Camp Edwards Massachusetts Military Reservation (MMR), located near Falmouth, MA [3]. Studies there have shown that the explosives, resulting from bombing and training, have migrated through the soil to a nearby sole-source drinking water aquifer. Levels of 
RDX had been detected in the water, which prompted the need to take soil samples at Camp Edwards. The explosives were present in both soil and groundwater with a concentration as high as $370 \mu \mathrm{g} / \mathrm{l}$ of RDX in one of the wells. This value exceeds the water quality limit of $2 \mu \mathrm{g} / \mathrm{l}$ of RDX (and TNT) in drinking water [39]. Since RDX leads to many toxicological effects (see Section 1.2.2) a charge which is more safely absorbed into the environment such as ammonium nitrate should be considered for removal of UXO.

While the sample gathering techniques and tools for EPA 8330b are ideal in certain environments and terrains, such as the flat Alaskan marshlands CRREL used to develop the multi-increment technique, the rocky, mountainous, and densely vegetated environments encountered during this research posed many challenges to the execution of the sampling. One challenge presented by the terrain involved the restriction of decision unit size. In order to be sampled, the entire decision unit must be scanned by a UXO Safety Specialist using the Schonstedt to locate magnetic anomalies. Some of the sites sampled in this research were so densely vegetated that the UXO Safety Specialist was unable to effectively scan the area. Entire portions of some decision units were omitted from sampling in some cases and in others the size of the decision unit was reduced to include only those areas safe for sampling. These restrictions resulted in the already reduced decision units $(10 \mathrm{~m} x$ $10 \mathrm{~m}$ vs. the recommended $50 \mathrm{~m} \times 50 \mathrm{~m}$ ) to be reduced further and, in more comprehensive studies, would require more decision units to be sampled before determining the proper course of action for the area of interest. In addition, when the desired 100 increments are gathered from a smaller area, the surface soil is 
disrupted more noticeably than if the same number of increments were spread out over a larger area. Such an impact on the environment is an issue that must be addressed when samples are gathered from protected land such as wilderness areas [103].

Negotiating the terrain during sampling also presented issues. First, safety needed to be minded when maneuvering over large rocks (which were slippery during this research due to rain), steep inclines, fast-flowing steams, and dense vegetation. Second, when gathering samples and attempting to stay in a straight line to accomplish the rows and columns necessary for the multi-increment sampling, avoiding multiple obstacles such as rocks and trees made the task more difficult. These two issues combined to slow the process of sampling a decision unit considerably, when compared to sampling the same decision unit in a flat environment, and often prohibited the performance of replicate analysis [103]. Consequently, EPA 8330b should be revised to include all different types of terrain. EPA 8330b utilizes LC/UV for the detection of explosives in soil extracts. For comparison, LC/MS/MS was employed for this study in order to reduce the amount of solvent used, shorten analysis time, accomplish lower limits of detection, and achieve definitive information using one LC column. For QC purposes, a comparison between the two methods was performed using a certified reference material containing explosives spiked in soil. Reference material from the same lot number was ground, extracted and ran on LC/UV and LC/MS. Although the LC/MS/MS method could only detect 9 of the 13 components in the reference material, 8 of them fell within the QC performance acceptance limits (Table 12). The 
concentration for NT was much lower than the lower QC limit. This was not surprising since NT does not ionize well using APCl. Comparing this information to LC/UV which can detect all 13 components, only 7 components fell within range. The concentrations for NB, TNT, and 3-NT were too low while HMX was too high. The explanation for these results is unclear. Since the values for the LC/MS analysis fell within range, the plausible cause of heat degradation during grinding is no longer a possibility.

The precision between the two methods was also tested by running an explosives mixture in triplicate. Areas were used to calculate the \%RSD value for each explosive. The results showed that the average \%RSD for the LC/MS/MS method was half than the LC/UV value (Table 13). Therefore, these results along with the data collected from the certified reference material reveals that LC/MS/MS is the better method for QC purposes; however, the inability to ionize NB or the NTs efficiently creates limitations for this method. This issue could be addressed in the future by exploring different adducts, such as glycine, to enhance ionization [108].

\subsubsection{Conclusions}

The research presented here confirms that explosive residues were found in soils in areas where 'blow-in-place' detonation of UXO occurred. Explosive residues were found in surface soil and at depths of up to $20.3 \mathrm{~cm}$ (8 in.) providing evidence that the contaminants are able to migrate. Instrumental analysis, by LC/MS/MS, of soil recovered from the sample sites showed the presence and concentrations of contaminants to be a function of parameters such as: time since detonation, type of 
original munitions, and type of charge used to destroy the UXO. Although the LC/MS/MS method is incapable of ionizing and separate all 14 components of EPA 8330, it was able to detect and quantify the explosives expected at the West Virginia Maneuver area within an acceptable QC performance limit with good precision. Future work for improving the method involves finding ways to ionize NB such as forming adducts with glycine to enhance ionization [108].

A modified method is required for effective and efficient sampling of rocky, mountainous, and densely vegetated environments. These types of terrain, such as those encountered in this research, pose many challenges to the execution of the sampling under the multi-increment method. While the sample gathering techniques and tools are ideal in certain environments and terrains, such as the flat Alaskan marshlands CRREL used to develop the multi-increment technique, the use of recommended tools was not always possible and the desired increment volume could not always be achieved in the wilderness area studied during this research. In addition, the disruption of surface soils and environments required to sample under these methods may be unacceptable in wilderness areas where environmental impact is strictly regulated [103].

For remediation purposes, Grids 19, 20, and XD showed high levels of explosives remaining in the soil. Although removal of UXO is necessary for the safety of the environment, this research shows that the type of charge used to detonate the UXO plays a key role in contamination. The results of the depth profile provide information that RDX and HMX are found at least $20.3 \mathrm{~cm}$ deep in the soil. This can lead to not only environmental problems, but human toxicity issues if these 
particulates reach the ground water [1, 2]. Because the RDX and HMX contamination at this site is due to $\mathrm{C} 4$, using more environmentally friendly explosive (like ammonium nitrate) for detonation needs to be considered. In addition, depth profile samples should be taken periodically to insure that contamination is not migrating down into the soil. These samples should be taken at fresh detonation sites as well as existing and aged craters [103]. 


\section{Chapter 4: Determination of Human Biomarkers of RDX, HMX, and Tetryl}

\subsubsection{Introduction}

Human exposure to energetic materials, as a result of explosive contamination at military firing ranges and ammunition manufacturing sites, may lead to serious health related problems. People that are exposed to these areas may be aware of their exposure; however, others may be unaware that they are being exposed to these toxic substances. An example of this type of exposure could be due to groundwater contamination, which is common in areas near firing ranges and ammunition factories $[69,112,113]$. TNT, RDX, HMX, and tetryl are common explosive contaminates found at these sites as described in EPA method 8330. The structures of these explosives are shown in Figure 35. To determine the amount of exposure, it is essential to find biomarkers that can be detected in biological fluids are essential for this verification.

Additionally, the threat of improvised explosive devices is both a forensic and homeland security threat. As such, forensic toxicologists need to develop a new suite of tools to provide probative information to investigators and the judicial system. The ability to detect biomarkers of energetic materials provides toxicologists a new technique for the identification of those who have been exposed to explosives.

Exposure to the chemical components that make up an explosive can lead to these compounds entering the body by dermal absorption, and/or inhalation [114]. Once these compounds enter the blood stream, they are metabolized by 
Figure 35 -Structures of TNT, RDX, HMX, and Tetryl.

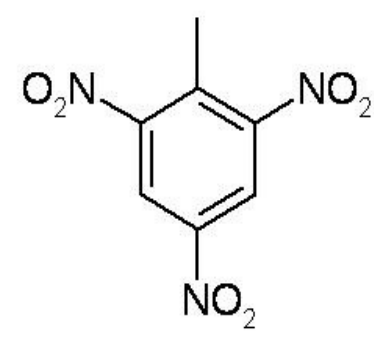

TNT

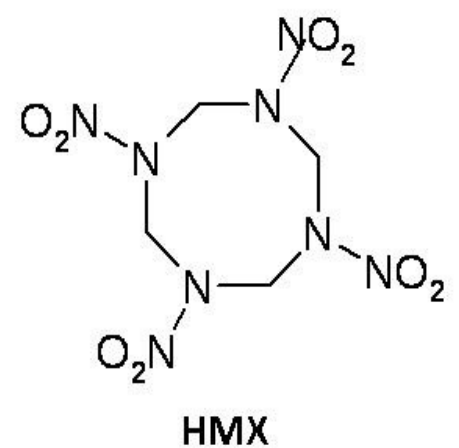

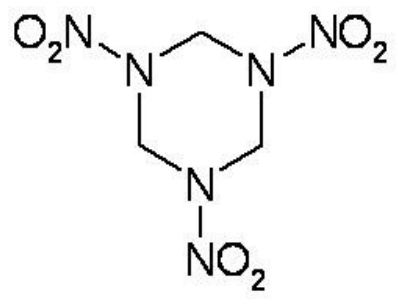

RDX

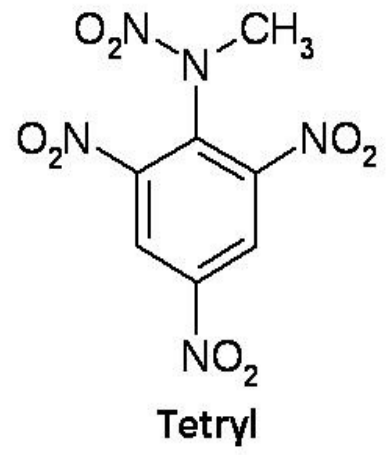


enzymes and excreted through the urine. The more common pathway for metabolism of exogenous compounds is via the liver, which contains a popular class of enzymes called the Cytochrome p450. These heme-containing enzymes are responsible for phase I metabolism, which consists of oxidation, reduction and hydrolysis reactions [115]. A simplified Cytochrome P450 cycle is shown in Figure 36 and further discussed in Chapter 1 . Some of these metabolites can be distinctive among all other compounds found in the body. In the case of explosive compounds, detecting these unique metabolites in blood or urine can lead to the identification of a person who has been exposed to an explosive. Previous research has been conducted on detecting metabolites of TNT exposed workers [114]. 4-Amino-2,6dinitrotoluene (4-ADNT) was found to be the main TNT metabolite from people primarily exposed by skin adsorption and inhalation of TNT. Figure 37 shows the main pathway for phase I metabolism of TNT. TNT undergoes a reduction at the 2 or 4 position to yield a hydroxylamine and further reduction to an amine. Resulting metabolites are 4-ADNT and 2-amino-4,6-dinitrotoluene (2-ADNT). Unlike TNT, human metabolites of RDX, HMX, and tetryl have not been widely studied.

Developing a method for the determination and detection of explosive metabolites is not only valuable for environmentalists and forensic toxicologists in identifying bomb-makers, but also to the toxicological research linking these metabolites and the affects these compounds have on the body. For example, contact with explosive compounds, such as TNT, can lead to health effects such as cataracts, hepatomegaly, and liver cancer [61]. However, developing such a method 
can be a difficult task given their chemical properties and low solubility in aqueous solutions.

For the present work, an in-vitro metabolism using human liver microsomes (HLMs) and NADPH was employed and the separation and identification of human metabolites of RDX, HMX, and tetryl were determined using LC/MS/MS by a linear ion trap. These explosives were chosen because they are commonly found at military firing ranges and often are the cause of environmental contamination. Since TNT metabolites have already been determined in humans, TNT was metabolized in conjunction with RDX, HMX, and tetryl under the same in-vitro conditions as a control. As of 2009, HLMs have not been used to metabolize RDX, HMX, and tetryl. This research has been submitted and accepted for publication into the journal of Analytical and Bioanalytical Chemistry. 
Figure 36 - Simplified Cytochrome p450 cycle. Figure Adapted from [116].

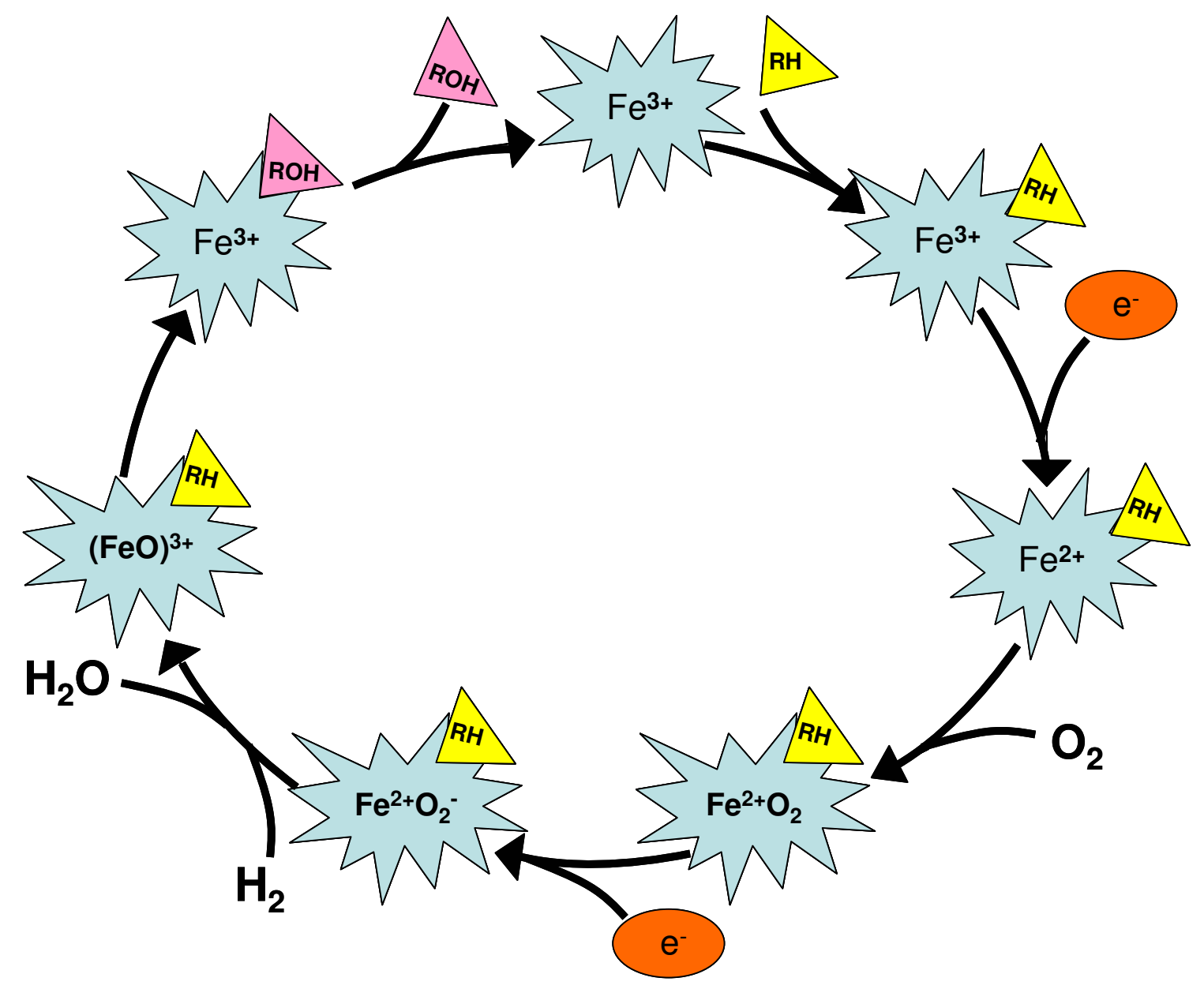


Figure 37 - The 2 main pathways for TNT phase I metabolism.

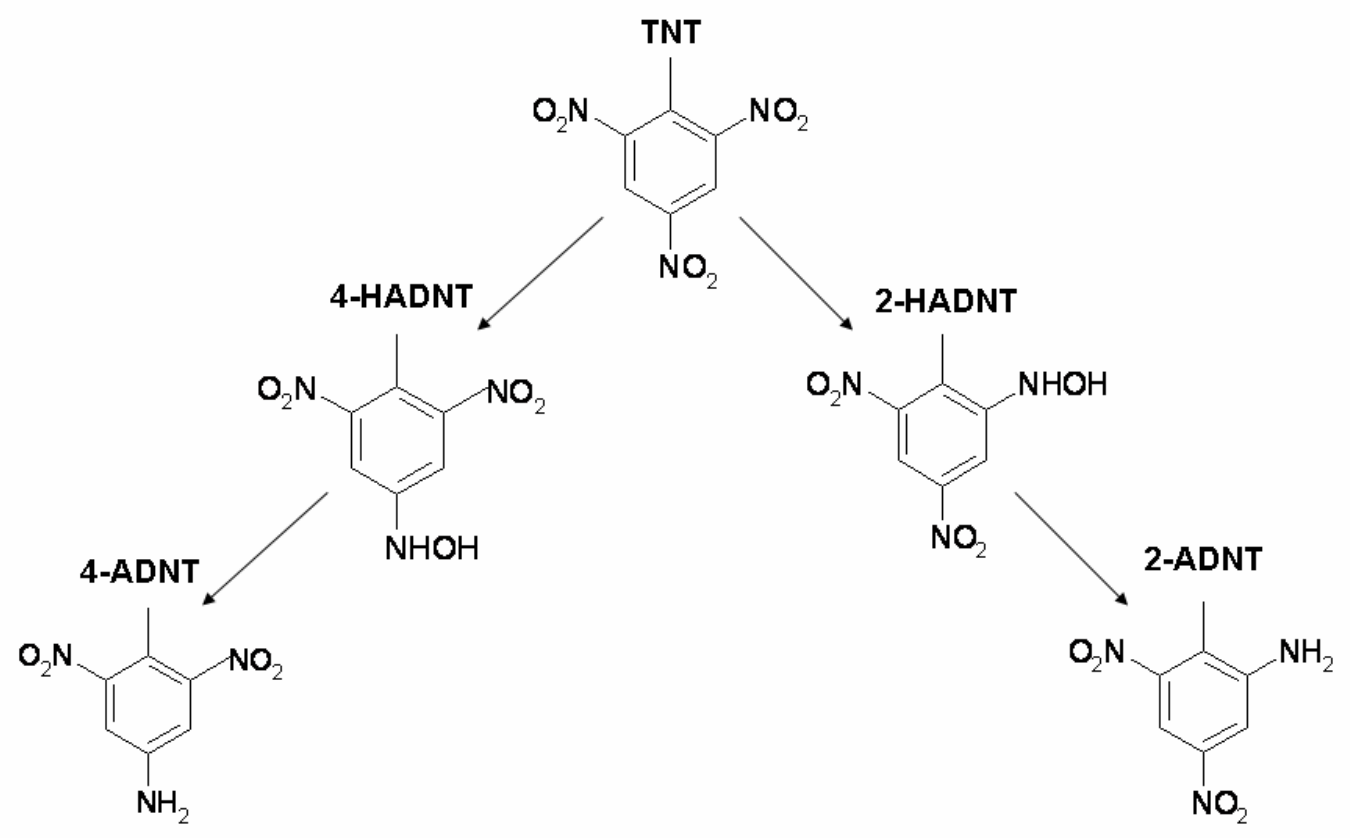

Note: Further metabolism may lead to 2,4-diamino-6-nitrotoluene or 2,6-diamino-4-nitrotoluene. 


\subsubsection{Materials and Methods}

RDX, HMX, and tetryl were purchased from Cerilliant (Round Rock, TX) and TNT was purchased in the solid form from Chem Service (West Chester, PA). Methanol, methanol with $0.1 \%$ ammonium acetate for LC/MS, $\mathrm{H}_{2} \mathrm{O}$ with $0.1 \%$ ammonium acetate for LC/MS, acetonitrile, $\beta$-nicotinamide adenine dinucleotide phosphate (NADPH), and potassium phosphate monobasic were all purchased from Sigma-Aldrich (St. Louis, MO). Human liver microsomes were purchased from BD Biosciences (San Jose, CA). The viability of the HLMs was verified by a control study using the drug, zolpidem [117].

To prepare the TNT, RDX, HMX and tetryl for metabolic studies, the contents of each $1.0 \mathrm{mg} / \mathrm{ml}$ ampule (nominally $1 \mathrm{~mL}$ ) was transferred to a centrifuge tube and evaporated under a gentle stream of ultrapure nitrogen. Because these explosives are relatively insoluble in water, the concentration of this initial solution could not be calculated. Using the following values for solubilities of $\sim 115 \mathrm{mg} / \mathrm{L}, 60 \mathrm{mg} / \mathrm{L}$, and $140 \mathrm{mg} / \mathrm{L}$ for TNT, RDX, HMX, and tetryl respectively [118], these initial solutions were estimated to be in the range of $0.1-1.0 \mathrm{mM}$. Although these solution could have been standardized using a spectrometer to determine the concentrations, this was not attempted. Concentrations for control samples were determined using $\mathrm{LC} / \mathrm{MS} / \mathrm{MS}$ with the recognition that this value represents only a reasonable estimate of the concentration of the parent compound initially present in the samples subsequently metabolized. Issues arising related to solubility are discussed in detail in Results and Discussion, below. 


\subsubsection{In-vitro Metabolism Procedure}

The in-vitro metabolism procedure using human liver microsomes was provided by Dr. Diaa Shakleya from the National Institute on Drug Abuse/Intramural Research facility in Baltimore, MD. Incubation time must be sufficient for metabolism to occur but not so long as to invite enzyme degradation. In drugs with nitroaromatic functionality such as flurnitrazepam and flutamide, incubation times of 20 minutes [119] and 60 minutes [120] have been reported. Typical incubation time in drug studies is 30 minutes [118] and this time was used here; however, a time study was conducted using TNT to confirm this as a reasonable selection. A control and metabolized sample was prepared for each explosive. First, $40 \mu \mathrm{L}$ of $500 \mathrm{mM}$ potassium phosphate, $15 \mu \mathrm{L}$ of microsome and $\mathrm{dlH}_{2} \mathrm{O}(125 \mu \mathrm{L}$ for the control and 85 $\mu \mathrm{L}$ for the metabolized sample) were added to a $650 \mu \mathrm{L}$ microcentrifuge tube, lightly vortexed and incubated at $37^{\circ} \mathrm{C}$ for 30 seconds. Then $20 \mu \mathrm{L}$ from a $10 \mathrm{mM}$ stock of the explosive (resulting concentration at $\sim 1 \mathrm{mM}$ ) was added to the reaction mixture, lightly vortexed and incubated in an oven set at $37^{\circ} \mathrm{C}$ for 30 seconds. Next, $40 \mu \mathrm{L}$ of 10mM NADPH was added ONLY to the metabolized sample. The sample was lightly vortexed and incubated at $37^{\circ} \mathrm{C}$ for 30 minutes. At this point, metabolism only occurs in the sample that contains NADPH. Both samples were quenched using $10 \mu \mathrm{L}$ of $85 \%$ perchloric acid, centrifuged and the supernatant was collected. A schematic of this procedure is shown in Figure 38. Last, a procedure was performed by adding $100 \mu \mathrm{L}$ of cold $\mathrm{ACN}$ to each sample to precipitate out any proteins. The 
Figure 38 - Schematic of the in-vitro metabolism procedure.
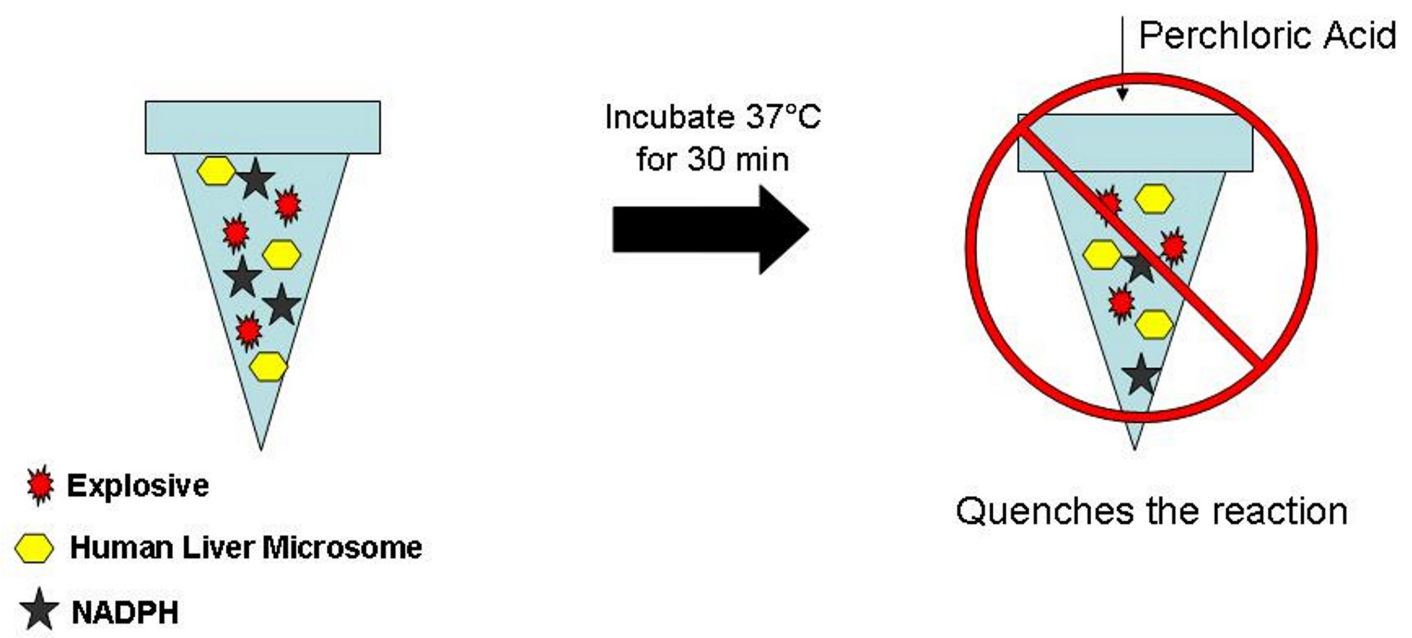

Quenches the reaction 
samples were centrifuged at $3500 \mathrm{rpm}$ for $10 \mathrm{~min}$ and the supernatants were collected and stored in $-20^{\circ} \mathrm{C}$ until LC/MS analysis.

\subsubsection{Large Volume TNT Solution}

A significant volume of solution of TNT was required for a time study and for control samples. To prepare this solution, approximately 0.6 grams of solid TNT was placed into a screw-cap plastic sample tube to which $50 \mathrm{~mL}$ of DI water was added. This was placed on a sample rotator for 36 hours to create a saturated solution. At the end of the rotation period, the solution was allowed to settle before aliquots were drawn off.

\subsubsection{Quantitation}

A 7 point external calibration curve was performed for each parent compound at a concentration range of $1.0 \mu \mathrm{g} / \mathrm{L}-1.0 \mathrm{mg} / \mathrm{L}$. Each calibration standard was prepared from a $1.0 \mathrm{mg} / \mathrm{ml}$ standard and stored at $4^{\circ} \mathrm{C}$. Previously reported MRM transitions of each explosive were used to determine the calibration. The MRM transitions were the following: $226 \rightarrow 46$ for TNT, $281 \rightarrow 46$ for RDX, $355 \rightarrow 46$ for HMX and $241 \rightarrow 213$ for tetryl. Limits of detection (LOD) were determined experimentally for the parent compounds at $8 . \mathrm{ng} / \mathrm{L}$ for TNT and $500 \mathrm{ng} / \mathrm{L}$ for the remaining parent explosives. The LOD's were determined at a MS S/N ratio of 3. 


\subsubsection{HPLC Conditions}

A Shimadzu Prominence HPLC system was used for the chromatographic separation of metabolites. For TNT analysis, Eluent A consisted of $\mathrm{H}_{2} \mathrm{O}$ and Eluent B consisted of methanol. Given that RDX and HMX do not readily ionize by ESI, acetate can be used to form an adduct to enhance ionization [121]. Thus, Eluent A consisted of $\mathrm{H}_{2} \mathrm{O}$ with $0.1 \%$ ammonium acetate and Eluent $\mathrm{B}$ was methanol with $0.1 \%$ ammonium acetate. Since tetryl was ionized using APCI, the same mobile phase for RDX and HMX was applied. $20 \mu \mathrm{L}$ of sample was injected onto an Allure C-18 $50 \times 2.1 \mathrm{~mm}, 5 \mu \mathrm{m}$ particle size column (Restek, Bellefonte, PA, USA). The gradient elution method applied to the TNT analysis started with $10 \%$ B for 3 min and then increased linearly to $100 \%$ B to 15 min. Between $15-20$ min, B was held at $100 \%$ and then decreased rapidly to $10 \% \mathrm{~B}$ at $21 \mathrm{~min}$. The run finished at $25 \mathrm{~min}$ and the total flow rate was $0.2 \mathrm{ml} / \mathrm{min}$. The isocratic elution applied to RDX, HMX and tetryl was $58 \%$ B with a total flow rate of $1.0 \mathrm{ml} / \mathrm{min}$.

\subsubsection{LC/MS/MS Conditions}

An Applied Biosystems (ABI) 3200 QTrap LC/MS/MS system using electrospray ionization (ESI) was employed for TNT analysis. Atmospheric pressure chemical ionization (APCI) was used for RDX, HMX, and tetryl. In all cases, the negative ion mode was employed and conditions are summarized in Table 16. Two TNT metabolites, 2,4-DANT and 2,6-DANT, were verified using the positive mode. Each explosive was metabolized in triplicate using different lot numbers and scanned using Enhanced MS (EMS). 
Table 16 - MS/MS conditions of TNT, Tetryl, RDX and HMX.

\begin{tabular}{|l|l|l|}
\hline MS Condition & TNT & RDX, HMX, and Tetryl \\
\hline Curtain Gas (psi) & 30 & 30 \\
\hline $\begin{array}{l}\text { Collision Activated Dissociation } \\
(\mathrm{CAD}) \text { gas }\end{array}$ & $\begin{array}{l}3.0 \times 10-5 \text { torr } \\
\text { (Medium) }\end{array}$ & $\begin{array}{l}3.0 \times 10-5 \text { torr } \\
\text { (Medium) }\end{array}$ \\
\hline Ionspray Voltage (V) & -4500 & -4500 \\
\hline Temperature ( $\left.{ }^{\circ} \mathrm{C}\right)$ & 600 & 350 \\
\hline Ion source gas 1 (psi) & 40 & 45 \\
\hline Ion source gas 2 (psi) & 40 & N/A \\
\hline
\end{tabular}


Final in-vitro samples were evaluated for metabolites using Lightsight software (version 2.0) provided by Applied Biosystems. EMS scans of the control and metabolized samples were uploaded into the software to search for different $\mathrm{m} / \mathrm{z}$ peaks. These differences were compared to a list of biotransformations common in phase I metabolism, (Table 17). In addition to using Lightsight, Multiple Reaction Monitoring (MRM) transitions of reported TNT human metabolites (Table 18) and animal/microbial metabolites of RDX (Table 19) were used to verify the presence of metabolites in in-vitro samples. 
Table 17 - Phase I metabolism biotransformations screened using Lightsight (highlighted biotransformations are seen in TNT).

\begin{tabular}{|l|l|l|}
\hline Biotransformation & Mass Shift & Formula \\
\hline 2(Nitro to Amine) & -60.0 & $-2\left(-\mathrm{O}_{2}+\mathrm{H}_{2}\right)$ \\
\hline Nitro to Amine & -30.0 & $-\mathrm{O}_{2}+\mathrm{H}_{2}$ \\
\hline Loss of $\mathrm{H}_{2} \mathrm{O}$ & -18.0 & $-\mathrm{H}_{2} \mathrm{O}$ \\
\hline Nitro to Nitroso & -16.0 & $-\mathrm{O}$ \\
\hline Demethylation & -14.0 & $-\mathrm{CH}_{2}$ \\
\hline Nitro to Hydroxylamine & -14.0 & $-\mathrm{O}+\mathrm{H}_{2}$ \\
\hline Dehydrogenation & -2.0 & $-\mathrm{H}_{2}$ \\
\hline Parent & 0 & --- \\
\hline Hydrogenation & +2.0 & $+\mathrm{H}_{2}$ \\
\hline Oxidation & +16.0 & $+\mathrm{O}$ \\
\hline Di-Oxidation & +32.0 & $+\mathrm{O}_{2}$ \\
\hline Tri-Oxidation & +48.0 & $+\mathrm{O}_{3}$ \\
\hline
\end{tabular}


Table 18 - MRM transitions of reported human TNT metabolites [122, 123]. See Table 10 for identification of parent and product.

\begin{tabular}{|l|l|l|}
\hline Explosive/Metabolite & Parent & Product \\
\hline 2,4,6-trinitrotoluene (TNT) & 226 & 46 \\
\hline 2-Amino-4,6-dinitrotoluene (2-ADNT) & 196 & 136 \\
\hline 4-Amino-2,6-dinitrotoluene (4-ADNT) & 196 & 46 \\
\hline 1,3-Dinitrobenzene (1,3-DNB) & 168 & 46 \\
\hline 1,3,5-Trinitrobenzene (1,3,5-TNB) & 213 & 183 \\
\hline 2,4-Dinitrotoluene (2,4-DNT) & 182 & 46 \\
\hline 2,6-Dinitrotoluene (2,6-DNT) & 182 & 46 \\
\hline 2,4-Diamino-6-nitrotoluene (2,4-DANT) & 168 & 121 \\
\hline 2,6- Diamino-4-nitrotoluene (2,6-DANT) & 168 & 121 \\
\hline
\end{tabular}


Table 19 - MRM transitions of reported animal/microbial metabolites of RDX [70, $71,122]$.

\begin{tabular}{|c|c|c|}
\hline Explosive/Metabolite & Parent & Product \\
\hline $\begin{array}{l}\text { 1,3,5-Trinitro-1,3,5- } \\
\text { triazacyclohexane (RDX) }\end{array}$ & $\begin{array}{l}281 \\
297\end{array}$ & $\begin{array}{l}46 \\
46\end{array}$ \\
\hline 4-nitro-2,4-diazabutamide & $\begin{array}{l}133 \\
118\end{array}$ & $\begin{array}{l}46,59,61 \\
44,46,61\end{array}$ \\
\hline $\begin{array}{l}\text { hexahydro-1-nitroso-3,5- } \\
\text { dinitro-1,3,5-triazine } \\
\text { (MNX) }\end{array}$ & 265 & 46 \\
\hline $\begin{array}{l}\text { hexahydro-1,3-dinitroso- } \\
\text { 5-nitro-1,3,5-triazine } \\
\text { (DNX) }\end{array}$ & 249 & 46 \\
\hline $\begin{array}{l}\text { hexahydro-1,3,5- } \\
\text { trinitroso-1,3,5-triazine } \\
\text { (TNX) }\end{array}$ & 249 & 113 \\
\hline $\begin{array}{l}\text { Methylenedinitramine } \\
\text { (MEDINA) }\end{array}$ & 233 & 61 \\
\hline
\end{tabular}




\subsubsection{Results and Discussion}

\subsubsection{Testing the in-vitro metabolism procedure}

Two experiments were performed to test the efficiency of the in-vitro metabolism procedure using HLMs. The first experiment involved reproducing the metabolites of Zolpidem provided by von Moltke et al. [118]; however, using the method described in section 4.2.1 of this dissertation. Similar to the paper, this method was shown to produce the 3 principal metabolites, M-3, M-4 and M-11.

Secondly, TNT was metabolized with the other explosives as a reference to confirm that the method was valid. After comparing the control and metabolized samples, TNT was shown to metabolize to 4-ADNT, 2,4-DNT using HLMs. The unmetabolized parent compound was also detected. The results from the MRM transitions listed in Table 18 are shown in Figure 39. 4-ADNT was the main metabolite, thus the biomarkers of exposure. This result agrees with previous literature about human metabolites of TNT $[53,61]$. CYPs have been shown to reduce other nitroaromatic compounds such as the flukicidal agent nitroxynil which reduces to 3-iodo-4-hydroxy-5-aminobenzonitrile and 3-iodo-4-hydroxy-5nitrobenzamide under anaerobic and aerobic conditions [124].

Once successful metabolism was confirmed, a time study was conducted to insure that 30 minutes was a reasonable incubation time. Using aliquots of the TNT solution described above, 3 replicates were prepared for study with incubation times of $1,10,20,60$, and 120 minutes. For the 30 minute trial and controls, 5 replicate solutions were prepared because these were used in another control experiment described in the next section. To evaluate the progress of metabolism, the 
appearance of the 4-ADNT metabolite was monitored quantitatively and the ratio of the concentration $(\mathrm{ppb})$ of the parent TNT to the metabolite was calculated. A detectable signal for the metabolite was observed at 20 minutes, but correlated to a 
Figure 39 - Results of TNT metabolism using MRM: (a) control sample, (b) metabolized sample. All other unidentified peaks are due to MS noise.

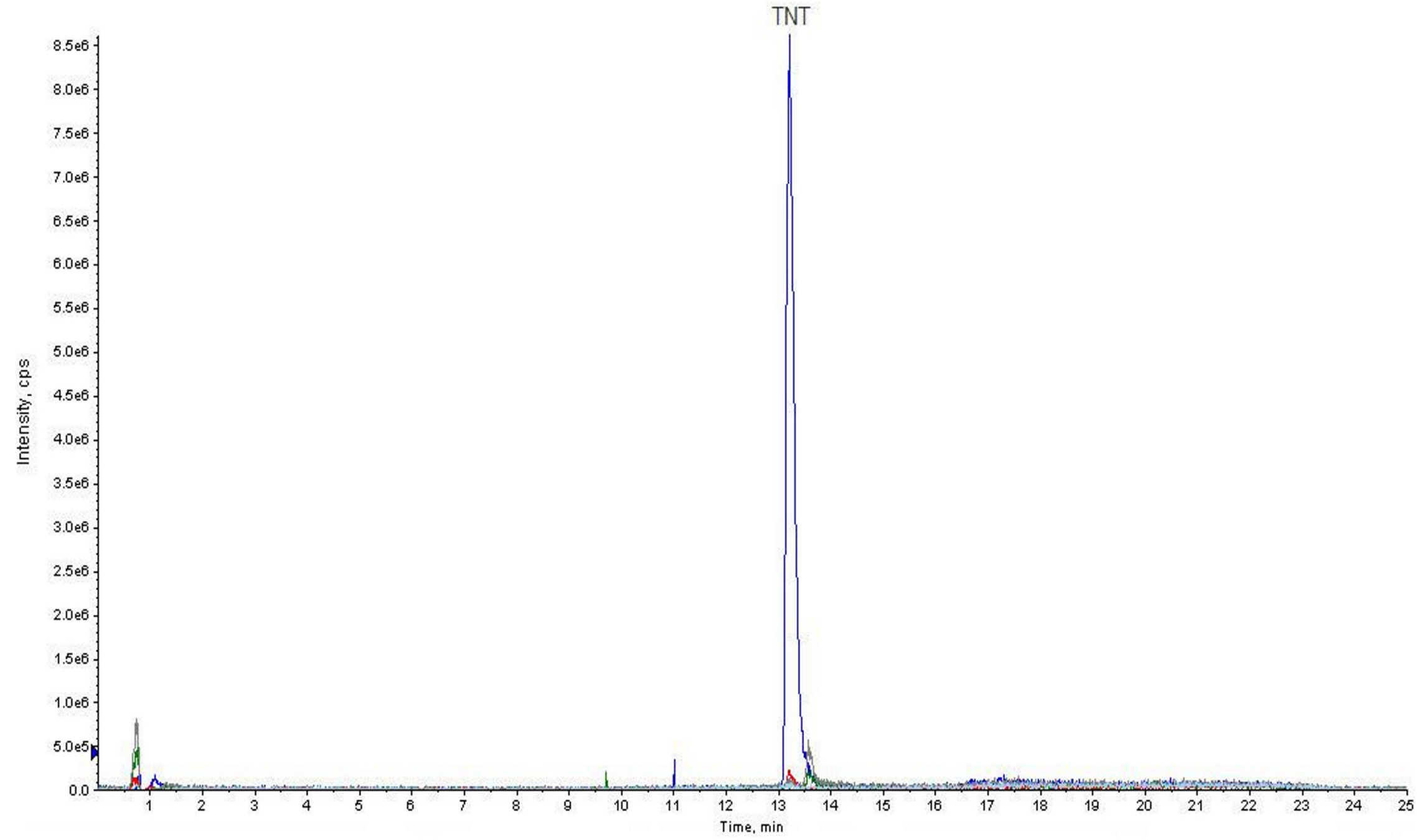

A. 


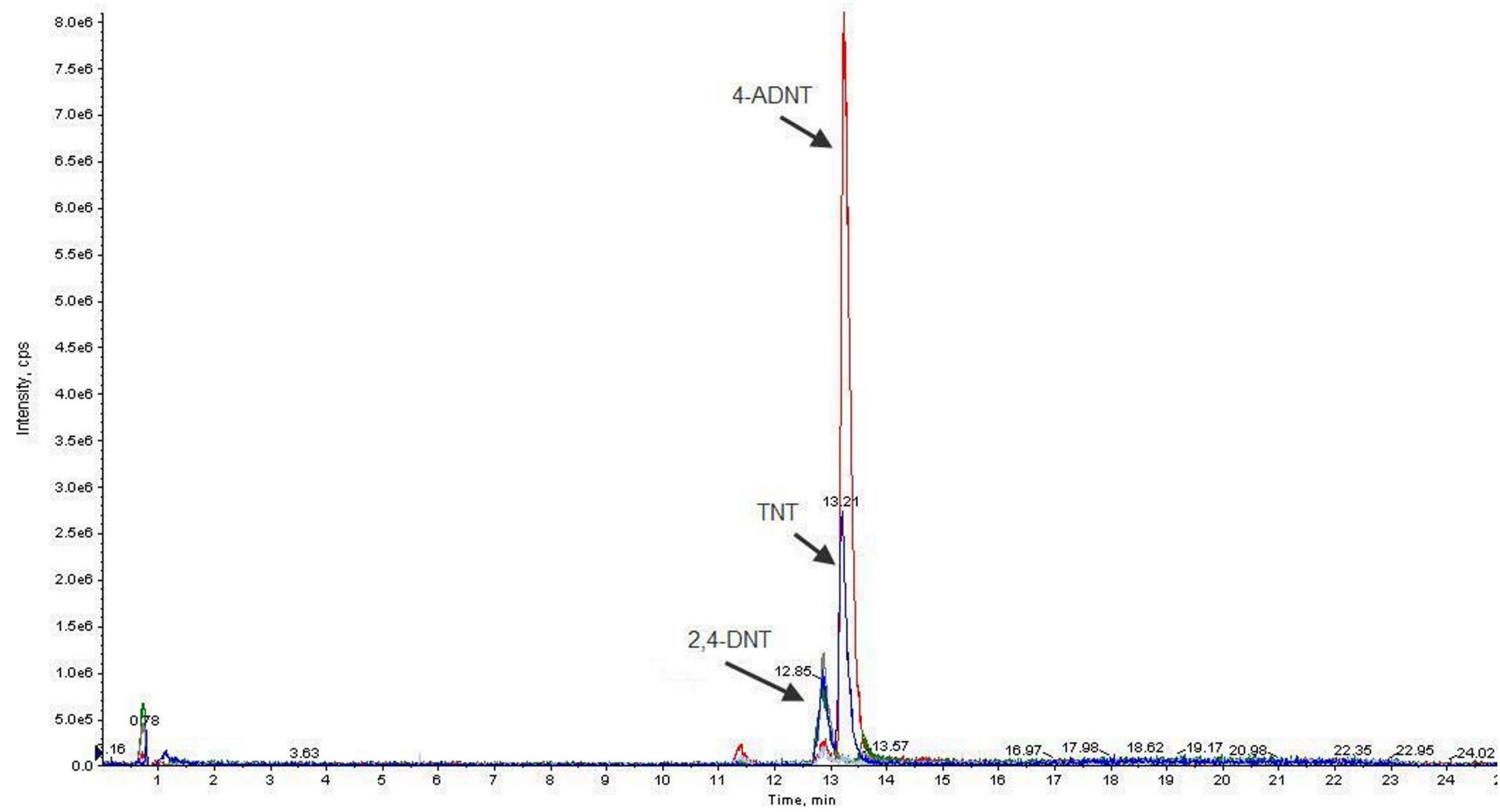

B. 
concentration below the LOQ of $1.0 \mathrm{ppb}$. At 30 minutes, the ratio was at the lowest (optimal value) of $5.2+/-4.0$ (95\% confidence interval). The values at 60 and 120 minutes were $9.8+/-2.8$ and $17.6+/-9.5$ respectively. It was felt that incubation times beyond this were impractical and were likely to result in enzyme degradation. These results confirmed that 30 minutes was a reasonable incubation time.

In part to explore possible sources of the relatively large uncertainties seen above, a series of TNT controls were analyzed quantitatively, five replicates each. The first set of five consisted of the aqueous TNT solution; the second, control samples prepared as per Figure 42 but without addition of NADPH (un-metabolized control); and the third, metabolized samples. All TNT aliquots were drawn from the same stock solution.

As seen in Figure 44, significant uncertainty arose from the stock solution. If the value of $\sim 115 \mathrm{mg} / \mathrm{L}$ for TNT solubility is used as a baseline, the average value of 107.4 ppm was determined. However, the range fell between 9 and $191 \mathrm{ppm}$. The primary reason for this was attributed to the solution; when it was removed from the rotator and allowed to settle, the solution remained slightly turbid with solid residue clearly visible on the surface. Even with careful drawing of aliquots from the clearest central portion of the solution, heterogeneity was obvious. Another interesting and important feature revealed in Figure 44 is the decrease in TNT concentration observed between the aqueous solution and the controls. Using the t-test of means, unequal variance, the difference between the means 
Figure 40 - Processed data of the replicate aqueous TNT standard, unmetabolized, and metabolized samples $(n=5)$.

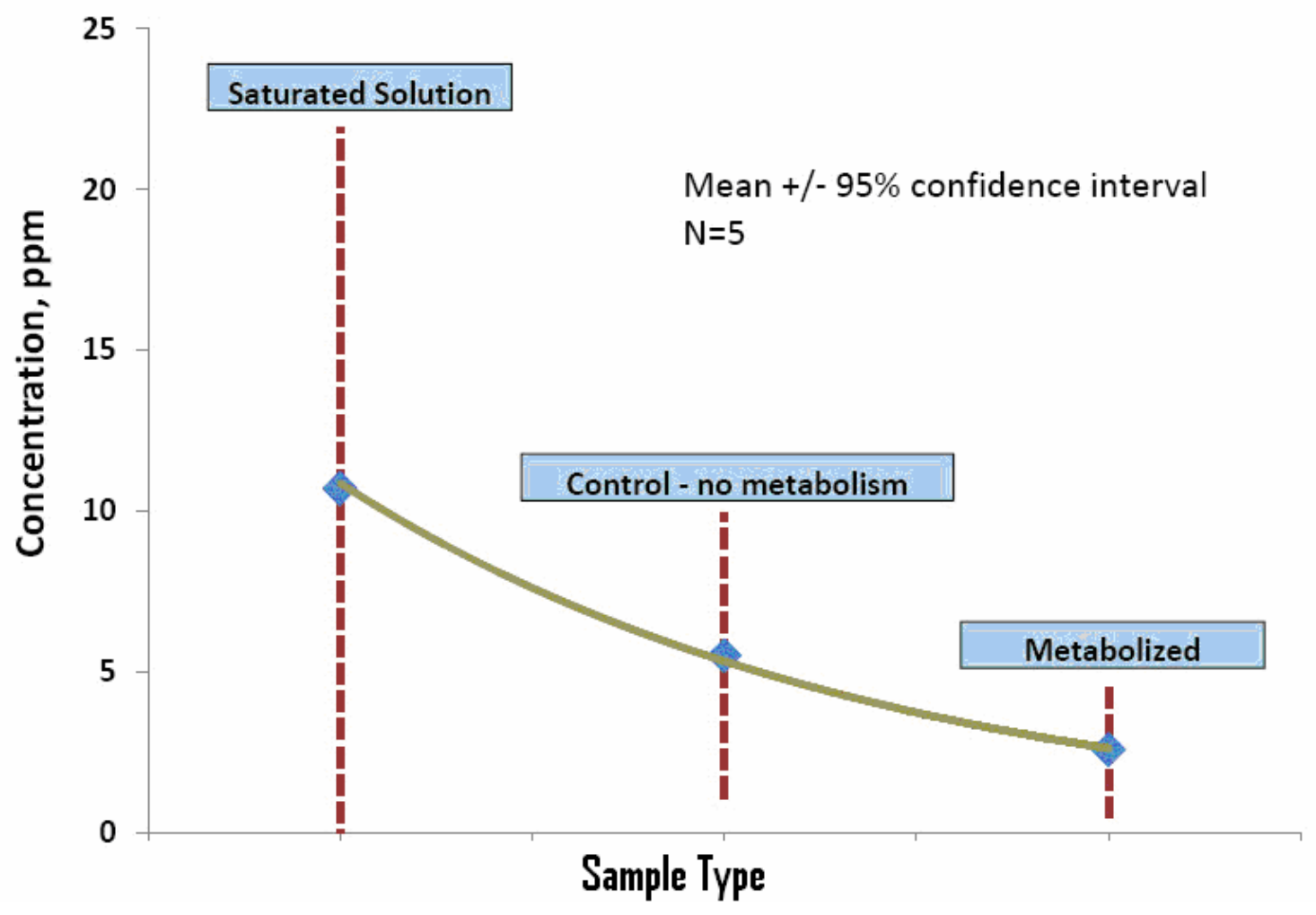


is not statistically significant, but this trend bears exploration once solubility issues are resolved.

\subsubsection{Results for RDX, HMX, and Tetryl}

The results for RDX, HMX, and tetryl revealed that these explosives do not metabolize using human liver microsomes. Each control and metabolized sample was scanned from $70-400 \mathrm{~m} / \mathrm{z}$ using Enhanced MS (EMS). The EMS scans were integrated into Lightsight software to determine any differences between the control and metabolized samples. The results showed that there were no main differences between the two samples. The differences that did occur were present in all the control versus metabolized comparisons and were found at low levels. In addition to using Lightsight, a precursor ion scan (Prec) was also used to determine metabolites that generated any product ion of $46 \mathrm{~m} / \mathrm{z}$ for RDX and HMX and $213 \mathrm{~m} / \mathrm{z}$ for tetryl. The Prec scans only revealed the parent compound and no metabolites. An example Prec scan of RDX is shown in Figure 45. The peak found at $4.10 \mathrm{~min}$ corresponds to a $\mathrm{m} / \mathrm{z}$ of 281 , which is RDX. Lastly, comparing the concentrations of the parent explosive found in the control and metabolized samples (Table 20) showed no major decrease in the parent compound, unlike TNT which underwent $\sim 5$ fold decrease in concentration. These results support that the parent explosive is the main metabolite and the biomarker of exposure. 
Figure 41 - Prec scan of $46 \mathrm{~m} / \mathrm{z}$ for the control and metabolized sample of RDX. MS data shows that the peak corresponds to an $\mathrm{m} / \mathrm{z}$ of 281 , which is RDX.

- TIC of-Prec (46.00): from Sample 10 (RDX met prec) of SET1.woiff (Heated Nebulizer)
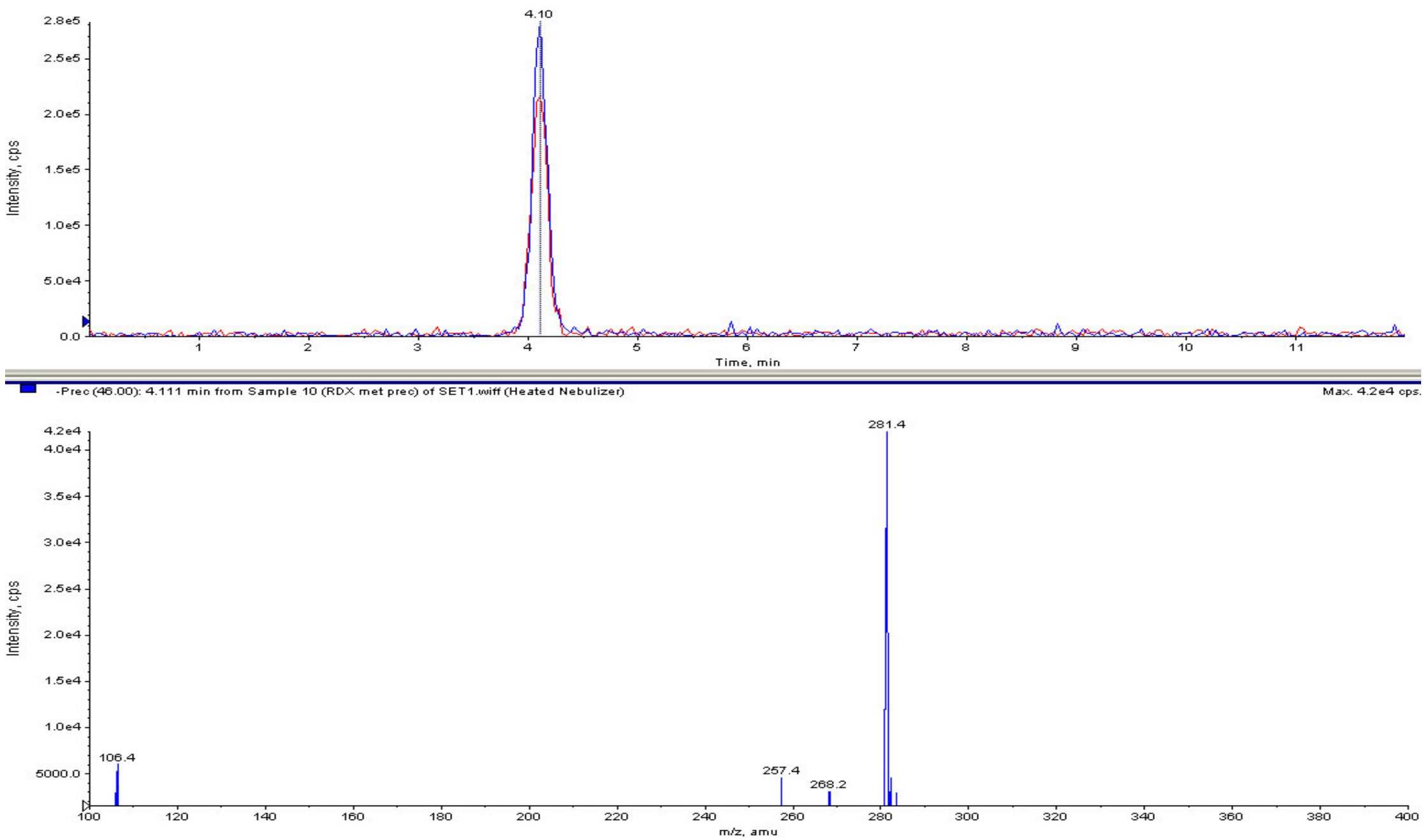
A plausible explanation as to why RDX, HMX, and tetryl do not metabolize could be due to their polarity. The dipole moments of TNT, RDX, HMX, and tetryl are 1.39, $2.09,10.3$ and 3.83 respectively [125]. Thus, the order of polarity from lowest to highest is TNT, RDX, tetryl and HMX. Since one of the purposes of metabolism is to make compounds more water soluble for excretion, one explanation to these results is that RDX, HMX, and tetryl are sufficiently polar and thus unaffected by the enzymes. Another reason is that the concentrations used in the metabolism procedure were high, possibly causing enzyme inhibition. Future work involves using various concentrations of these explosives to determine of metabolites are produced at lower concentrations. Lastly, NADPH is commonly replenished during the metabolism procedure. More studies employing the addition of NADPH during the incubation period need to be performed.

Although the results of using HLMs to demonstrate phase I metabolism revealed that these compounds remain unchanged, future work involves exploring products of phase II metabolism. Phase II metabolism causes exogenous substances to form adducts with proteins in the body. In the case of TNT, 4-ADNT and 2-ADNT are commonly seen bound to hemoglobin in blood [61]. It is possible that these explosives may form adducts after phase II metabolism and thus, produce another biomarker of exposure.

\subsubsection{Concentration issues: solubility}

Since the explosives were sparingly soluble in water, this became a problem when trying to calculate the concentration of the parent compound in each sample. 
At an attempt to quantify the parent compound after metabolism, calibration curves were created. $R^{2}$ values for each calibration curve were greater than 0.9985 and the limit of detection (LOD) was less than $500 \mathrm{ng} / \mathrm{L}$. Given that the concentration of each explosive was higher than $1.0 \mathrm{mg} / \mathrm{L}$, the samples were diluted to fit within the calibration curve. Concentrations listed in Table 20 have been adjusted with the dilution factor.

The concentration results shown in Table 20 reveal that quantitating compounds that are insoluble in the matrix will produce inconsistent data. The $\sim 5$ fold decrease in TNT concentration between the control and the metabolized sample does not raise any questions. In addition, the HMX concentration slightly decreases, which could be due to low level metabolites that are undetected using our method. However, the RDX and tetryl results show a surprising increase in concentration from the control to metabolized sample. Pipetting error may be a cause for this increase though the solubility issue is more plausible. Each explosive standard that was prepared at $10 \mathrm{mM}$ in water (see section 4.2.1) contained some particulate of undissolved explosive. When taking $20 \mu \mathrm{l}$ of this solution for the reaction, some undissolved explosive may be pipetted. The particulates would remain undissolved throughout the reaction (the reaction mixture is aqeous) but would dissolve during the crash and shoot method. ACN is added to precipitate any remaining proteins but would also increase the solubility of the particulate explosives. Since this problem could have occurred with TNT as well, the fact that TNT still produced metabolites shows that some explosive is indeed being metabolized using this method. It should also be noted that the slight increase in RDX and tetryl concentrations along with the 
Table 20 - Concentration of parent explosive in the control and metabolized samples. LOD was determined using MS noise.

\begin{tabular}{|l|l|l|l|}
\hline Sample & $\mathbf{R}^{2}$ value & LOD & $\begin{array}{l}\text { Concentration of } \\
\text { Parent }\end{array}$ \\
\hline TNT Control & 0.9985 & $8 \mathrm{ng} / \mathrm{L}$ & $11.4 \mathrm{mg} / \mathrm{L}$ \\
\hline TNT Metabolized & 0.9985 & $8 \mathrm{ng} / \mathrm{L}$ & $2.35 \mathrm{mg} / \mathrm{L}$ \\
\hline RDX Control & 0.9991 & $500 \mathrm{ng} / \mathrm{L}$ & $25.4 \mathrm{mg} / \mathrm{L}$ \\
\hline RDX Metabolized & 0.9991 & $500 \mathrm{ng} / \mathrm{L}$ & $29.0 \mathrm{mg} / \mathrm{L}$ \\
\hline HMX Control & 0.9996 & $500 \mathrm{ng} / \mathrm{L}$ & $10.7 \mathrm{mg} / \mathrm{L}$ \\
\hline HMX Metabolized & 0.9996 & $500 \mathrm{ng} / \mathrm{L}$ & $6.43 \mathrm{mg} / \mathrm{L}$ \\
\hline Tetryl Control & 0.9989 & $500 \mathrm{ng} / \mathrm{L}$ & $34.9 \mu \mathrm{g} / \mathrm{L}$ \\
\hline Tetryl Metabolized & 0.9989 & $500 \mathrm{ng} / \mathrm{L}$ & $40.0 \mu \mathrm{g} / \mathrm{L}$ \\
\hline
\end{tabular}


TNT results, demonstrate that this problem only affects quantitation and not the metabolism. Because of these results, no further quantitive measurements were pursued. Future work involves developing standards and controls that can assist quantitative measurements. An analyte that is soluble in water, similar in structure to the explosive compounds and is unaffected by HLMs can be a useful spike to track any quantitative loss during the in-vitro procedure. However, finding such a standard can be challenging.

\subsubsection{Enzyme efficiency}

Enzyme efficiency was tested by metabolizing TNT after purchase of the HLMs (Figure 39) and again after 6 freeze thaw cycles (Figure 42). The same 3 products, 4-ADNT, 2,4-DNT and unmetabolized TNT, were produced after 6 freeze thaw cycles. However, the difference found with this metabolism is that more unmetabolized TNT was present than the other two metabolites. 4-ADNT was the second most abundant peak followed by 2,4-DNT. The metabolism results from after purchase showed 4-ADNT as the most abundant and unmetabolized TNT as the second highest peak. These results show that freeze thaw cycles decrease the efficiency of the enzymes. Using HLM's after one freeze thaw cycle will produce more metabolites and thus recommended. Future research involves also testing the NADPH efficiency after several freeze thaw cycles. 
Figure 42 - TNT metabolized sample after 6 freeze thaw cycles.

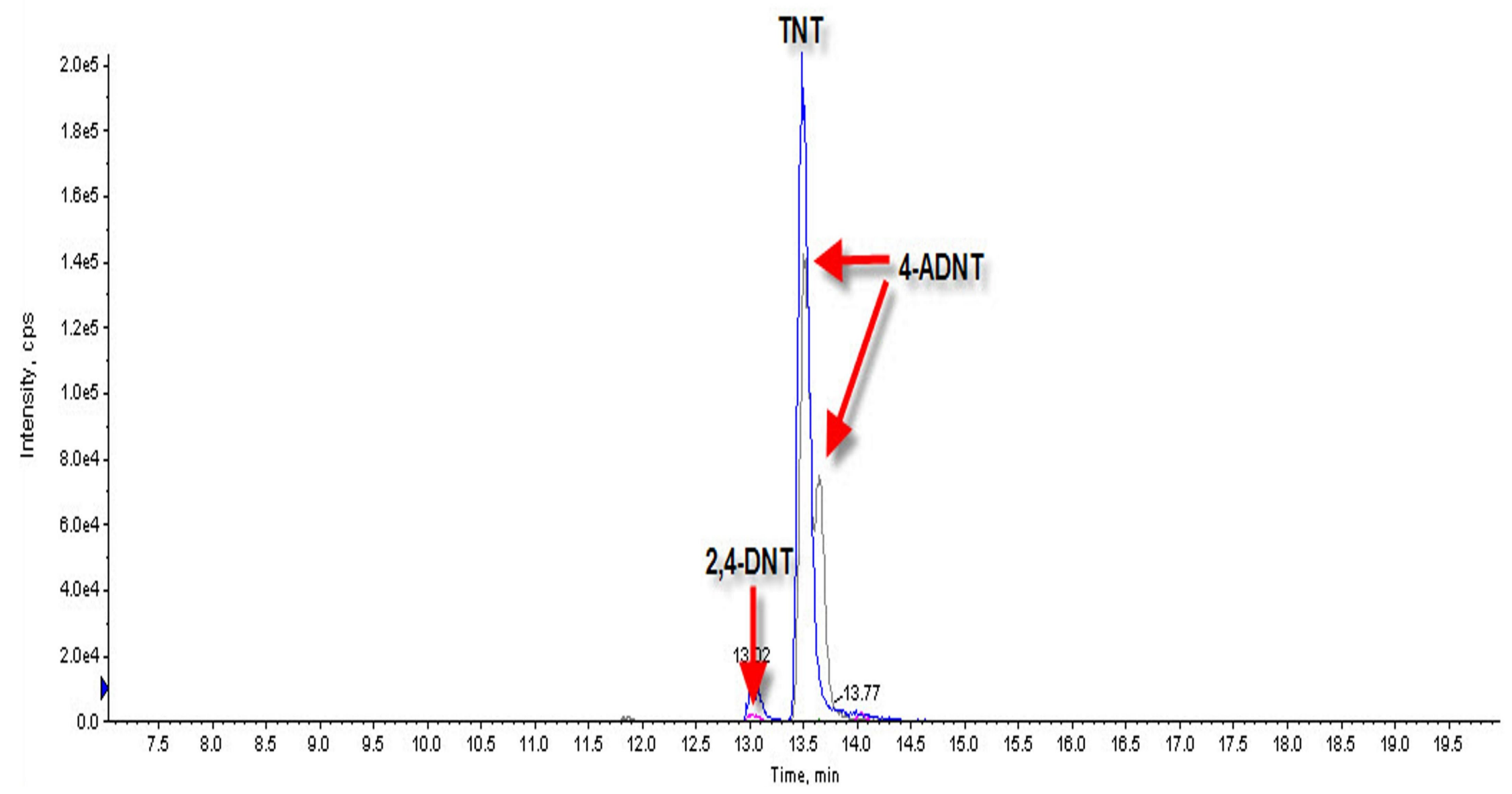




\subsubsection{Conclusions}

The goal of this work was to identify human biomarkers of RDX, HMX, and tetryl. In other words, to identify the most abundant metabolite produced by HLMs. RDX, HMX, and tetryl were shown to not metabolize using an in-vitro method incorporating HLMs, revealing that the parent compound is the biomarker of exposure. The purpose of this work was to not only identify human biomarkers but also to serve as a proof of concept of this method. HLMs did metabolize TNT to produce 4-ADNT and 2,4-DNT; however, reliable quantitative data needs to be determined with the use of standards and controls. Additionally, this project forms groundwork that can later be applied to other types of complex explosive formulations, especially those used by terrorists. 
Appendix A: Example GC chromatogram and MS spectra of the pyrolysis of methamphetamine (aerobic conditions).

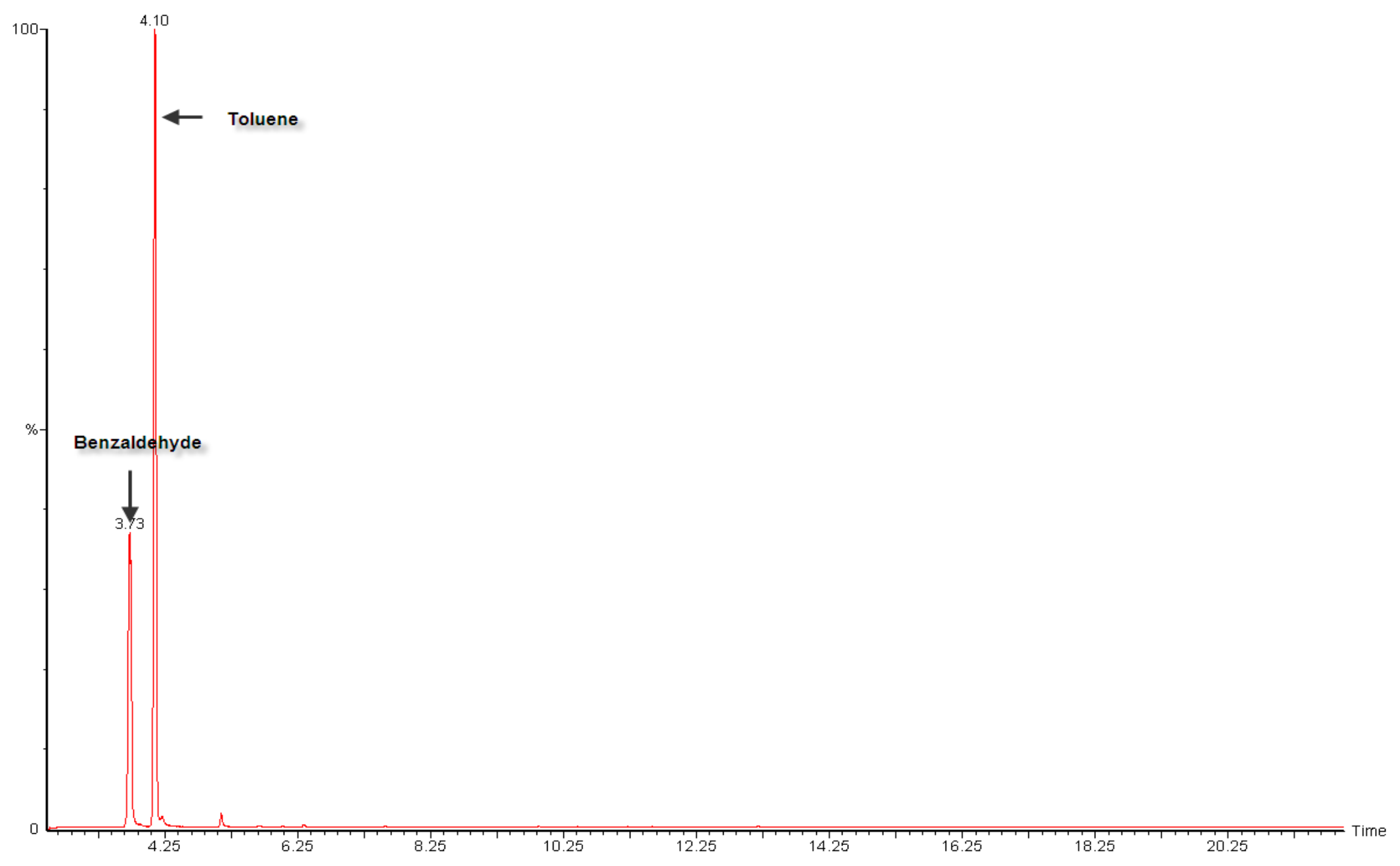


Overlay MS of 3.73 min to NIST library MS spectra of benzaldehyde.

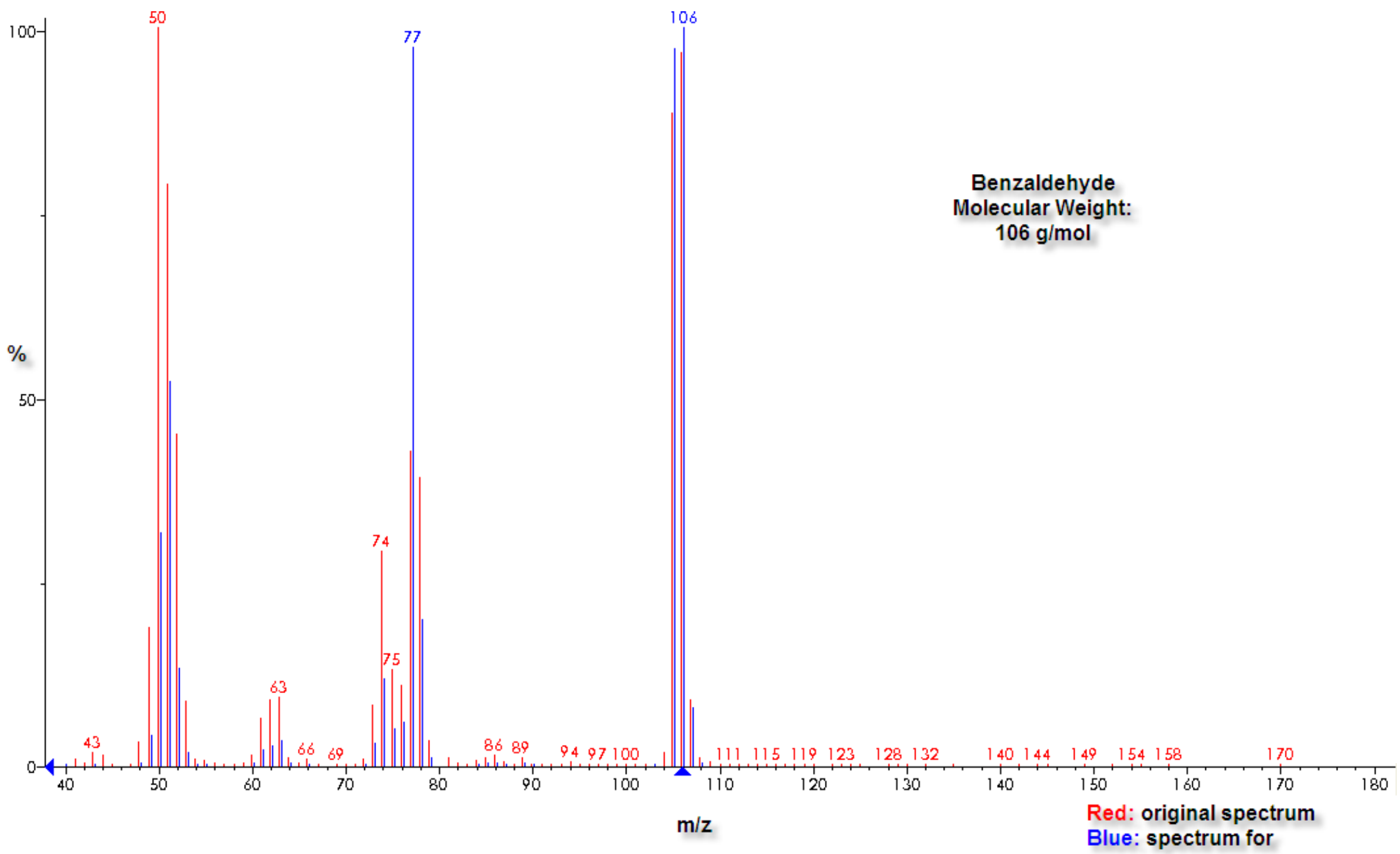


Overlay MS of $4.10 \mathrm{~min}$ to NIST library MS spectra of toluene.

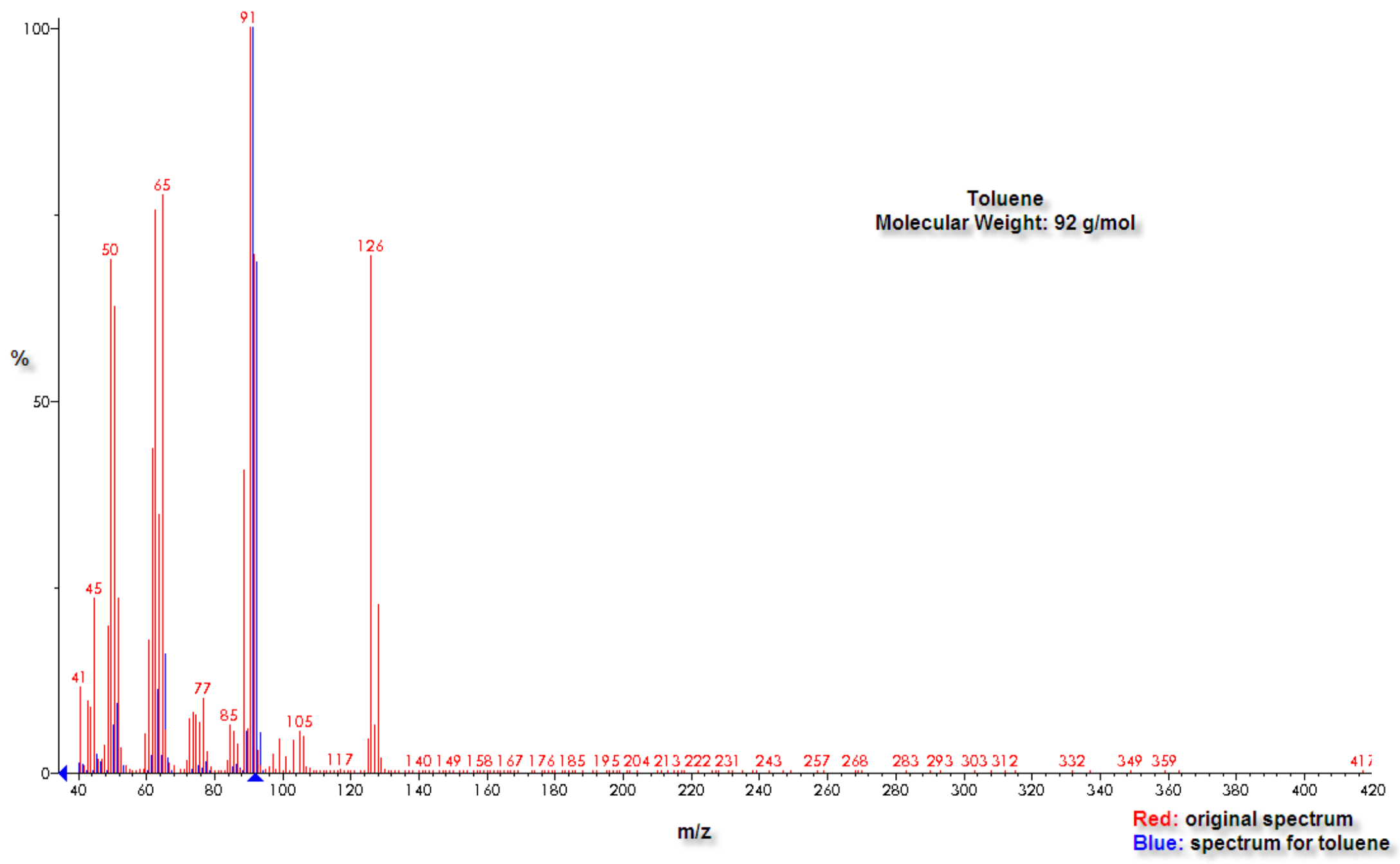


Appendix B: Example GC chromatogram and MS spectra of the pyrolysis of cocaine (aerobic conditions). The 5 largest peaks were identified using a NIST library; however, peaks at 3.87 and 6.03 min were not identifiable using this library.

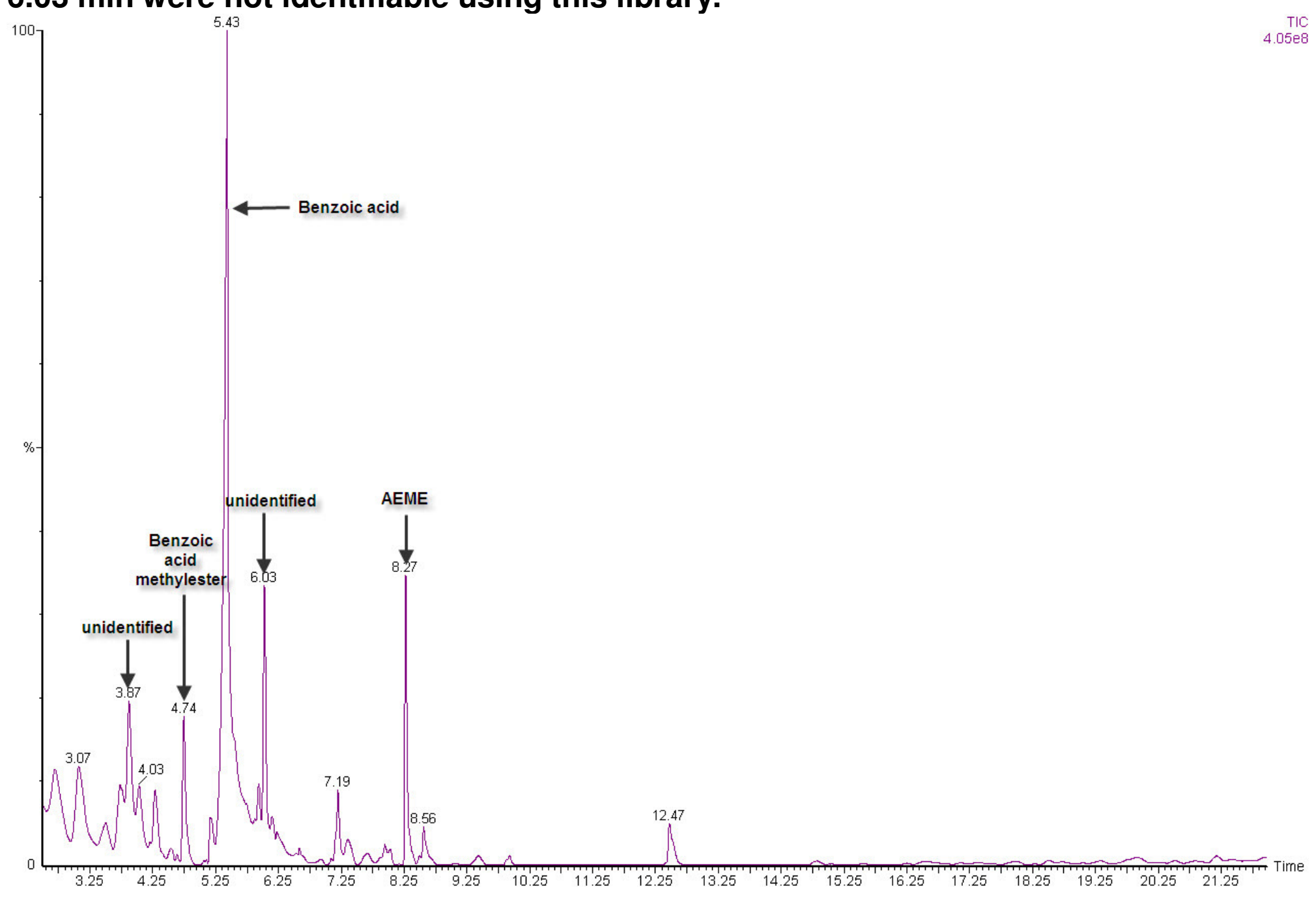


Overlay MS of 4.74 min to NIST library MS spectra of benzoic acid methylester.

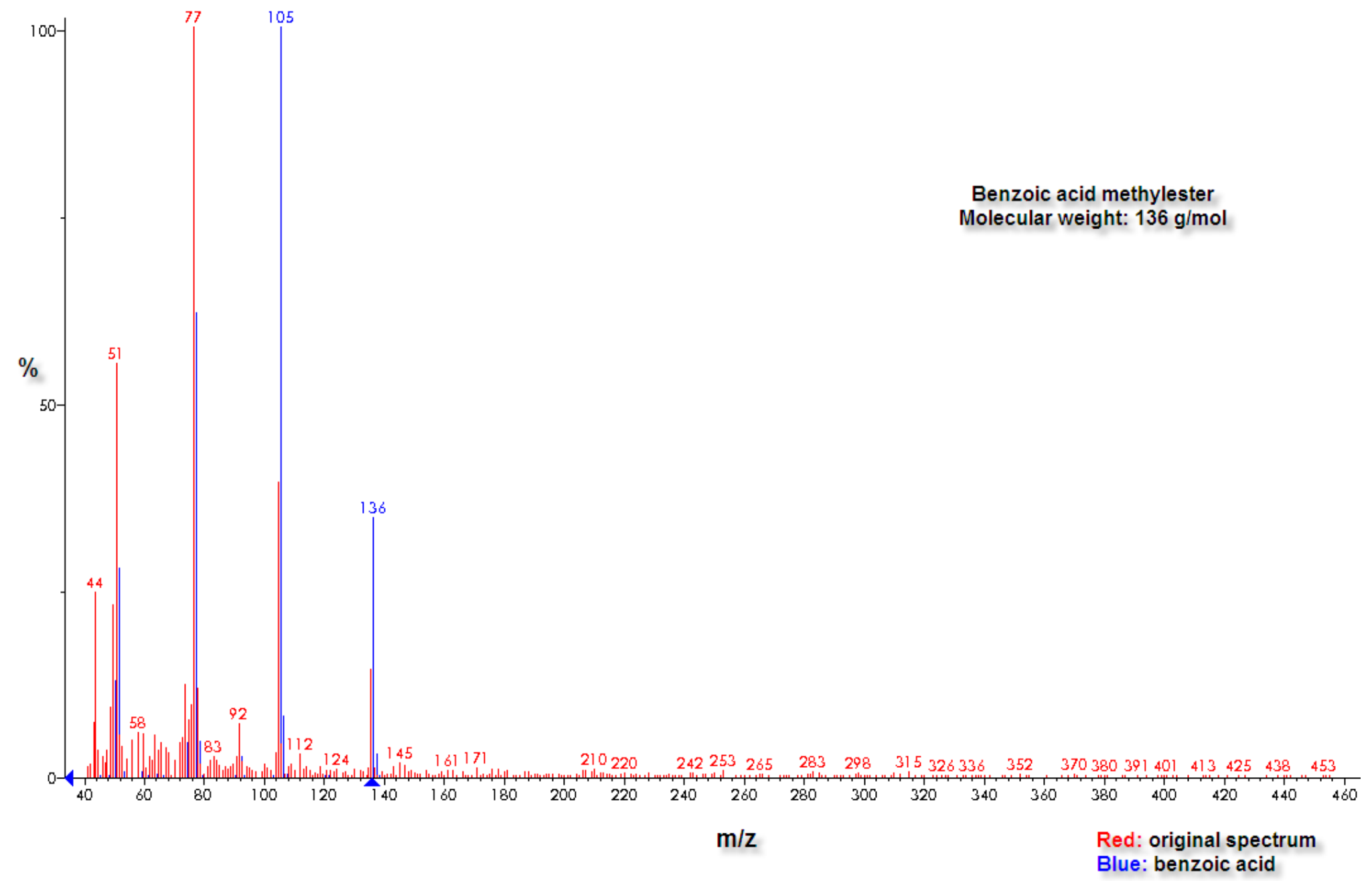


Overlay MS of 5.43 min to NIST library MS spectra of benzoic acid.

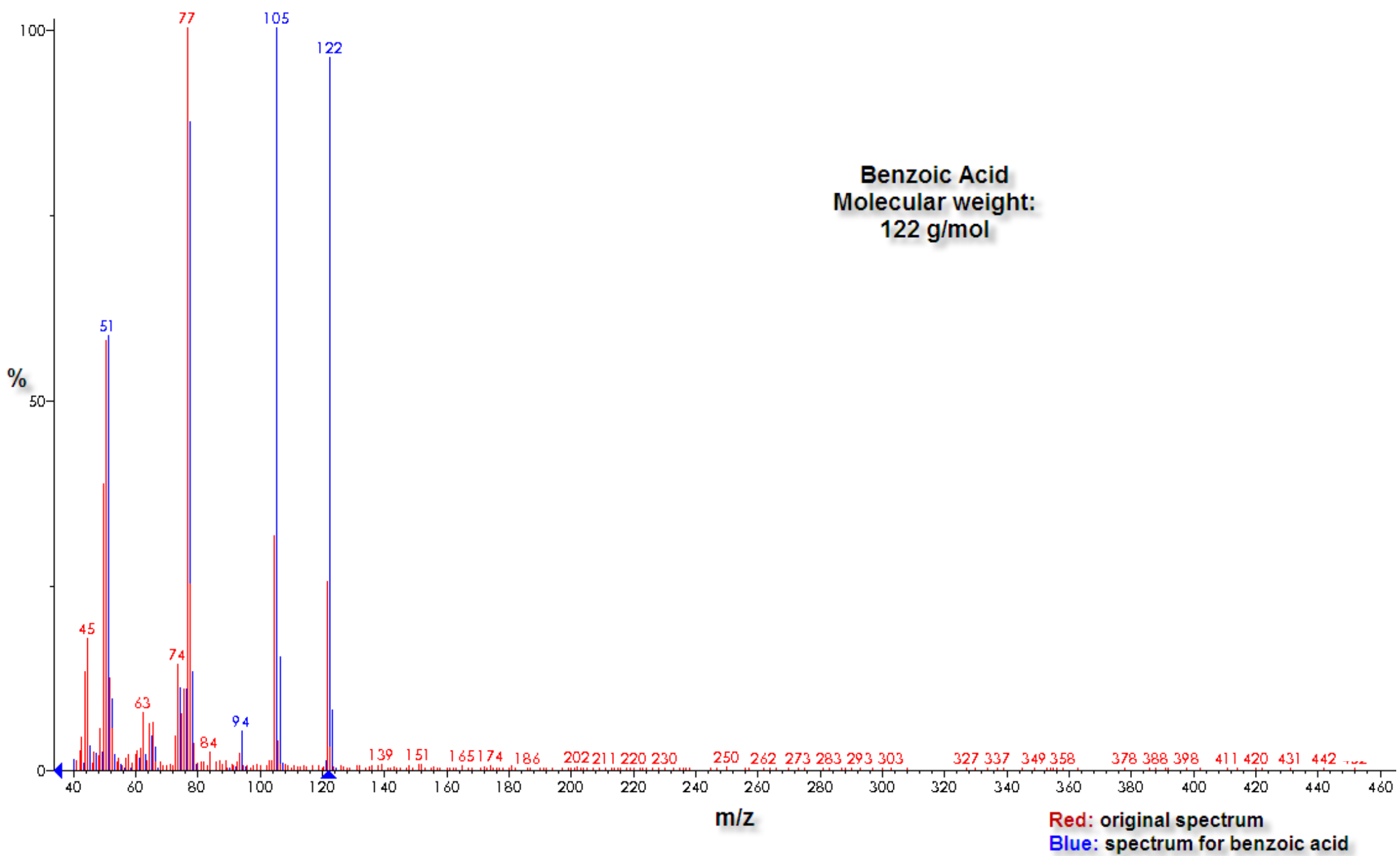


Overlay MS of $8.27 \mathrm{~min}$ to NIST library MS spectra of AEME.

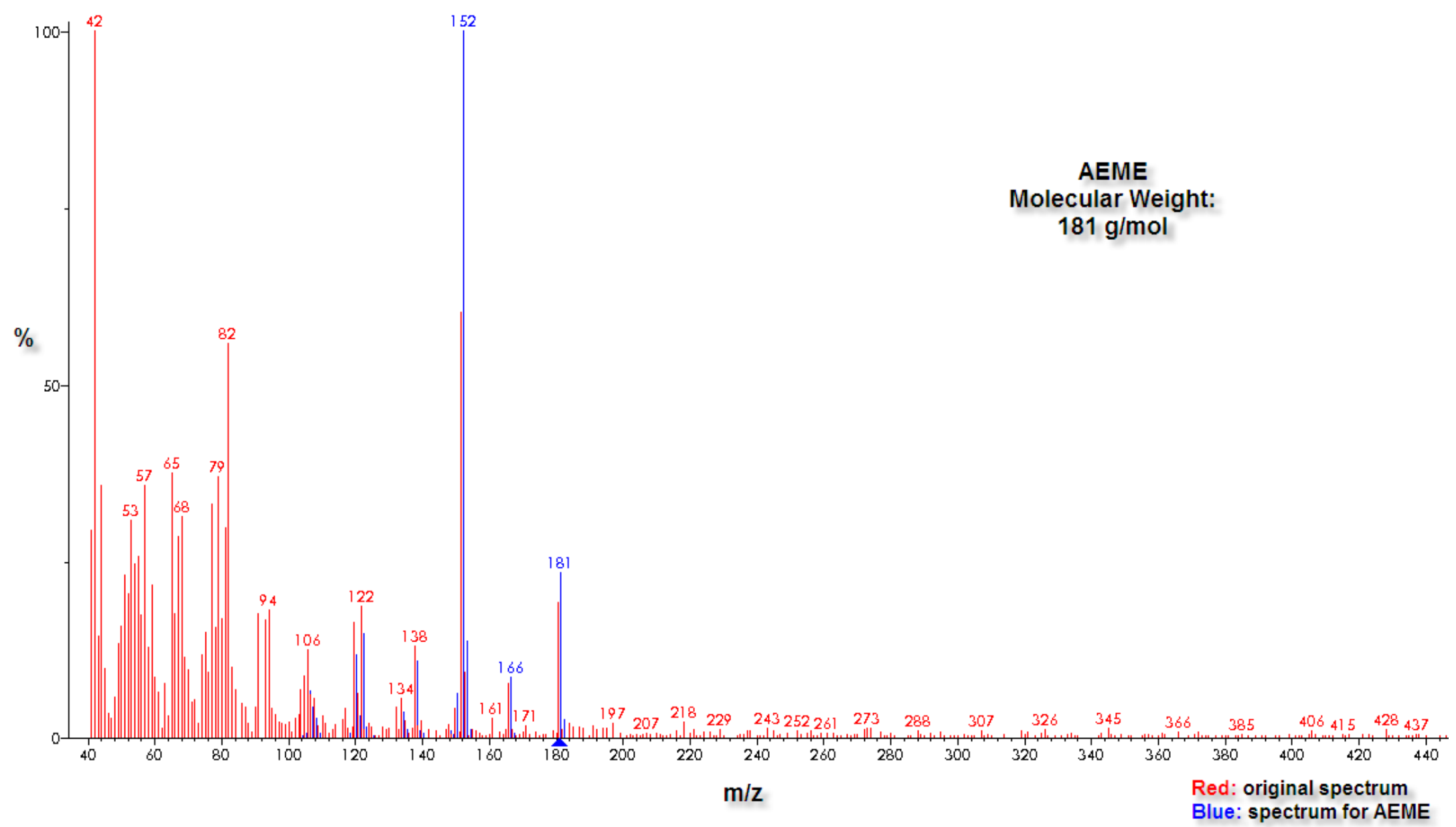


MS spectra of unknown peak at $3.87 \mathrm{~min}$.

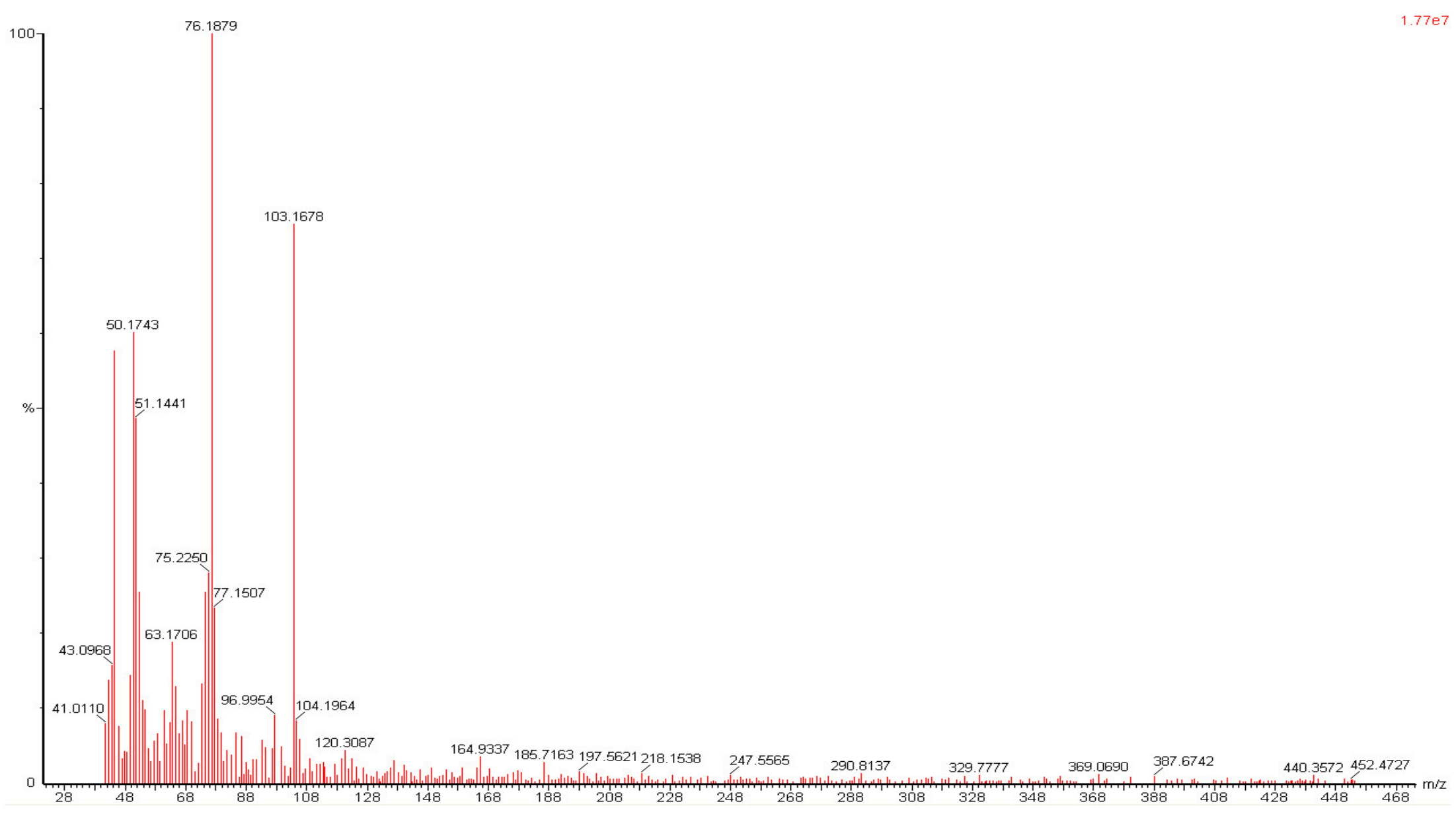




\section{MS spectra of unknown peak at $6.03 \mathrm{~min}$.}

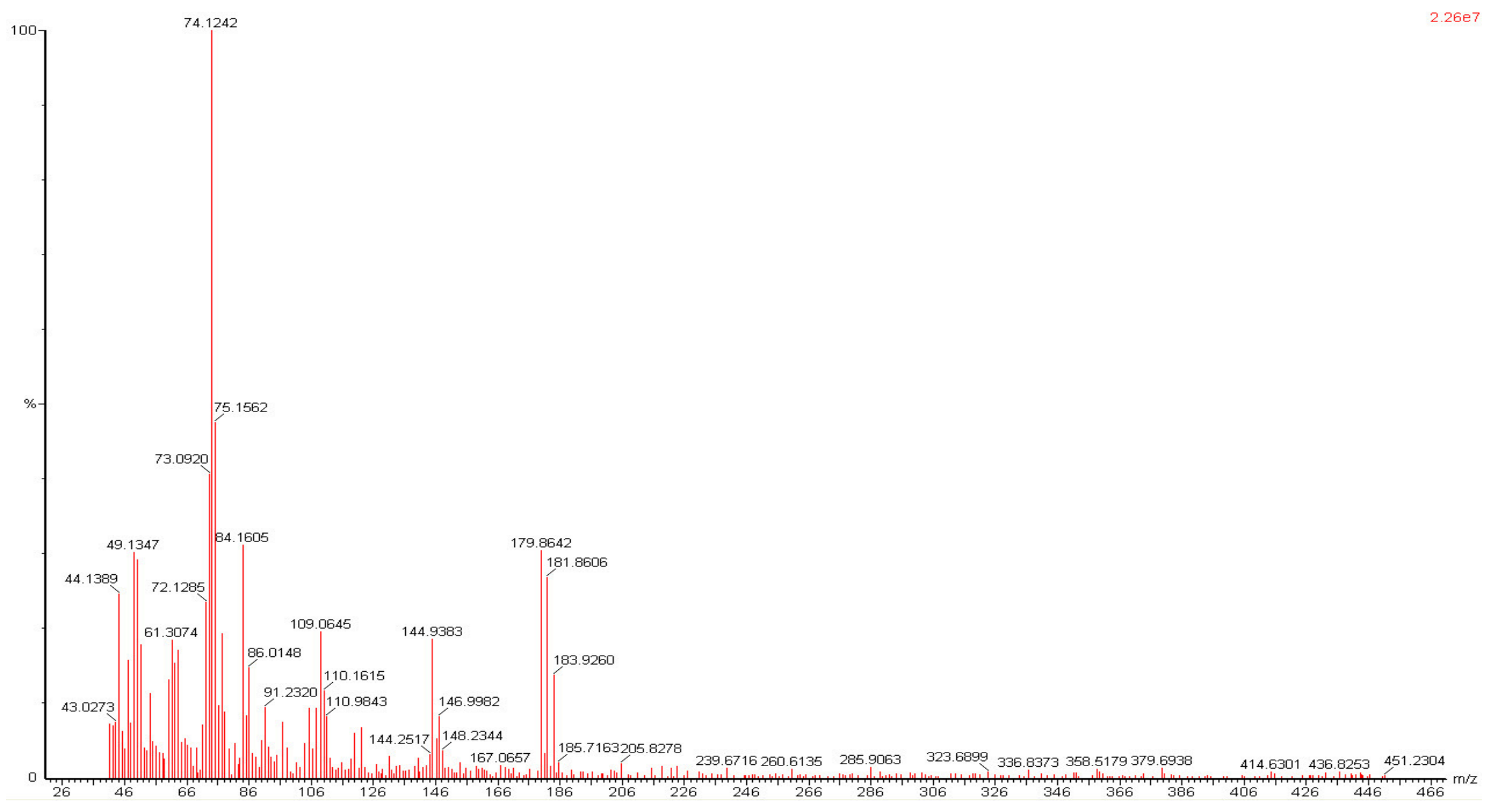


Appendix C: Example of LOD determination using MRM spectra of 1,3,5-TNB: a) noise and peak are highlighted from extracted MRM, b) Analyst software calculates $\mathbf{S} / \mathrm{N}$ ratio.

A)

XIC of -MRM (10 pairs): 213.0/183.0 amu from Sample 11 (6ppb 8330 mix) of SET1. woiff (Heated Nebulizer)

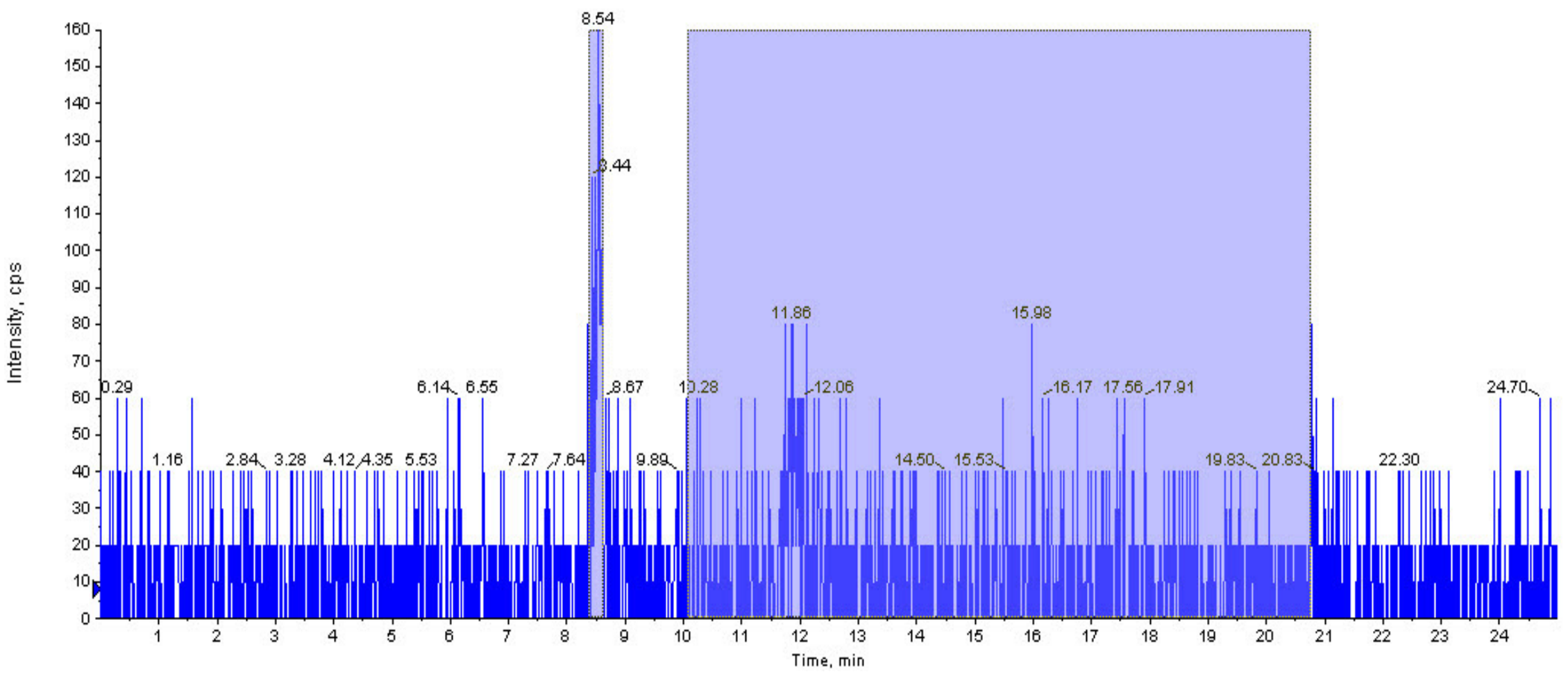


B)

- XIC of -MRM (10 paiss): 213.0/183.0 amu from Sample 11 (6ppb 8330 mix) of SET1. wiiff (Heated Nebulizer)

$\operatorname{Max} .160 .0 \mathrm{cps}$

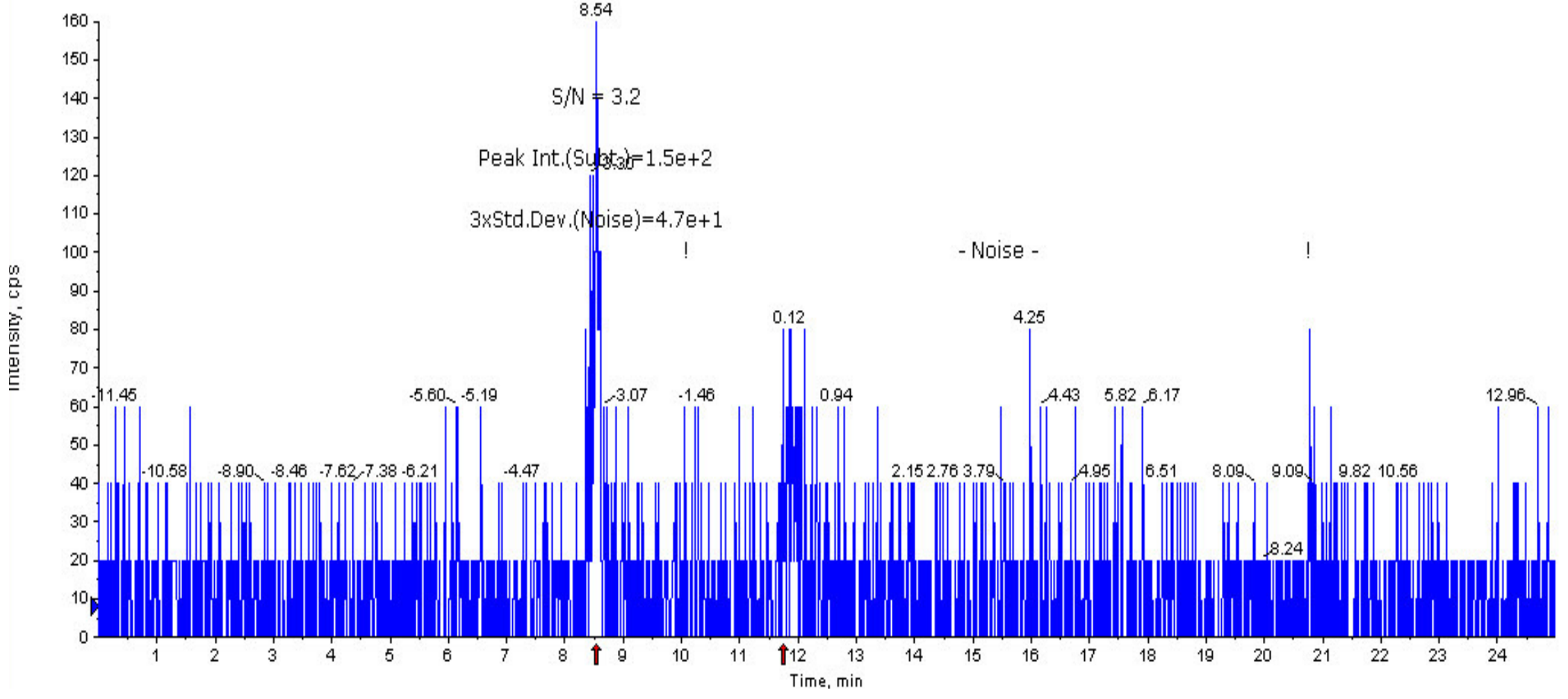




\section{Appendix D: LC/MS/MS (MRM) data from Chapter 3.}

\section{Sample 20_MI_1}

- XIC of -MRM (10 pairs): 355.0446.0 amu from Sample 1 (3.4 WNU_2007_20_ML_1 MRM) of SET2.wiff (Heated Nebulizer)
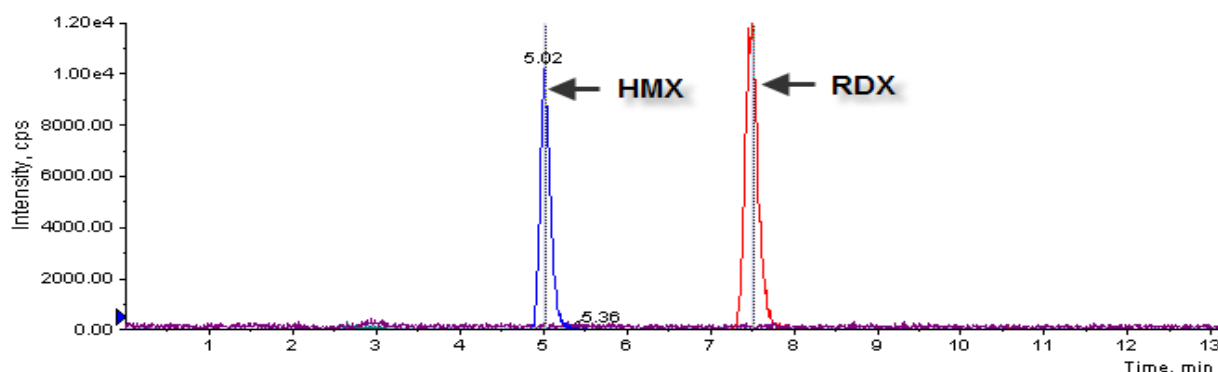

14

$16 \quad 17 \quad 18$

1920

21

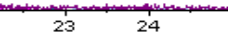

- -MRM (10 pairs): 7.520 min from Sample 1 (3.4 WhNU_2007_20_MI_1 MRM) of SET2.wiff (Heated Nebulizer)

$\operatorname{Max} .9960 .0 \mathrm{cps}$

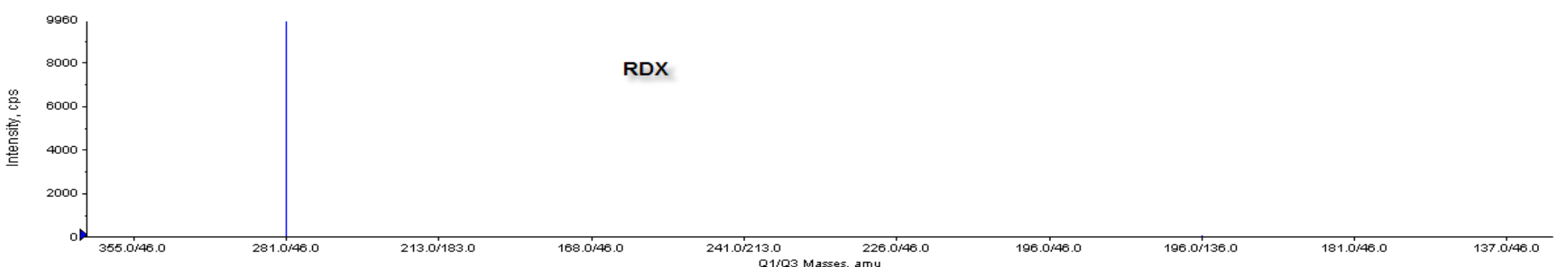

- -MRM (10 pairs): 5.026 min from Sample 1 (3.4 MnNU_2007_20_MI_1 MRM) of SET2.woiff (Heated Nebulizer)

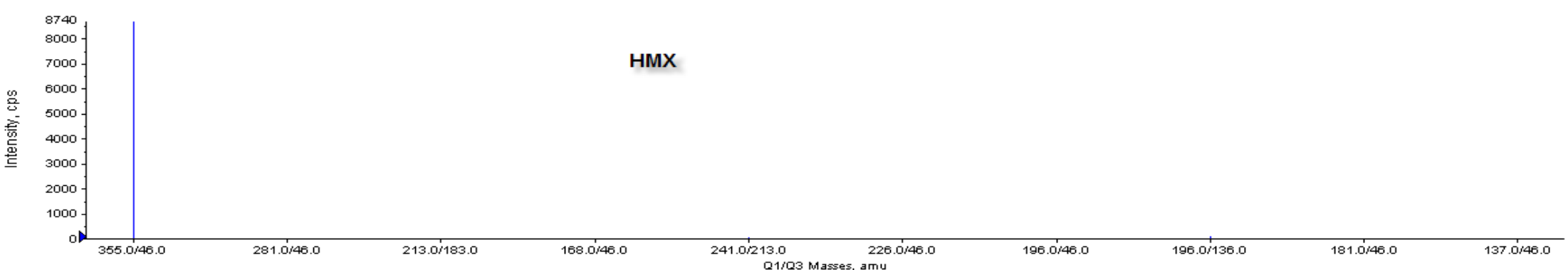




\section{Sample 20_MI_2}

- XIC of-MRM (10 pairs): 355.0/46.0 amu from Sample 16 (2.5 MNNU_2007_20_MI_2) of SET1.wiff (Heated Nebulizer)

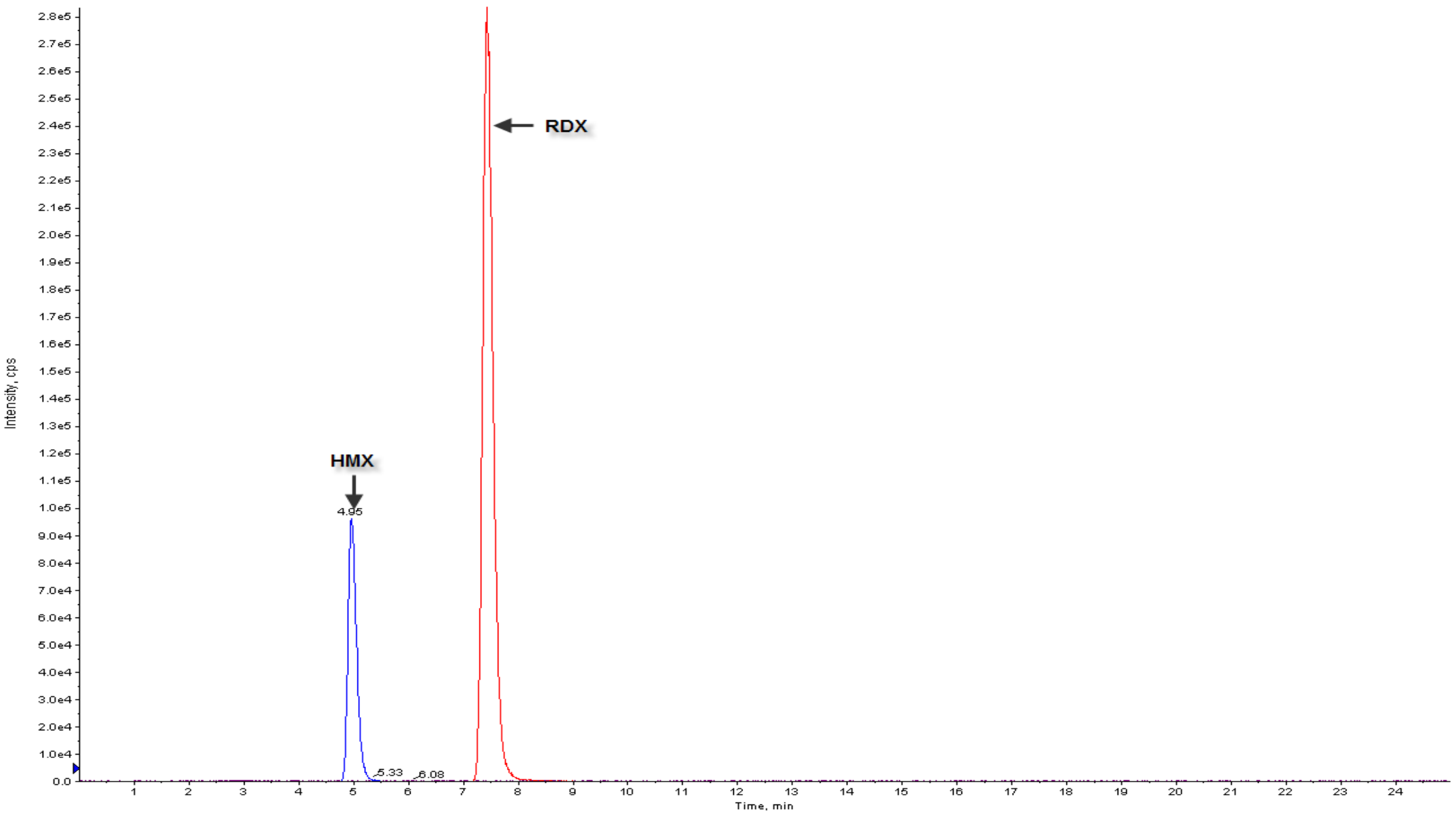




\section{Sample 20_MI_3}

- XIC of-MRM (10 pairs): 355.0746.0 amu from Sample 13 (3.3 WNU__2007_20_MI_3 MRM) of SET1.wijtf(Heated Nebulizer)

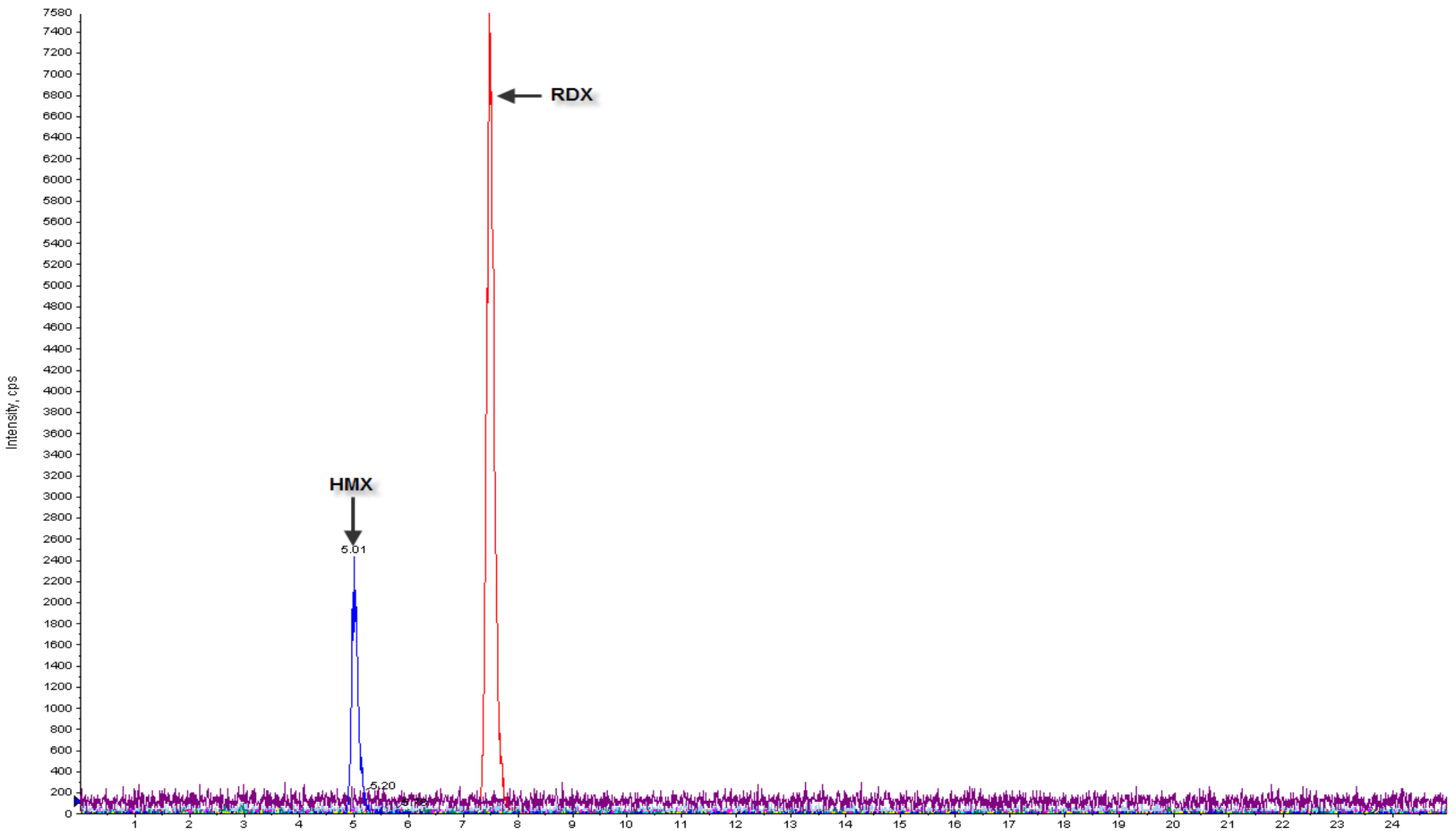




\section{Sample 20_core_1}

- XIC of-MRM (10 pairs): 355.0446.0 amu from Sample 6 (3.9 WNU__2007_20_core_1 MRM) of SET2.wiff (Heated Nebulizer)

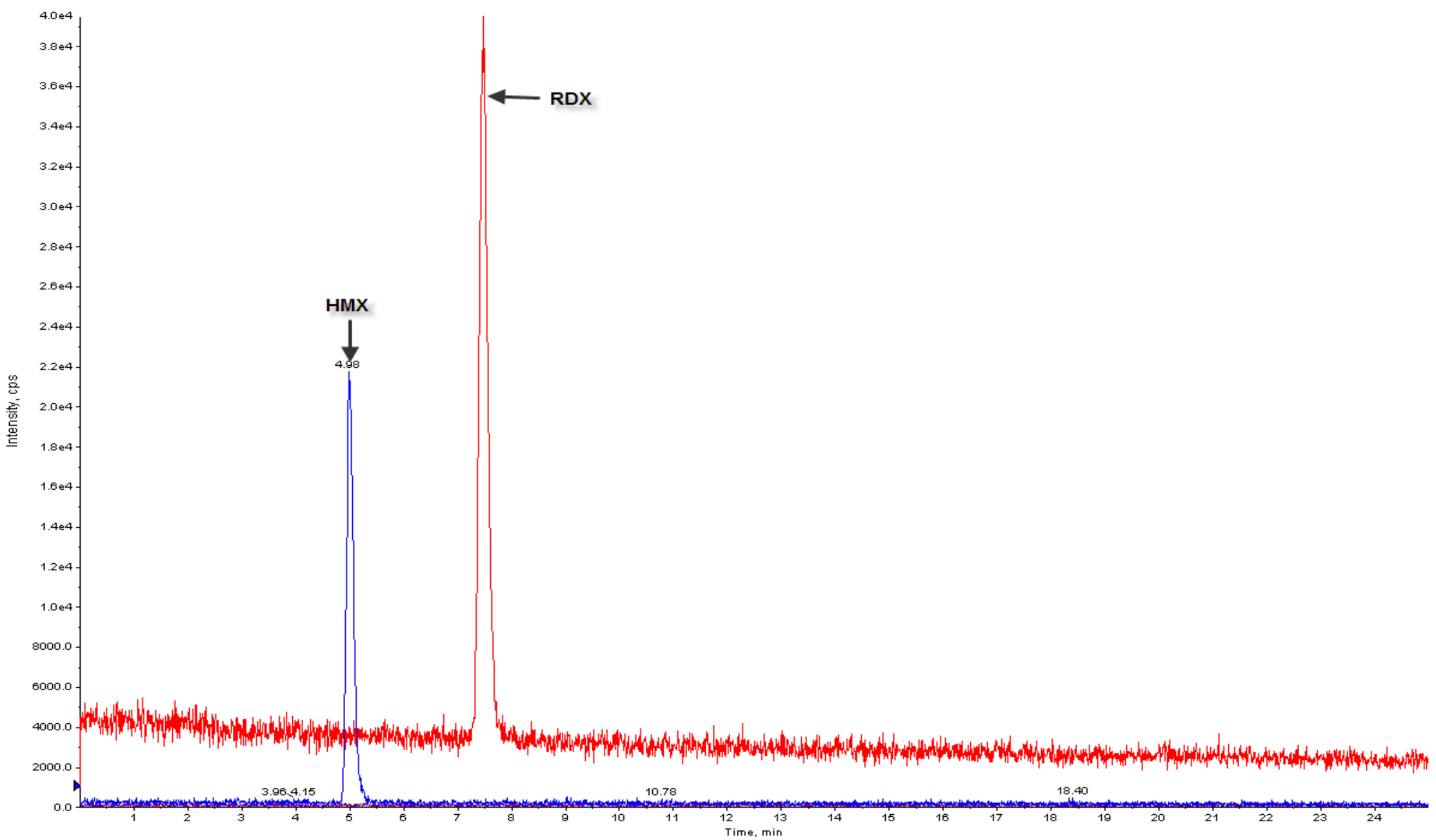


Sample 20_core_2

XIC of -MRM (10 pairs): 355.0/46.0 amu from Sample 12 (1.9 WNU_2007_20_core_2 MRM) of SET1.wiff (Heated Nebulizer)

Max. $8360.0 \mathrm{cps}$

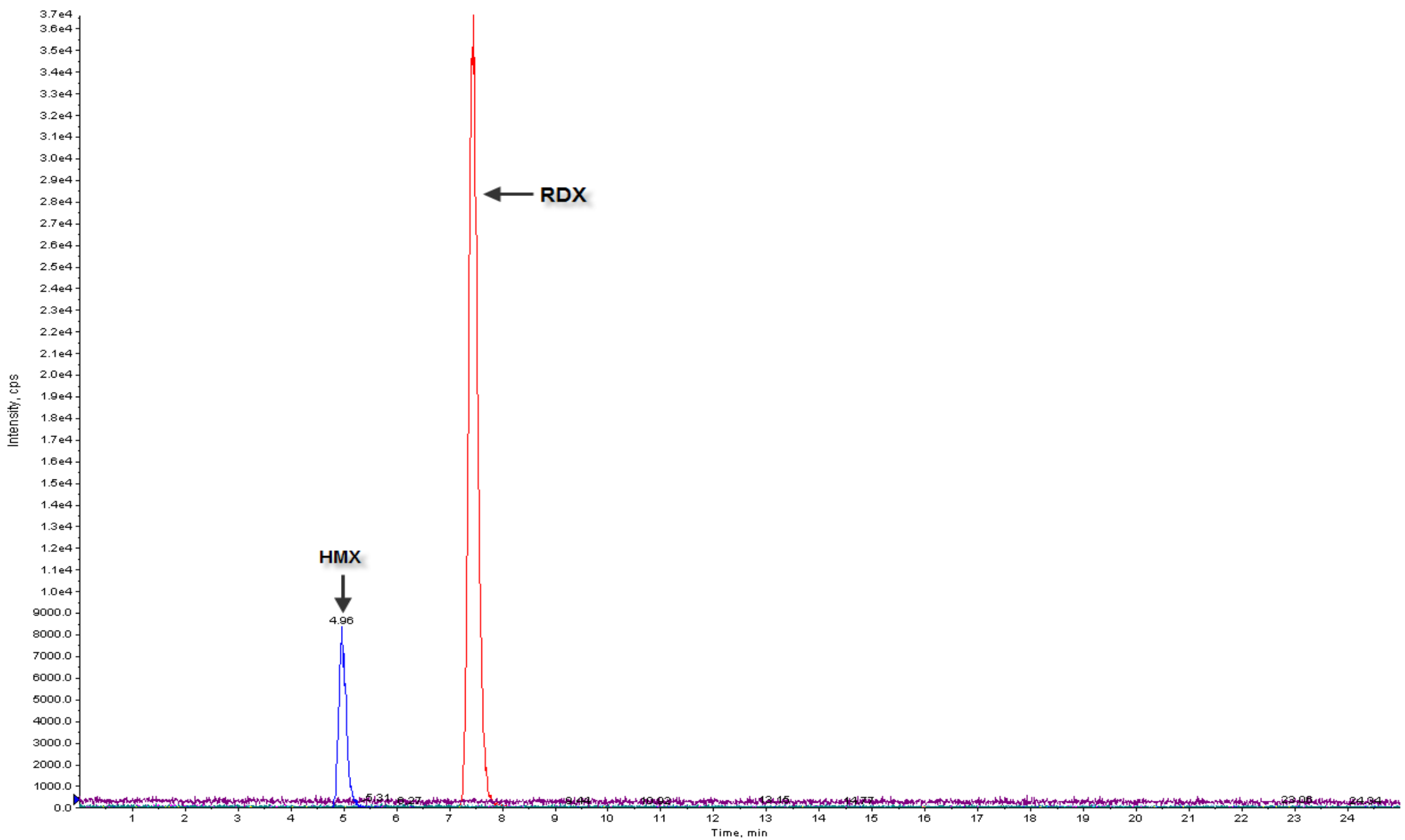

162 


\section{Sample XD_2}

- XIC of-MRM (10 pairs): 355.0/46.0 amu from Sample 8 (2.8 wnvU_2007_XD_2 MRM) of SET1.wiff(Heated Nebulizer)

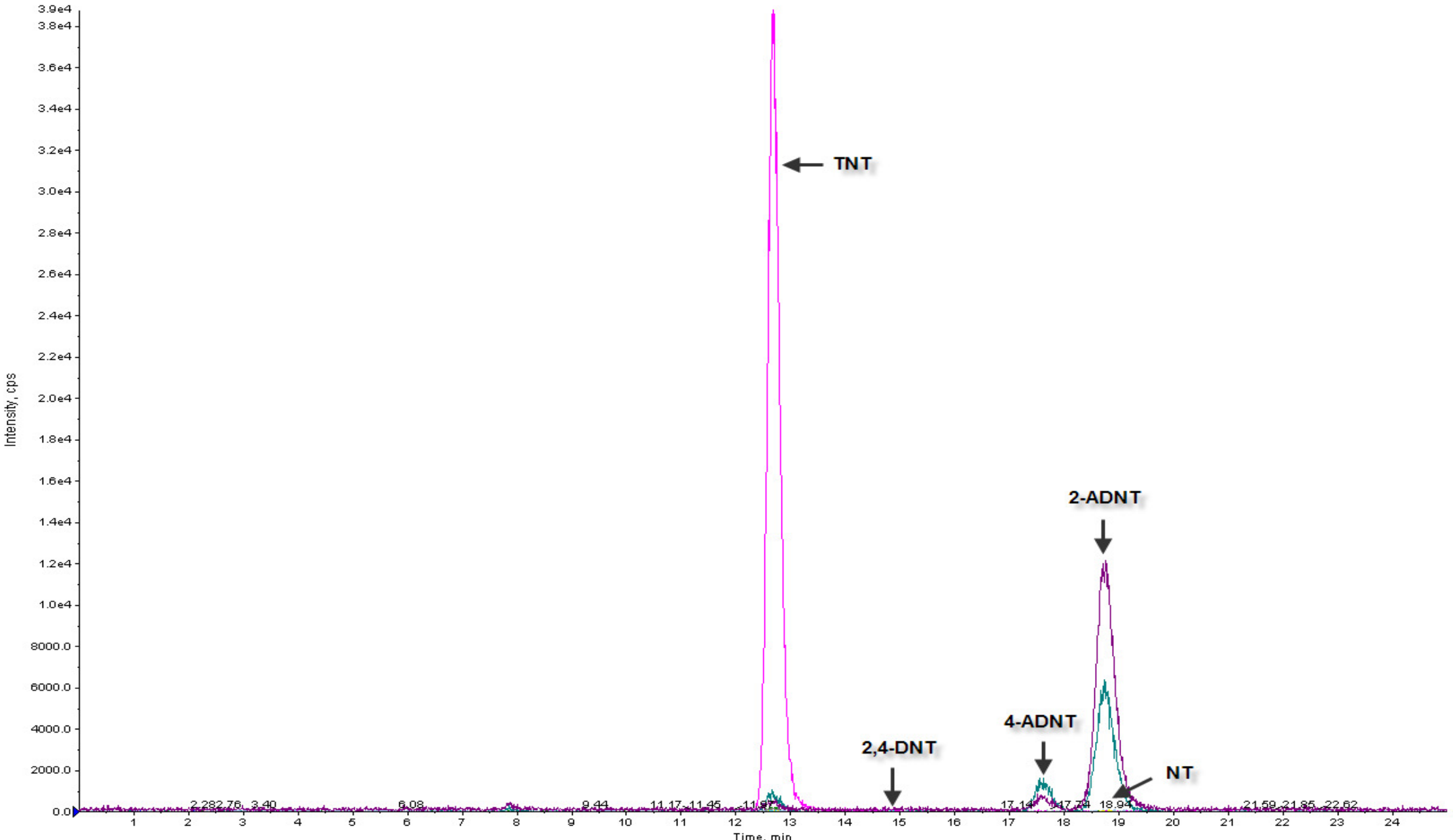




\section{Sample XD_3a}

- XIC of-MRM (10 pairs): 355.0/46.0 amu trom Sample 4 (1.5 vrvu_2007_XD_3a MRM) of SET1.,witt (Heated Nebulizer)

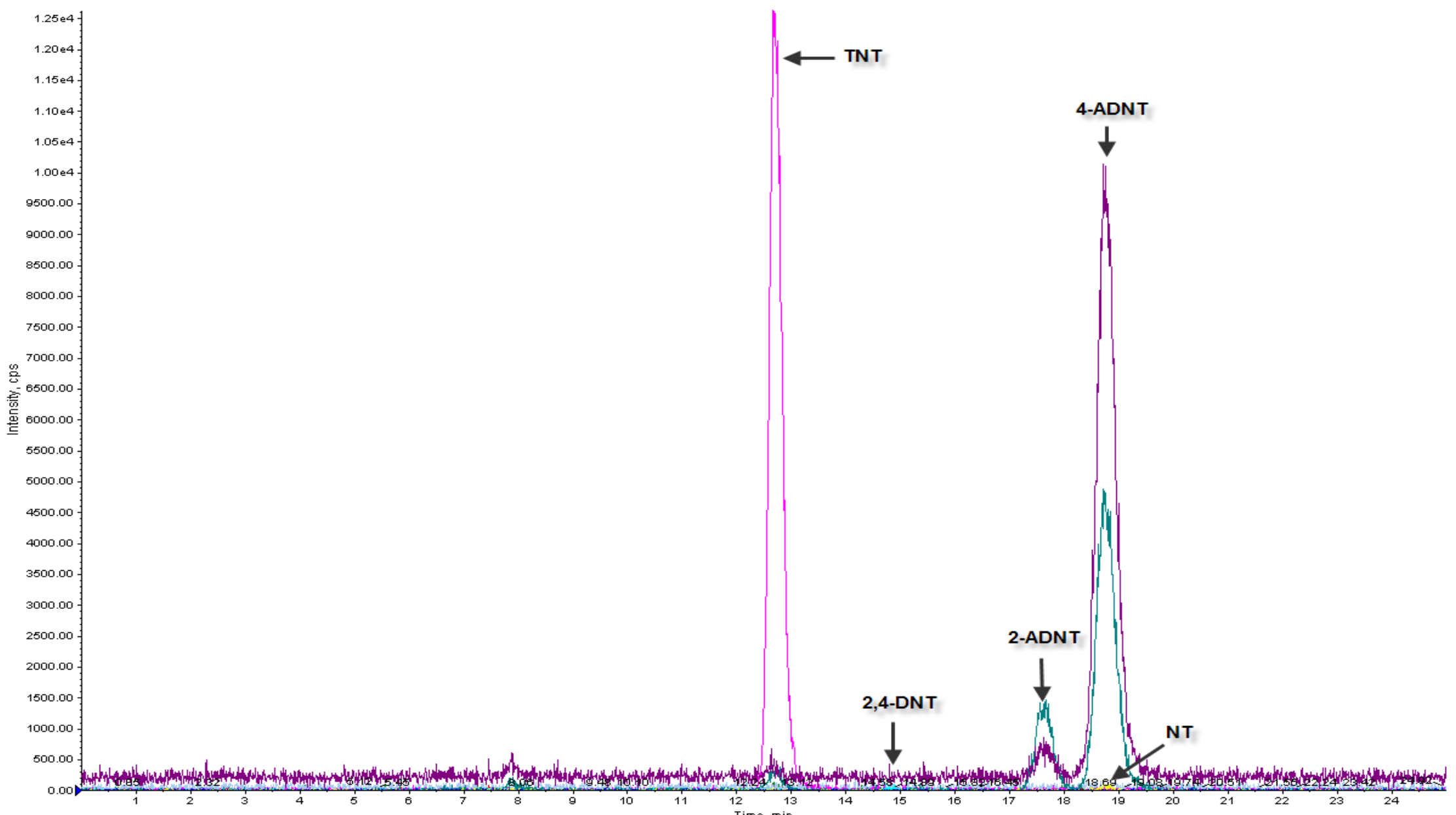




\section{Sample XD_3b}

- XIC of-MRM (10 pairs): 355.0/46.0 amu from Sample 13 (1.10 mNU_2007_XD_3b MRM) of SET1..viff (Heated Nebulizer)

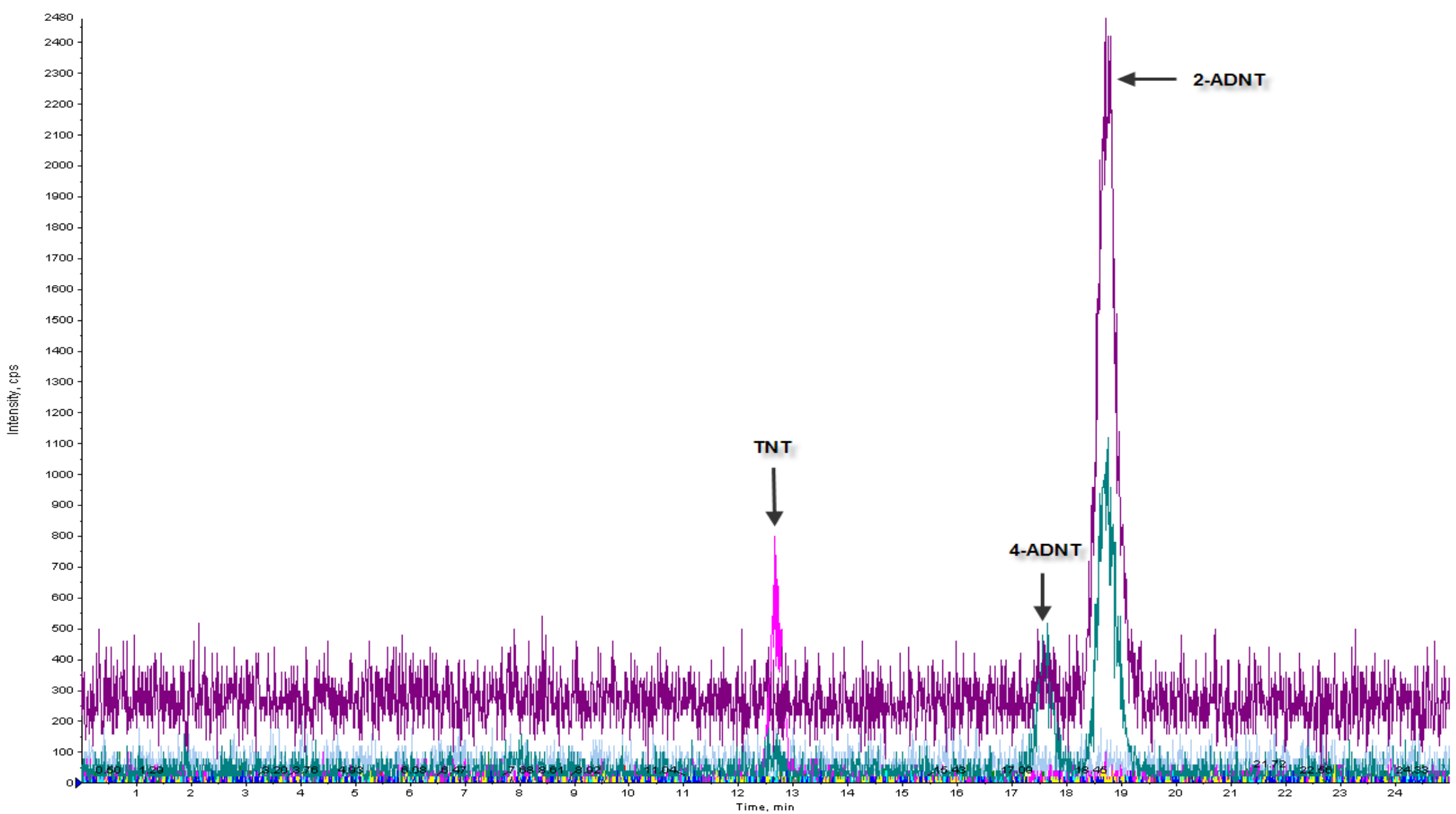




\section{Sample XD_4}

- XIC of-MRM (10 pairs): 355.0/46.0 amu from Sample 8 (1.4 WNUU_2007_XD_4 MRM) of SET2.vviff(Heated Nebulizer)

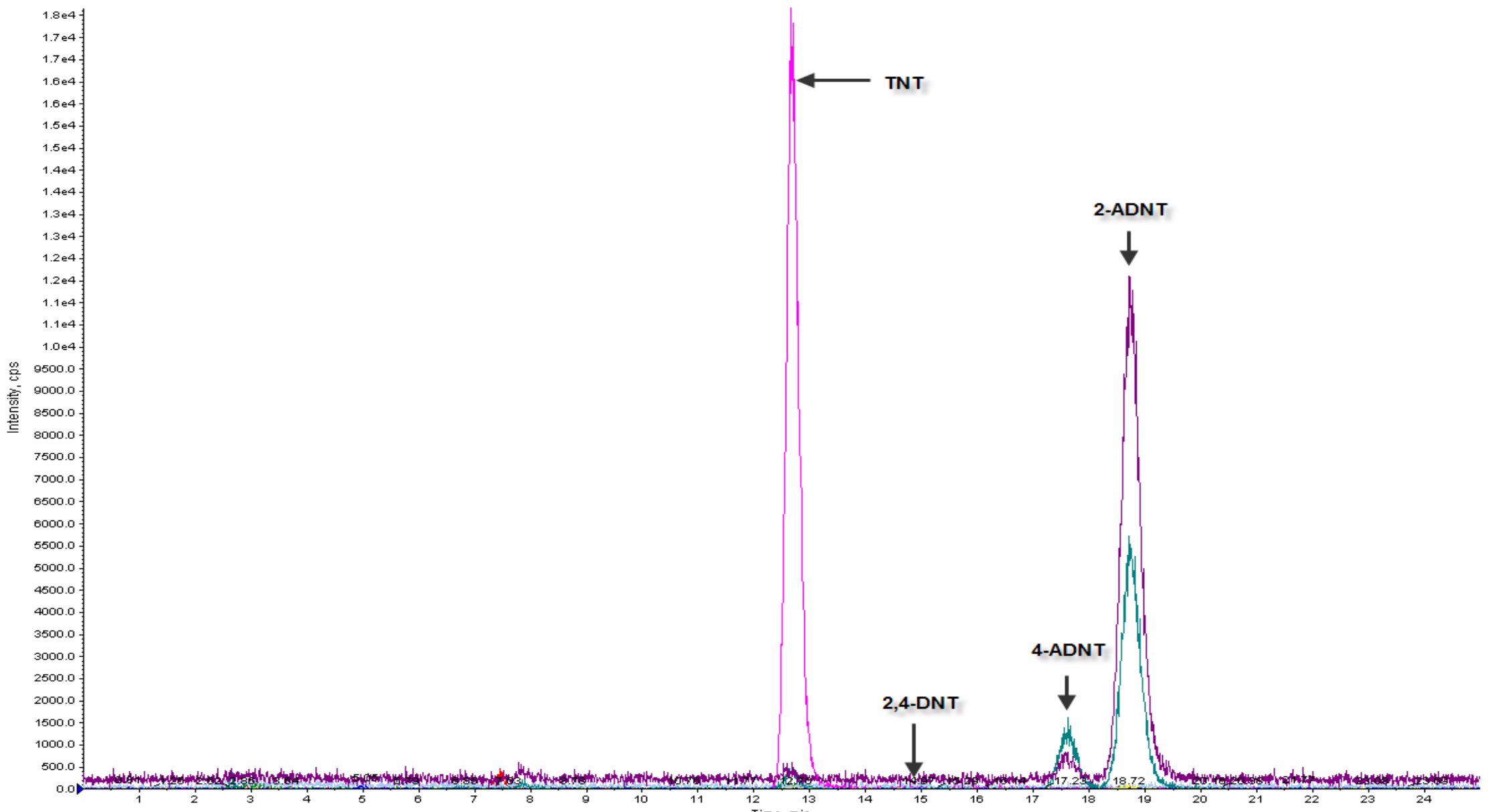




\section{References}

1. Yinon, J. Toxicity and Metabolism of Explosives; CRC Press, Inc: Boca Raton, 1990.

2. Letzel, S.; Göen, T.; Bader, M.; Angerer, J.; Kraus, T. Occup Environ Med 2003, 60, 483-488.

3. Clausen, J.; Robb, J.; Curry, D.; Korte, N. Environ. Pollut. 2004, 129, 13-21.

4. Weiss, M.; Mirin, S.; Bartel, D. R. Cocaine, 2 ed.; American Psychiatric Pub, 1994.

5. Karch, B. S. B. Karch's pathology of drug abuse, 3 ed.; CRC Press, 2001.

6. Logan, B. K. Forensic Sci Rev 2002, 14, 134-151.

7. Benjamin, D. "Forensic Pharmacology," in R. Saferstein, ed., Forensic Science Handbook, Volume 3. Englewood Cliffs NJ; Prentice Hall, 1993.

8. Volkow, N. NIDA Research Report Series; Health, NIH Publication Number 99-4342,1999.

9. Yudko, E.; Hall, H. V.; McPherson, S. B. Methamphetamine Use: Clinical and Forensic Aspects; CRC Press, 2003.

10. Covey, H. C. The methamphetamine crisis: strategies to save addicts, families, and communities; Greenwood Publishing Group, 2007.

11. Allen, A. C.; Kiser., W. O. J. Forensic Sci. 1987, 32, 953-962.

12. Akhavan, J. The Chemistry of Explosives, 2nd ed.; The Roral Society of Chemistry: Cambridge, 2004.

13. Agrawal, J. P. a. H., Robert Dale Organic Chemistry of Explosives; John Wiley \& Songs, Ltd: West Sussex, 2007.

14. Gaurav, D.; Malik, A. K.; Rai, P. K. Crit. Rev. Anal. Chem. 2007, 37, 227-268.

15. Yinon, J.; Hwang, D. G. J. Chromatogr. 1987, 394, 253-257.

16. Lachance, B.; Robidoux, P. Y.; Hawari, J.; Ampleman, G.; Thiboutot, S.; Sunahara, G. I. Mutat. Res., Genet. Toxicol. Environ. Mutagen. 1999, 444, 25-39.

17. Kucukardali, Y.; Acar, H. V.; Ozkan, S.; Nalbant, S.; Yazgan, Y.; Atasoyu, E. M.; Keskin, O.; Naz, A.; Akyatan, N.; Gokben, M.; Danaci, M.; GATA Haydarpasa Training Hospital, 81327 Uskudar, Istanbul, Turkey.: United States, 2003, pp 42-46.

18. Wampler, T. P. Applied pyrolysis handbook; CRC Press, 2006.

19. Moldoveanu, D. Analytical pyrolysis of synthetic organic polymers; Elsevier, 2005.

20. McNeil, I. C. J. Anal. Appl. Pyrolysis 1997, 40-41, 21-41.

21. Maeno, S.; Eddy, C.; Smith, S.; Rodriguez, P. J Chromatogr A 1997, 791, 151-161.

22. Blazsó, M. J. Anal. Appl. Pyrolysis 1997, 39, 1-25.

23. Francisco, F.-R.; Georges, G. Anal. Chem 1968, 40, 998-1000.

24. Hughes, J.; Wheals, B.; Whitehouse, M. Analyst 1978, 103, 482-491.

25. Burns, D.; Doolan, K. Anal Chim Acta 2006, 571, 25-29.

26. Armitage, S.; Saywell, S.; Roux, C.; Lennard, C.; Greenwood, P. J Forensic Sci 2001, 46, 1043-1052. 
27. Jansson, K. D.; Zawodny, C. P.; Wampler, T. P. J. Anal. Appl. Pyrolysis 2007, 79, 353-361.

28. Clausen, P.; Rowe, W. J Forensic Sci 1980, 25, 765-778.

29. Sekine, H.; Nakahara, Y. J Forensic Sci 1987, 32, 1271-1280.

30. Lee, M.-R.; Jeng, J.; Hsiang, W.-S.; Hwang, B.-H. J Anal Toxicol 1999, 23, 41-45.

31. Sato, M.; Hida, M.; Nagase, H. J Anal Toxicol 2004, 28, 638-643.

32. Baker, R. R. Nature 1974, 247, 405-406.

33. Martin, B. R.; Lue, L. P. J Anal Toxicol 1989, 13, 158-162.

34. Cognarda, E.; Rudazb, S.; Bouchonnetc, S.; Staub, C. J. Chromatogr. B 2005, 826, 17-25.

35. Shakleya, D. M.; Plumley, A. E.; Kraner, J. C.; Bell, S. C.; Callery, P. S. J Anal Toxicol 2008, 32, 705-708.

36. Shakleya, D. M.; Kraner, J. C.; Clay, D. J.; Callery, P. S.; Bell, S. C. J Anal Toxicol 2006, 30, 559-562.

37. Yinon, J. Forensic and Environmental Detection of Explosives; John Wiley \& Sons Ltd: West Sussex, 1999.

38. McCormick, N. G.; Cornell, J. H.; Kaplan, A. M. Appl. Environ. Microbiol. 1981, 42, 817-823.

39. Aken, B. V.; Yoon, J. M.; Schnoor, J. L. Appl. Environ. Microbiol. 2004, 70, 508-517.

40. Kaplan, D. L.; Kaplan, A. M. Appl. Environ. Microbiol. 1982, 44, 757-760.

41. Fournier, D.; Halasz, A.; Thiboutot, S.; Ampleman, G.; Manno, D.; Hawari, J. Environ. Sci. Technol. 2004, 38, 4130-4133.

42. Hawari, J.; Halasz, A.; Beaudet, S.; Paquet, L.; Ampleman, G.; Thiboutot, S. Environ. Sci. Technol. 2001, 35, 70-75.

43. Boopathy, R.; Manning, J. Water Environ. Fed. 1998, 1049.

44. Kayser, E. G.; Burlinson, N. E.; Rosenblatt, D. H.; Technical Report No. 8478. Naval Surface Weapons Center, Silver Spring, MD, 1984.

45. Guengerich, F. P. Curr. Drug Metab. 2001, 2, 93-115.

46. Lewis, D. F. Pharmacogenomics 2003, 4, 387-395.

47. Guengerich, F. P. Chem. Res. Toxicol. 2001, 14, 611-650.

48. Isin, E. M.; Guengerich, F. P. J. Anal. Bioanal. Chem. 2008, 392, 1019-1030.

49. Channon, H. J.; Mills, G. T.; Williams, R. T. Biochem. J. 1944, 38, 70-85.

50. Farey, M. G.; Wilson, S. E. J. Chromatogr. 1975, 114.

51. Devlin, T. M. Textbook of biochemistry with clinical correlations; Wiley-Liss: Canada, 2002.

52. Bhushan, B.; Paquet, L.; Jim, J. S.; Hawari, J. Appl. Environ. Microbiol. 2003, 69, 5216-5221.

53. Leung, K. H.; Yao, M.; Stearns, R.; Chiu, S.-H. L. Chem.-Biol. Interact. 1995, 97, 37-51.

54. Aken, B. V.; Yoon, J.; Schnoor, J. Appl. Environ. Microbiol. 2004, 70, 508517.

55. Banerjee, H.; Verma, M.; Hou, L.; Ashraf, M.; Dutta, S. Yale J Biol. Med. 1999, 72, 1-4.

56. Pennington, J. Soil \& Sediment Contam. 2001, 10, 45-70. 
57. Oh, B.-T.; Shea, P. J.; Drijber, R. A.; K.Vasilyenz, G.; Sarath, G. Biodegradation 2003, 14, 309-319.

58. Nikolic, S.; Saric-Medic, M.; Rendic, S.; Trinajstic, N. Drug Metab. Rev. 1994, 26, 717-738.

59. Esteve-Nunez, A.; Ramos, J. L. Environ. Sci. Technol. 1998, 32, 3802-3808.

60. Bhushan, B.; Trott, S.; Spain, J. C.; Halasz, A.; Paquet, L.; Hawari, J. Appl. Environ. Microbiol. 2003, 69, 1347-1351.

61. Sabbioni, G.; Liu, Y.-Y.; Yan, H.; Sepai, O. Carcinogenesis 2005, 26, $1272-$ 1279.

62. Sabbioni, G.; Rumler, R. Biomarkers 2007, 12, 559-573.

63. Coleman, N. V.; Spain, J. C.; Duxbury, T. J. Appl. Microbiol. 2002, 93, 463472.

64. Bhushan, B.; Halasz, A.; Thiboutot, S.; Ampleman, G.; Hawari, J. Biochem. Biophys. Res. Commun. 2004, 316, 816-821.

65. Dass, C. Fundamentals of Contemporary Mass Spectrometry; John Wiley \& Sons, Inc Hoboken, NJ, 2007.

66. Kebarle, P.; Tang, L. Anal. Chem. 1993, 65, 972A-986A.

67. Watson, J. T.; Sparkman, O. D. Introduction to Mass Spectrometry, 4th ed.; John Wiley \& Sons, Inc 2007.

68. Perret, D.; Marchese, S.; Gentili, A.; Curini, R.; Terracciano, A.; Bafile, E.; Romolo, F. Chromatographia 2008, 68, 517-524.

69. Schmidt, A.-C.; Niehus, B.; Matysik, F.-M.; Engewald, W. Chromatographia 2006, 63, 1-11.

70. Beller, H. R.; Tiemeier, K. Environ. Sci. Technol. 2002, 36, 2060-2066.

71. Major, M. A.; Reddy, G.; Berge, M. A.; Patzer, S. S.; Li, A. C.; Gohdes, M. J. Toxicol. Environ. Health Part A 2007, 70, 1191-1202.

72. Spiegel, K.; Headley, J. V.; b, K. M. P.; Haidar, N.; Gurprasard, N. P. Commun. Soil Sci. Plant Anal. 2005, 36, 133 - 153.

73. Methamphetamine. In NIDA InfoFacts, 2008.

74. Sekine, H.; Nakahara, Y. J. Forensic Sci. 1990, 35, 580-590.

75. Cook, C.; Jeffcoat, A.; Hill, J.; Pugh, D.; Patetta, P.; Sadler, B. 21 1993, 4, 717-723.

76. Lewis, R.; Johnson, R.; Angier, M.; Ritter, R. J. Chromatogr., B: Anal. Technol. Biomed. Life Sci. 2004, 806, 141-150.

77. Kintz, P.; Cirimele, V.; Sengler, C.; Mangin, P. J. Anal. Toxicol. 1995, 19, 479482.

78. Peterson, K.; Logan, B.; Christian, G. Forensic Sci. Int. 1995, 73, 183-196.

79. Sato, M.; Ito, K.; Nagase, H. J. Health Sci. 2004, 50, 389-395.

80. Bake, R. R.; Bishop, L. J. J. Anal. Appl. Pyrolysis 2004, 71, 223-311.

81. Analytical, O. Proper Trap Selection for the Ol Analytical Model 4560 Purgeand-Trap Sample Concentrator; Application Note 12861198.

82. Lide, D. R. CRC Handbook of Chemistry and Physics, 86th ed.; Taylor \& Francis: Boca Raton, 2005.

83. Myers, A.; Williams, H.; Kraner, J.; Callery, P. J Forensic Sci 2005, 50, 14811485.

84. Military Munitions Rule 40 CFR 266.201. 
85. Batlle, R.; Nerin, C.; Crescenzi, C.; Carlsson, H. Anal. Chem. 2005, 77, 42414247.

86. Halasz, A.; Groom, C.; Zhou, E.; Paquet, L.; Beaulieu, C.; Deschamps, S.; Corriveau, A.; Thiboutot, S.; Ampleman, G.; Dubois, C.; Hawari, J. J. Chromatogr., A 2002, 963, 411-418.

87. Ragnvaldsson, D.; Brochu, S.; Wingfors, H. J. Hazard. Mater. 2007, 142, 418424.

88. Mayfield, H. T.; Burr, E.; Cantrell, M. Anal. Lett. 2006, 39, 1463-1474.

89. Jenkins, T. F.; Grant, C. L. Anal. Chem. 1987, 59, 1326-1331.

90. United States Environmental Protection Agency. Method 8330: Nitroaromatics and Nitramines by High Performance Liquid Chromatography (HPLC), 1994.

91. Bauer, C. F.; Koza, S. M.; Jenkins, T. F. J AOAC 1990, 73, 541-552.

92. Walsh, M. E.; Jenkins, T. F. Anal. Chim. Acta 1990, 231, 313-315.

93. Lindeman, S.; Läärä, E.; Vuori, E.; Lönnqvist, J. Acta Physiol. Scand. 2007, $96,68-71$.

94. Tomkins, B. A.; Barnardb, A. R. J. Chromatogr. A 2002, 964, 21-33.

95. Campbell, S.; Ogoshi, R.; Uehara, G.; Li, Q. X. J. Chromatogr. Sci. 2003, 41, 284-288.

96. Feltes, J.; Levsen, K. J. High. Resolut. Chromatogr. 1989, 12, 613-616.

97. Jenkins, T. F.; Walsh, M. E.; Schumacher, P. W.; Miyares, P. H.; Bauer, C. F.; Grant, C. L. J. Assoc. Off. Anal. Chem. 1989, 72, 890-899.

98. Giordano Braden, C.; Copper Christine, L.; Collins Greg, E. Electrophoresis 2006, 27, 778-786.

99. Casetta, B.; Garofolo, F. Org. Mass Spectrom. 1994, 29, 517-525.

100. Yinon, J.; McClellan, J. E.; Yost, R. A. Rapid Commun. Mass Spectrom. 1997, 11, 1961-1970.

101. M Walsh; Collins, C.; C Ramsey; Douglas, T.; Bailey, R.; Walsh, M.; Hewitt, A.; Clausen, J. 2007, ERDC/CRREL TR 07-09.

102. Hewitt, A.; Jenkins, T.; Walsh, M. E.; Walsh, M. R.; Bigl, S.; Ramsey, C. 2007, ERDC/CRREL TR 07-10.

103. Quaranta, J. D.; Fulton, J.; Bell, S.; McDonald, L.; Ely, M.; Aylor, A.; Oldfield, L.; Borsa, C.; West Virginia University, 2008.

104. Quaranta, J.; Ely, M., Ed., 2007.

105. Felt, D. R.; Bednar, A. J.; Georgian, T. Talanta 2008, 77, 380-387.

106. Walsh, M. E.; Ramsey, C. A.; Jenkins, T. F. Chemosphere 2002, 49, 12671273.

107. Pitard, B. F. F. Pierre Gy's sampling theory and sampling practice: heterogeneity, sampling correctness, and statistical process control; CRC Press, 1993.

108. Xu, X.; Craats, A. M. v. d.; Bruyn, P. C. A. M. d. J Forensic Sci 2004, 49, 110.

109. Yinon, J. Advances in forensic applications of mass spectrometry; CRC Press, 2003.

110. Jenkin, T.; Ely, M., Ed.: Hanover, 2007.

111. DuBois, F. W.; Baytos, J. F.; Los Alamos National Laboratoy, 1991, pp 4. 
112. Martel, R.; Mailloux, M.; Gabriel, U.; Lefebvre, R.; Thiboutot, S.; Ampleman, G. J. Environ. Qual. 2008, 38, 75-92.

113. Bordeleau, G.; Martel, R.; Ampleman, G.; Thiboutot, S. J. Environ. Qual. 2008, 37, 308-317.

114. Liu, Y.-Y.; Yao, M.; Fang, J.-L.; Wang, Y.-W. Toxicol. Lett. 1995, 77, 281-287.

115. Iyanagi, T. Int. Rev. Cytol. 2007, 260, 35-112.

116. Wang, Y.; Li, Y.; Li, Y.; Ma, X.; Yang, S.; Yang, L. J. Phys. Chem. B 2006, 110, 10139-10143.

117. Von Moltke, L. L.; Greenblatt, D. J.; Granda, B. W.; Duan, S. X.; Grassi, J. M.; Venkatakrishnan, K.; Harmatz, J. S.; Shader, R. I. Br. J. Clin. Pharmacol. 1999, 48, 89-97.

118. Nambayah M.; Quickenden T.I. Talanta 2004, 63, 461.

119. Tanaka, E.; Nakamura, T.; Terada, T. Basic Clin Pharmacol Toxicol 2005, 96, 88.

120. Wen, B.; Coe, K. J.; Rademacher, P. Chem Res Toxicol 2008, 21, 2393.

121. Gapeev, A.; Sigman, M.; Yinon, J. Rapid Commun. Mass Spectrom. 2003, 17, 943-948.

122. Biosystems, A. Application Note: Trace Level Analysis of Explosives in Ground Water and Soil. , 2006.

123. Biosystems, A. Application Note: Quantitative Analysis of Explosives in Surface Water Comparing Off-Line Solid Phase Extraction and Direct Injection LC/MS/MS, 2008.

124. Maffei Facino, R.; Pitre, D.; Carini, M. Farmaco, Ed. Sci. 1982, 37, 463-474.

125. Tomaszewski, W.; Gun'ko, V. M.; Skubiszewska-Zi, eba, J.; Leboda, R. J. Colloid Interface Sci. 2003, 266, 388-402. 
MELISSA GAYTON-ELY, BA

CURRICULUM VITAE
5002 Monterey Ave

Morgantown, WV 26505

Cell Phone: (304) 685-6619

Email: melissagely@gmail.com

\title{
I. EDUCATION:
}

1999-2003

B.A. Chemistry

West Virginia University

GPA: 3.82

Honors: Graduated Summa Cum Laude

Presidential award and Dean's list 2000-2003.

Awarded Most Outstanding Undergraduate Teaching Assistant

2003-present Ph.D. August 2009 (expected), Analytical Chemistry West Virginia University

GPA: 3.66

Honors: Awarded Most Outstanding First Year Graduate Teaching Assistant

Awarded the HERF Supplementary Fellowship

Eberly College Outstanding Graduate Teaching Assistant

\section{PROFESSIONAL EXPERIENCE:}

Jan - May 2008:

Chemistry Instructor

Supervisor: Dr. Michelle Richards-Babb

West Virginia University

Bennett Department of Chemistry

Morgantown, WV 26506

- Taught a general chemistry course (CHEM 115:

Fundamentals of Chemistry) and supervised the laboratory to 188 undergraduate students.

June 2005- Present:

\author{
Graduate Research Assistant \\ Supervisor: Dr. Suzanne Bell \\ West Virginia University \\ Bennett Department of Chemistry \\ Morgantown, WV 26506
}


- Conducted forensic chemistry research in the following areas:

- Pyrolysis of abused drugs using a pyroprobe coupled to $\mathrm{GC} / \mathrm{MS}$. This project involves using pyrolysis as a tool for smoked drug analysis.

- Analytical analysis of volatile TNT and metabolites using purge and trap GC/MS and IMS.

- Metabolism of explosives: developing methods for predicting and identifying potential biomarkers of explosives by in-vitro metabolism using human liver microsomes.

- Identification of TNT and degradation products in soil and water. This project was in partnership with the West Virginia Water Research Institute.

- Provided assistance in forensic training and workshops.

- Laboratory Group Responsibility: In charge of handling chemical storage and waste.

Dec 2002 - August 2003

Aug 2003 - June 2005

Aug 2002 - present:

\section{Undergraduate Research Assistant Graduate Research Assistant \\ Supervisor: Dr. Lisa Holland \\ West Virginia University \\ Bennett Department of Chemistry \\ Morgantown, WV 26506}

- Project involved the bacterial expression and protein purification of proteins. Some techniques used include the construction of primers, DNA ligation and digestion with restricted endonucleases, vector expression and preparing competent e.coli cells.

- Assisted in packing capillary HPLC columns (C-18 packing material) using a high pressure system.

- The analysis of peptide-lipid and peptide-glycosaminoglycan binding and the monitoring of fusion-protein cleavage by an enzyme using affinity capillary electrophoresis. Incorporated techniques such as FITC and maleimide tagging and the reduction of thiols.

- The quantification of the carcinogen, beta-asarone extracted from the popular medicinal rhizome of Acorus calamus using micellar electrokinetic chromatography.

- Developed a neutral coating using bicelles for capillary zone electrophoresis.

- Responsible for organizing/updating all chemical inventories and collecting MSDS's.

\section{Laboratory Teaching Assistant}

Supervisors: Dr. Ronald Smart- Chem 215: Analytical Chemistry (Fall 2002 (Super TA position and TA), 2003 and 2008) 
Dr. Mohammad Ahmed- Chem 116: Fundamentals of Chemistry II (Summer 2005)

Dr. Alan Stolzenberg- Chem 115: Fundamentals of Chemistry I (Fall 2005)

Dr. Harry Finklea- Chem 215: Analytical Chemistry (Fall 2006)

Dr. Tabitha Chigwada - Chem 116: Fundamentals of Chemistry II (Summer 2008)

Dr. James Ziegler - Chem 111: Survey of Chemistry (Fall 2008)

West Virginia University

Bennett Department of Chemistry

Morgantown, WV

- Assisted 20-24 students with laboratory and safety procedures.

- Aided students in answering questions about procedures and fundamental chemistry.

- Prepared solutions for laboratory use.

\section{INSTRUMENTATION/TECHNIQUES AND SOFTWARE PROFICIENCIES}

Instrumentation/ Techniques:
Computer Skills/

Software:
Shimadzu UPLC (LC-20A Prominence Series) coupled to an Applied Biosystems 3200 QTrap LC/MS/MS System

PerkinEImer Clarus 500 Gas Chromatograph and Mass

Spectrometer

CDS Analytical Pyroprobe 5150

PerkinElmer Headspace Sampler Hs40XL

PerkinElmer Clarus 500 Gas Chromatograph with FID detection PerkinEImer Liquid Chromatograph Series 200 with UV-vis and fluorescence Detection

Agilent 6890 Series Gas Chromatograph System coupled to an Agilent 5973 Network Mass Selective Detector Teledyne TEKMAR HT3 ${ }^{\mathrm{TM}}$ Headspace Autosampler (Purge and Trap)

Beckman Coulter P/ACE MDQ Capillary Electrophoresis with photodiode array, UV-vis, and fluorescence detection Smiths Detection's IONSCAN-LS Ion Mobility Spectrometer Smiths Detection's Sabre 4000 Hand-held Ion Mobility Spectrometer Leica DMEP Polarizing Light Microscope

Craic QDI Microspectrophotometer

Craic QDSII Microspectrophotometer

SDS-PAGE electrophoresis

Agarose gel electrophoresis

PCR Thermocycler

TurboMass version 5.0.0

TotalChrom 
CDS 5000 Pyroprobe

MSD Chemstation for Agilent GC/MS

Teledyne TEKMAR HT3 TekLink

IM-Station 5.383

32 Karat [TM] software version 5.0

Grams/Al

Analyst

\section{MEMBERSHIPS:}

- Phi Lambda Upsilon Honorary Society- Vice President (2002-2005)

- American Academy of Forensic Sciences - Student Affiliate (2003-2008)

- Golden Key National Honor Society (2001-2003)

- Gamma Beta Phi Honor Society (2001-2003)

.

\section{PUBLICATIONS:}

Bell SC, Gayton-Ely M, Nida C, "Bioassays for Bombmakers: Proof of Concept." Submitted and accept to Analytical and Bioanalytical Chemistry 2009.

Gayton-Ely M, Shakleya DM, Bell SC, "Application of a Pyroprobe to Simulate Smoking and Metabolic Degradation of Abused Drugs through Analytical Pyrolysis." Journal of Forensic Science 2007, 52(2):473-8.

Gayton-Ely M, Pappas TJ, Holland LA, "Probing Affinity via Capillary Electrophoresis: Advances in 2003-2004." Analytical and Bioanalytical Chemistry 2005, 382: 570-580.

Pappas TJ, Gayton-Ely M, Holland LA, "Recent Advances in MEKC." Electrophoresis 2005, 26:719-734.

Hanson KM, Gayton-Ely M, Holland LA, Zehr P, Söderberg BCG, "Rapid Assessment of B-asarone Content of Acorus calamus by Micellar Electrokinetic Chromatography." Electrophoresis 2005, 26: 943-946.

\section{Reports:}

Quaranta J, Fulton J, Bell S, McDonald L, Gayton-Ely M, Aylor A, Oldfield L, Borsa C, "Environmental Forensics for Characterization of Unexploded Ordnance at the Dolly Sods Wilderness Area Final Report (Ne-23)." Report submitted to the National Environmental Education and Training Center, Inc. in February 2008. 


\section{PRESENTATIONS AND WORKSHOPS:}

Gayton-Ely, M. Determination of Human Biomarkers of RDX via LC/MS/MS. American Academy of Forensic Toxicologist 2008 Annual Meeting, Phoenix, AZ, October 29, 2008

Gayton-Ely, M. Detection of Biomarkers of Explosives. Toxicology Poster Session. American Academy of Forensic Science $59^{\text {th }}$ Annual Meeting, San Antonio, TX, February 21,2007

Gayton-Ely, M. Utilization of a Pyroprobe Coupled to GC/MS for Drug Analysis and Toxicology. YFSF BYOS and Toxicology Session. American Academy of Forensic Science $58^{\text {th }}$ Annual Meeting, Seattle, WA, February 22 and 24, 2006

Gayton-Ely M. Rapid Assessment Using Separations Chemistry for a CE-based Assay. $15^{\text {th }}$ Annual Frederick Conference on CE/Proteomics, NCI, Frederick, MD, October 2004

\section{Workshops Taken:}

Overview and Review of Forensic Toxicology - American Academy of Forensic Toxicologist 2008 Annual Meeting, Phoenix, AZ (October 2008)

Applications of LC-MS in Human and Veterinary Toxicology - American Academy of Forensic Toxicologist 2008 Annual Meeting, Phoenix, AZ (October 2008)

Pharmacogenomics as Autopsy - American Academy of Forensic Science $59^{\text {th }}$ Annual Meeting, San Antonio, TX (February 2007)

Young Forensic Scientist Forum - American Academy of Forensic Science $59^{\text {th }}$ Annual Meeting,

San Antonio, TX (February 2007)

Research, Writing and Reviewing: A Guide to Designing, Conducting, Writing, Publishing and Analyzing Scientific Research - American Academy of Forensic Science $58^{\text {th }}$ Annual Meeting,

Seattle, WA (February 2006)

Young Forensic Scientist Forum - American Academy of Forensic Science $58^{\text {th }}$ Annual Meeting, Seattle, WA (February 2006)

Forensic Microscopy (1204) - McCrone Research Institute, Chicago, IL (November 2005)

\section{Workshops Given:}

Gun Shot Residue - West Virginia University Forensic Science Initiative with Kentucky State Police (2005)

Gun Shot Residue - Forensic Science Educational Conference at WVU (2005). 


\section{CONFERENCES:}

- American Academy of Forensic Toxicologist 2008 Annual Meeting, Phoenix, AZ, October 2008

- American Academy of Forensic Science $59^{\text {th }}$ Annual Meeting, San Antonio, TX, February 2007

- American Academy of Forensic Science $58^{\text {th }}$ Annual Meeting, Seattle, WA, February 2006

- Arthur M. Sackler Colloquia- National Academy of Science, Washington DC, November 2005

- $15^{\text {th }}$ Annual Frederick Conference on CE/Proteomics, NCI, Frederick, MD, October 2004 